DISSERTAÇÃO DE MESTRADO Nº 795

METODOLOGIA PARA IDENTIFICAÇÃO

E CLUSTERIZAÇÃO ESPACIAL DE PERDAS

NÃO-TÉCNICAS EM SISTEMAS

DE DISTRIBUIÇÃO DE ENERGIA ELÉTRICA

Wellington Fazzi Cancian

DATA DA DEFESA: 30/08/2013 
Universidade Federal de Minas Gerais - UFMG

Escola de Engenharia

Programa de Pós-Graduação em Engenharia Elétrica - PPGEE

\section{METODOLOGIA PARA IDENTIFICAÇÃO E \\ CLUSTERIZAÇÃO ESPACIAL DE PERDAS \\ NÃO-TÉCNICAS EM SISTEMAS DE \\ DISTRIBUIÇÃO DE ENERGIA ELÉTRICA}

\section{Wellington Fazzi Cancian}

Dissertação submetida à banca examinadora designada pelo Colegiado do Programa de Pós-Graduação em Engenharia Elétrica da Universidade Federal de Minas Gerais, como parte dos requisitos necessários à obtenção do grau de Mestre em Engenharia Elétrica.

Orientador: Prof. José Osvaldo Saldanha Paulino, Dr.

Co-orientador: Prof. Rodney Rezende Saldanha, Dr.

Belo Horizonte - MG

Agosto de 2013 
"Metodologia para Identificação e Clusterização Espacial de Perdas Năo-técnicas em Sistemas de Distribuição de Energia Elétrica"

\author{
Wellington Fazzi Cancian
}

Dissertaçăo de Mestrado submetida à Banca Examinadora designada pelo Colegiado do Programa de Pós-Graduaçăo em Engenharia Elétrica da Escola de Engenharia da Universidade Federal de Minas Gerais, como requisito para obtençăo do grau de Mestre em Engenharia Elétrica.

Aprovada em 30 de agosto de 2013.

Por:

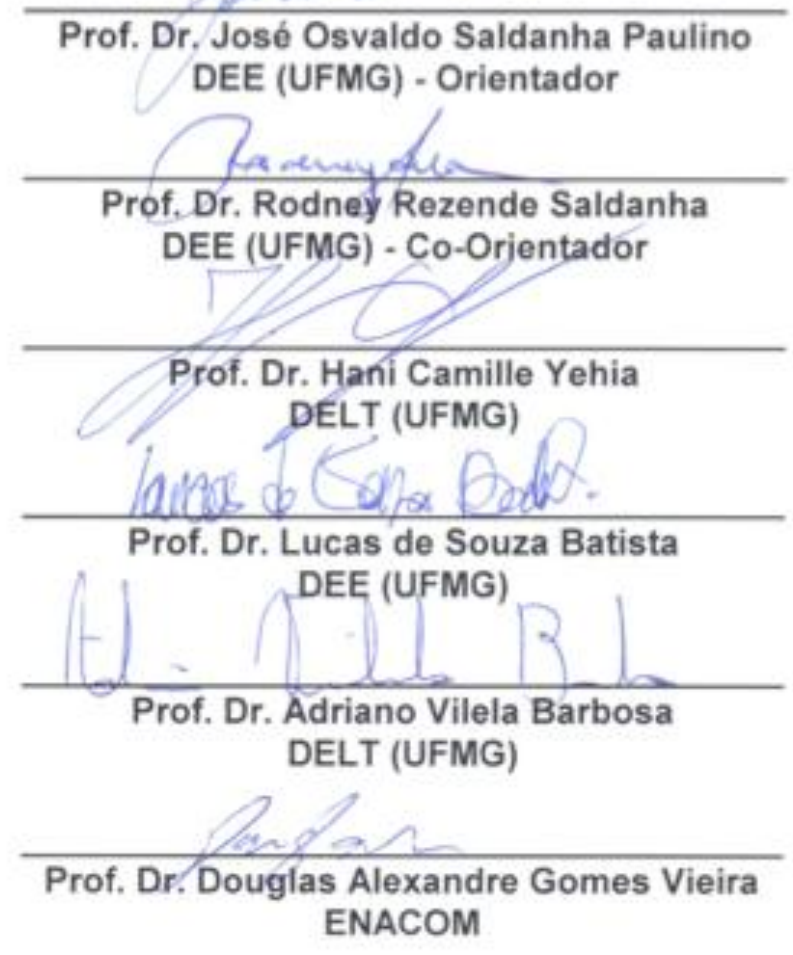




\section{Agradecimentos}

Inicialmente a Deus, por dar-me forças, parcimônia e sabedoria para alcançar os objetivos e superar desafios impostos.

Agradeço à minha família pelo apoio e confiança, especialmente aos meus pais, por me inspirar, apresentar-me valores, pelo amor e pelas suas preces.

À minha namorada, Letícia, pelo carinho, acompanhamento, cumplicidade e suporte nos momentos difíceis, mantendo-me confiante na busca pelo objetivo deste trabalho.

Aos mestres, Dr. Rodney Saldanha e Dr. José Osvaldo Paulino, pela disposição em minha linha de pesquisa, direcionamento e orientação aos estudos e à mestre Dra. Wadaed Uturbey, por me apresentar ao Programa e despertar em mim a intenção em prosseguir com os trabalhos.

Aos professores, Dr. Hani Yehia, Dr. Lucas Batista, Dr. Adriano Barbosa, Dr. Douglas Vieira, e MSc, Eduardo Nogueira, por aceitar o convite como integrantes da Banca Examinadora, honrando-me com a presença, e pelas valiosas contribuições no trabalho.

Aos colegas de trabalho, especialmente aos gerentes Rafael Pimenta e Silvia Cristiane pelo incentivo e por viabilizar a conclusão dos estudos.

Ao grande amigo, Olival Schultz, pelas horas de estudo em conjunto e suporte às dúvidas e a todos os meus amigos, que de certa forma, contribuíram com o meu trabalho, em especial, meu primo Luís Otavio Cancian e aos companheiros Ezequiel e Estanislau, pelas caronas e conversas que geraram novas ideias às atividades.

Às colegas da Secretaria do PPGEE da UFMG, Anete e Arlete, por suportar-me em todas as fases da minha estada no Programa e ao coordenador, Dr. Reinaldo Palhares, por, mesmo nas situações críticas vividas por mim, dar-me apoio e me fazer confiar cada vez mais em Ética e trabalho duro. 
A todas as pessoas que de um modo ou de outro estiveram envolvidas nesta jornada, meu muito obrigado. 
Eu penso

Você pensa

A vida é

(Fernando Soares)

"A Deus, minha família, Gilda e Marco, minhas irmãs, Veruscka e Renata e minha amada Letícia." 


\section{Resumo}

CANCIAN, Wellington Fazzi, Metodologia para identificação e clusterização espacial de perdas não-técnicas em sistemas de distribuição de energia elétrica

Escola de Engenharia, Universidade Federal de Minas Gerais, 2013. 132p. Dissertação (Mestrado).

Com a crescente demanda por energia elétrica em contrapartida à oferta, as tarifas acompanharam esse ritmo de elevação, apesar da busca incessante do órgão regulador ANEEL - por modicidade, fazendo com que os custos aos consumidores finais comprometam o interesse da coletividade, especialmente em um dos processos de cálculo tarifário mais completos e complexos do mundo e num país com desigualdades sociais extremas como o Brasil.

A principal fonte de receita em uma distribuidora é a venda de energia elétrica para seus consumidores cativos. Neste sentido, o crescente nível de perdas não-técnicas e de inadimplência fizeram com que o setor de distribuição de energia elétrica se preocupasse cada vez mais com procedimentos de gestão e controle da proteção da receita.

Apesar do avanço tecnológico, que permitiu maior capilaridade e eficiência nas ações de combate a esse tipo de segmento de mercado (bad credit), os níveis de perdas nãotécnicas não cessaram no volume esperado. O fato é que a proliferação de pontos de consumo que apresentam consumo de energia de forma irregular é semelhante a um processo virótico e cíclico, uma vez que a "indústria da fraude" sempre renova conhecimentos, mesmo que em tempo de maturação mais longo do que o avanço de patamar tecnológico anterior.

Somado a este fato e considerando que as ferramentas de Smart Grid (Redes Inteligentes) ainda não estão difundidas no mercado brasileiro, observa-se que a maioria das distribuidoras operam este processo através de visitas às unidades consumidoras em campo, seja para detecção de irregularidades, que geram perdas não-técnicas, seja por execução de cobrança de débitos por suspensão de fornecimento. 
Neste contexto e esperando cumprir com o dever cidadão da melhoria da qualidade de energia elétrica e isonomia de tratamento, é interessante e bem-vinda a gestão operacional das equipes de campo visando à otimização de rotas de atuação através de uma seleção de alvos que permita o mínimo de esforço com a máxima recuperação de receita.

O presente trabalho apresenta uma metodologia de identificação de perdas comercias em sistemas de distribuição de energia elétrica, procurando avaliar a aplicação de técnicas espaciais e de agrupamento - como a regra dos "k-Vizinhos Mais Próximos" alinhada a metodologias de análise gráfica e visual, como as transformadas wavelet.

Nessa metodologia, desenvolvida em 11 etapas, o comportamento do sistema elétrico frente a evolução de consumo de energia dos elementos e de cada ponto ou agrupamento é adquirido por técnicas clássicas de análises de circuito e comparado aos valores medidos por leitura periódica.

As simulações realizadas com a metodologia proposta resultaram na identificação dos pontos de consumo irregular, selecionados aleatoriamente no início dos testes, dentre os mais indicados para regularização no mercado potencial, em classificação superior ao primeiro quartil do conjunto de dados, em média. Nestas oportunidades verificou-se também que o ponto de instalação mais crítico (maior ou constante queda de consumo) se assemelha ao verificado na realidade e análises pontuais dos pontos ou agrupamentos identificados indicaram que a evolução de seu consumo de energia apresenta-se, na maioria dos casos, menor que o esperado para a classe de consumo e daqueles verificados nos vizinhos lógicos mais próximos, indicando provável consumo irregular.

Palavras Chave: Perdas não-técnicas, energia elétrica, wavelet, modelos matemáticos, mineração de dados, faturamento. 


\section{Abstract}

CANCIAN, Wellington Fazzi, Metodologia para identificação e clusterização espacial de perdas não-técnicas em sistemas de distribuição de energia elétrica Escola de Engenharia, Universidade Federal de Minas Gerais, 2013. 132p. Dissertação (Mestrado).

Considering the growing demand for electricity in contrast to supply, the price of electricity keeps on raise, despite the relentless pursuit of the regulatory institution for equality, the costs to final consumers may commit the community's interest, specially in one of most complete and complex tariff methodology of the world and in a country with extreme social inequalities such as Brazil.

The main source of revenue of a distributor is the sale of electric energy for their captive market. Thus the increasing level of non-technical losses and default caused the sector distribution of electricity has developed increasingly with management of Recovery Revenue's procedures and control.

Despite the technological advances that allowed greater capillarity and efficiency in actions to eliminate this kind of market segment (bad credit), the levels of non-technical losses did not stop on the expected volume.

The fact is that the proliferation of points that present irregular energy consumption is similar to a viral and cyclic process, since the "fraud industry" always renews knowledge, even with maturation time longer than the progress technological level.

Added to this fact and considering that the tools of Smart Grid are not widespread in the Brazilian market yet, it's observed that most companies operate this process by visiting the consumer units in the field, being detecting irregularities - that generate non-technical losses - either running the collection of debts by disconnection.

In this context and expecting comply with the civic duty of improving power quality and equality of treatment, it is interesting the operational management of field teams, 
searching for optimize the action's routes through clustering - allowing minimal effort and maximum revenue recovery.

This thesis presents a methodology for identification of non-technical losses in distribution systems of electric power, evaluating the application of spatial and clustering techniques - as the rule of "k-nearest neighbors" - aligned to methodologies for graphical and visual analysis such as wavelet transform.

In this approach, developed in 11 steps, the behavior of the electrical system front to the element's and cluster's consumption of energy is acquired by classical techniques of circuit analysis and compared to the values measured by periodic reading.

Simulations with the proposed methodology have resulted in the identification of irregular consumption points, randomly selected at the beginning of the tests, among the most suitable for regulating, being ranked on the first quartile of the data set, on average. During that time it was also found that the most critical point of installation (or higher steady decrease in consumption) resembles that seen in reality and analyzes of clusters identified have indicated that the development of its energy consumption is presented, in most cases, lower than expected for the consumer class and those verified in the nearest logical neighbors, indicating probable irregular consumption.

Keywords: non-technical losses, electricity, wavelet, mathematical models, data mining, billing. 


\section{O AUTOR}

Wellington Fazzi Cancian nasceu em Poços de Caldas, MG, em
16/09/1983. É formado em Engenharia Elétrica e sua experiência
profissional foi construída no setor de distribuição de energia elétrica,
incluindo o Departamento Municipal de Eletricidade de Poços de
Caldas (DME-PC), e atualmente trabalha como engenheiro de
comercialização na Cemig Distribuição S.A.. Seus principais campos
de pesquisa no setor são referentes a área de comercialização de
energia, tarifação, gestão de receitas irrecuperáveis e perdas de
energia não-técnicas.

\section{Contatos}

Endereço: Rua Aimorés, 2139 - Lourdes - Belo Horizonte - MG - CEP:30140-072

Telefones: (31) 3275.0226

(31) 9644.4500

E-mail: $\quad$ wfcancian@gmail.com

O autor antecipadamente agradece futuros contatos, que se transformarão em valiosas contribuições a respeito do tema. 
“O que sabemos não é muito. O que não sabemos é imenso."

Pierre Simon Laplace 


\section{Sumário}

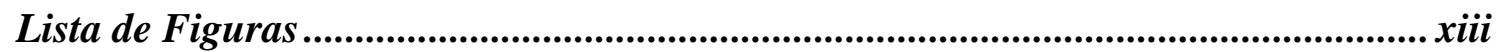

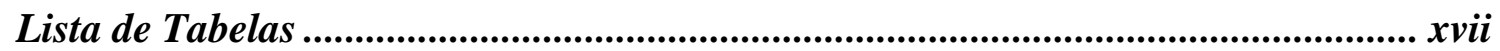

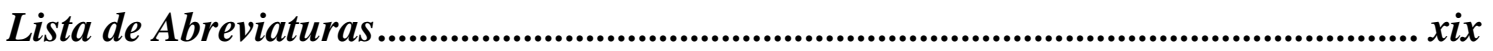

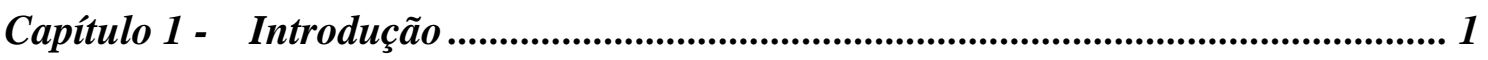

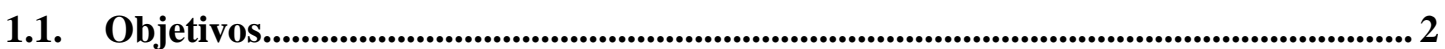

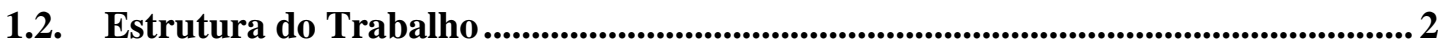

Capítulo 2 - Perdas em sistemas de energia elétrica ................................................ 4

2.1 O Consumo de Energia Elétrica e suas perdas ................................................................... 4

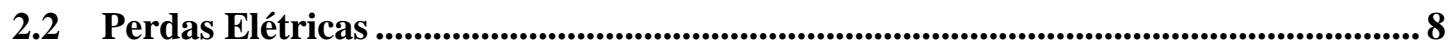

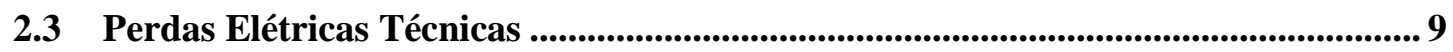

2.4 Perdas Elétricas Não-Técnicas (Comerciais) ........................................................... 12

2.5 Perdas Elétricas: Relação nas tarifas de energia elétrica ........................................... 19

Capítulo 3 - Metodologias de classificação por técnicas inteligentes/agrupamento 25

3.1 Metodologias utilizadas para identificação de focos de consumo irregular ............ 25

3.2 Técnicas não-paramétricas ................................................................................................ 26

3.2.1 Regra do "Vizinho Mais Próximo" ................................................................................ 26

3.2.1.1 A regra dos "k-Vizinhos Mais Próximos" ................................................................ 28

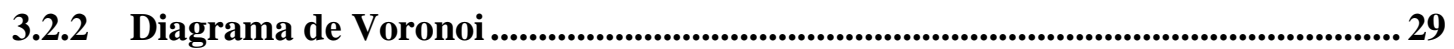

3.3 Máquina de Vetores de Suporte - Support Vector Machine (SVM) ......................... 31

3.4 Análise ou transformada Wavelet......................................................................................... 35

3.4.1 A transformada Wavelet contínua ................................................................................... 37

3.4.2 A transformada discreta Wavelet (Discrete Wavelet Transform) ......................... 38

3.4.3 A transformada rápida Wavelet (Fast Wavelet Transform) ..................................40

3.5 O sistema de cor RGB (Red/Green/Blue) ........................................................................ 43

3.6 Síntese do Capítulo ................................................................................................................ 45 


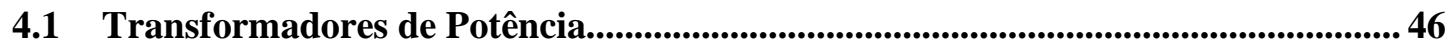

4.1.1 Tempo de vida de um transformador de potência em relação às perdas ............. 52

4.2 Distribuição e cálculo das perdas em Iluminação Pública........................................... 53

4.3 Cálculo de Fluxo de Potência..............................................................................56

Capítulo 5 - Descrição da Metodologia Proposta ................................................... 58

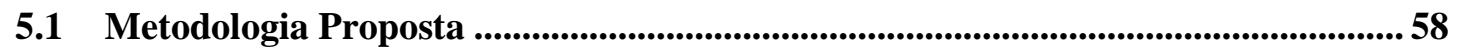

5.2 Tratamento do conjunto de dados de entrada ............................................................... 60

5.3 Distribuição da Iluminação Pública e respectivo cálculo das perdas técnicas....... 63

5.4 Identificação da localização dos agrupamentos e transformadores ao trecho do

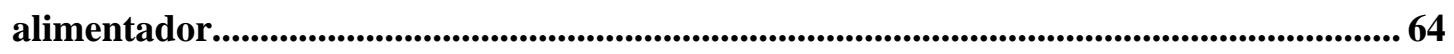

5.5 Cálculo das perdas técnicas dos transformadores...................................................6 64

5.6 Análise de consumo atual em relação ao nominal ........................................................... 65

5.7 Execução de análise de fluxo de potência ............................................................................. 66

5.8 Análise combinatória Wavelet das imagens históricas................................................... 66

5.9 Seleção das regiões e agrupamentos mais críticos ......................................................6 68

5.10 Análise comparativa e pontual dos maiores alvos ..................................................69

5.11 Perfis de Consumo Irregular Típicos................................................................................ 70

Capítulo 6 - Resultados obtidos e Estudo de Caso ........................................................ 76

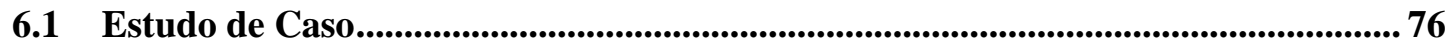

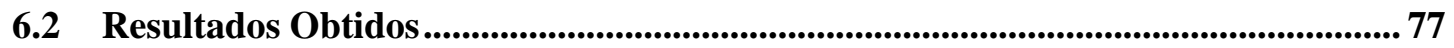

6.2.1 Primeira avaliação................................................................................................. 77

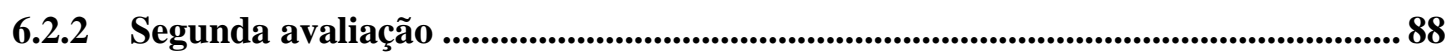

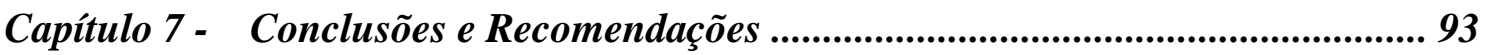

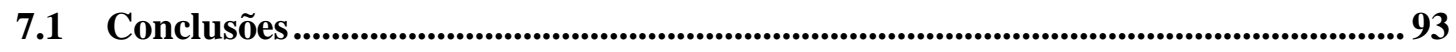

7.2 Recomendações para Trabalhos Futuros ........................................................................... 94

Bibliografia e Referências ................................................................................................... 96 
Apêndice A - Relação do consumo de energia elétrica das instalações que compuseram os perfis típicos de consumo irregular (em formato "Separado por vírgulas" - Comma-separated values - CSV) ........................................................ 101

Apêndice B - Interpolação de funç̃̃es ...................................................................... 108

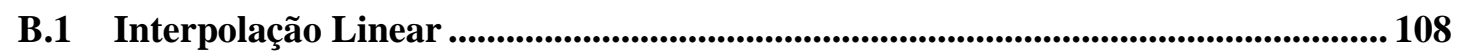

B.2 Interpolação Polinomial: Polinômios de Lagrange .....................................................110 


\section{Lista de Figuras}

Figura 2-1 - Variação do Produto Interno Bruto (PIB) no Brasil em relação à variação de consumo de energia (1998-2007).

Figura 2-2 - Distribuição mundial do Produto Interno Bruto (PIB) em paridade com o poder aquisitivo $(P P P)$ per capita.

Figura 2-3 - Distribuição de perdas de energia elétrica, técnica e não-técnica, no segmento de distribuição de energia elétrica brasileiro.

Figura 2-4 - Medidor convencional de energia elétrica manipulado, com o travamento do disco.

Figura 2-5 - Medidor convencional de energia elétrica manipulado, com o disco serrado, impossibilitando a medição correta. 14

Figura 2-6 - Medidor eletrônico de energia elétrica manipulado, através de jumper.. 15 Figura 2-7 - Percentual de perdas não-técnicas vs percentual de consumidores sem medição.

Figura 2-8 - Panfletos e chamadas veiculadas livremente na mídia com a promessa de reverter penalidades aos consumidores fraudadores.

Figura 2-9 - Nível de escolaridade em comparação com perfil de consumo da população atendida pela distribuidora brasileira Elektro. A distribuidora atende municípios do interior do estado de São Paulo. 18

Figura 3-1 - Demonstração gráfica sobre a regra do "Vizinho Mais Próximo". 28 Figura 3-2 - A busca pelos k-vizinhos mais próximos inicia-se a partir do ponto de teste x. Deste, cresce uma região esférica até que a mesma englobe k amostras préclassificadas. Assim, a classificação do ponto de teste x é dada pela maioria dos votos (classificações) dessas amostras. No caso de $k=5$, o ponto de teste x seria classificado na categoria de pontos pretos.

Figura 3-3 - Exemplo de um Diagrama de Voronoi de n pontos em um plano. Nesse caso, os pontos são as instalações, objeto de análise deste trabalho.

Figura 3-4 -Em duas dimensões (lado esquerdo da figura), o algoritmo do "Vizinho Mais Próximo" leva a uma partição do espaço de entrada em células Voronoi, cada qual classificada pela categoria do ponto de treinamento. Em três dimensões (lado direito da figura), as células Voronoi são tridimensionais e as fronteiras de decisão são semelhantes à superfície de um cristal. 
Figura 3-5 - Duas classes de vetores são representadas pelos círculos pretos e brancos. Nos exemplos, as imagens não podem ser separados com erros, os quais são indicados por cruzes, e os vetores de suporte por círculos duplos.

Figura 3-6 - O treinamento de uma máquina de vetores de suporte - SVM consiste em encontrar o hiperplano ótimo, ou seja, com a distância máxima a partir dos padrões, apurados no treinamento, mais próximas. Os vetores de suporte são os padrões (mais próximos), ou distância b do hiperplano. Os três vetores de suporte são representados como pontos sólidos.

Figura 3-7 - Relação especial entre os conjuntos/espaços de escalonamento e função wavelet.

Figura 3-8 - Análise do banco de filtros da transformada rápida wavelet e sua inversa.

Figura 3-9 - Análise do banco de filtros da transformada rápida wavelet para duas dimensões e exemplo de decomposição.

Figura 3-10 - Diagrama de Venn representando as três cores básicas do sistema RGB (Red/Blue/Green ou Vermelho/Azul/Verde) e algumas de suas possíveis combinações. Os valores dos vetores $R G B$, na figura, estão representados em hexadecimal.

Figura 4-1 - Circuito equivalente completo de um equipamento transformador, com carga.

Figura 4-2 - Diagrama de ligações para ensaio de perdas em vazio e corrente de excitação em transformadores, sem transformadores para instrumentos.

Figura 4-3 - Diagrama de ligações para ensaio de perdas em vazio e corrente de excitação em transformadores, com transformadores para instrumentos.

Neste intuito, Gouda, Amer, Salem et al. [37] desenvolveram um método analítico para predição da elevação de temperatura e redução de vida útil dos equipamentos transformadores em função da presença de correntes harmônicas. Neste trabalho, verificou-se que o nível de perdas elétricas se eleva em períodos intermediários de sua vida útil e, ao final do período, apresenta certa saturação em valores equivalentes a 2,2 p.u. (por unidade) de perdas elétricas, conforme verificado pela Figura 4-4.

Figura 4-5 - Relação entre vida útil do transformador e perdas elétricas , em p.u., estimada para até quatro vezes o período de vida útil nominal do equipamento.

Figura 4-6 - Relação de tipos e quantidades percentuais de lâmpadas instaladas no Brasil. 
Figura 4-7 - Esquemático simplificado de um sistema de iluminação Unilateral - visão aérea. 55

Figura 5-1 - Representação da metodologia para identificação e clusterização espacial de perdas não-técnicas em sistemas de distribuição de energia elétrica.

Figura 5-2 - Diagrama Entidade Relacionamento (DER) simplificado dos conjuntos de dados de entrada utilizados.

Figura 5-3 - Modelo analítico para definição de consumo crítico. Neste caso, o percentual do período para determinação das médias max/min foi de 10\% (ou 6 períodos). Em azul, os consumos de energia acima do nominal/esperado. Em vermelho, os consumos de energia que se lograram abaixo do nominal/esperado. As linhas pontilhadas representam os valores médios dos maiores e menores consumos verificados. Os pontos destacados em negrito representam os valores de consumo de energia máximos e mínimos considerados para determinação das médias (linhas pontilhadas).

Figura 5-4 - Os cinco perfis típicos de instalações que apresentam consumo irregular, disponíveis no modelo. 75

Figura 6-1 - Distribuição do alimentador por trecho (cor vermelha), pontos de instalação (destacados em azul) e transformadores de rede (destacados em verde) em um determinado município.

Figura 6-2 - Evolução de consumo de energia elétrica (regular e irregular) no alimentador e instalações. A análise visual é por temperatura de cor, sendo: "vermelho" - consumo a menor e; "azul" - consumo a maior em comparação com o período anterior. Na primeira das imagens são apresentadas as instalações-teste lançadas no modelo.

Figura 6-3 - Análise do Fluxo de Potência, especialmente em relação à queda de tensão (em p.u.) para cada trecho do alimentador, para cada uma das iterações.

Figura 6-4 - Análise wavelet das imagens/séries históricas de cada período.

Figura 6-5 - Representação gráfica de consumo de energia elétrica dos pontos estudados. As linhas tracejadas representam o consumo dos 5 vizinhos lógicos mais próximos ao ponto estudado. A linha horizontal representa a média de consumo esperada na classe de consumo no qual a instalação se enquadra.

Figura 6-6 - Representação gráfica de consumo de energia elétrica dos pontos estudados, destacados pela linha vermelha de cada gráfico. A ordenação dos pontos de 
consumo é crescente e segue a seguinte: da parte superior para a inferior, da esquerda para a direita. 91

Figura 6-7 - Instalação com desempenho de consumo crítico identificado pelo modelo. Pela análise do gráfico, percebe-se que houve queda significativa de consumo por 15 períodos (cerca de $41 \%$ do total), -entre os períodos 19 e 34 - recuperada no período 35 .

Figura B-1 - Representação gráfica de um método de interpolação. Os pontos preenchidos, representam os valores $\mathrm{x} e \mathrm{y}$ da função original $\mathrm{f}(\mathrm{x})$, enquanto os pontos destacados sem preenchimento são resultantes da operação de interpolação (representados pelos vetores xi $e$ yi).

Figura B-2 - Representação gráfica da utilização de interpolação por Polinômios de Lagrange. Em azul, a função original (função tangente: $\mathrm{fx}=\tan (\mathrm{x})$ ) e em verde, a função interpolada. 


\section{Lista de Tabelas}

Tabela 2-1 - Relação da distribuição de perdas não-técnicas em relação à

prosperidade econômica.

Tabela 2-2 - Resumo das variáveis analisadas na metodologia de tratamento

regulatório para perdas não técnicas de energia elétrica.

Tabela 2-3 - Modelo "A" para cálculo do índice de complexidade da área de concessão de cada distribuidora nacional.

Tabela 2-4 - Modelo "B” para cálculo do índice de complexidade da área de concessão de cada distribuidora nacional.

Tabela 2-5 - Modelo "C" para cálculo do índice de complexidade da área de concessão de cada distribuidora nacional.

Tabela 3-1-Metodologias e técnicas utilizadas para identificação de indícios de consumo irregular.

Tabela 3-2 - Funções kernel mais utilizadas.

Tabela 3-3 - Exemplo de cores utilizando a escala RGB. Entre parênteses, a codificação em escala hexadecimal.

Tabela 4-1 - Relação de transformadores em comparação com o número de instalações consumidoras por empresa distribuidora de energia elétrica do sistema nacional. ..... 47 Tabela 4-2 - Valores garantidos de perdas para transformadores trifásicos com tensão máxima de 15 kV. Para o cálculo da coluna "Perda Total/Potência do transformador", foi considerado o fator de potência (FP) equivalente a $92 \%$. 50

Tabela 4-3 - Valores percentuais típicos a serem utilizados nas variáveis Wh ou Wf, caso haja impossibilidade de medição de tais grandezas.

Tabela 4-4 - Dados de carga para Iluminação Pública, considerando valores médios de fabricantes e fator de potência $92 \%$.

Tabela 5-1 - Análise de correlação entre as curvas de consumo irregular e formação de grupos das instalações de amostragem.

Tabela 5-2 - Relação das instalações cuja distribuição de consumo irregular apresentou melhor correlação em comparação com as demais disponíveis na amostragem sendo: (a) frequência dentre as 5 melhores $e(b)$ frequência sendo a de melhor correlação.

Tabela 5-3 - Formação dos 5 grupos que representam os perfis de consumo irregular típicos. 
Tabela 5-4 - Coeficientes de correlação Pearson utilizado na composição dos 5 grupos que representam os perfis de consumo irregular típicos. .............................................. 73

Tabela 6-1 - Instalações-teste para o modelo, bem como suas respectivas curvas típicas, selecionadas de forma aleatória.

Tabela 6-2 - Informações das cinco instalações lançadas ao modelo para identificação das mesmas dentre os 905 alvos, bem como suas respectivas curvas típicas, selecionadas de forma aleatória. 88 


\section{Lista de Abreviaturas}

\begin{tabular}{ll} 
ABNT & Associação Brasileira de Normas Técnicas \\
ANEEL & Agência Nacional de Energia Elétrica \\
AT & Alta Tensão \\
BT & Baixa Tensão \\
CEMIG & Companhia Energética de Minas Gerais \\
DER & Diagrama Entidade Relacional \\
DWT & Transformada Discreta Wavelet (Discrete Wavelet Transform) \\
FC & Fator de Carga \\
FWT & Transformada Rápida Wavelet (Fast Wavelet Transform) \\
IBGE & Instituto Brasileiro de Geografia e Estatística \\
IMF & Fundo Monetário Internacional (International Monetary Fund) \\
IP & Iluminação Pública \\
IWT & Transformada Integral Wavelet (Integral Wavelet Transform) \\
k-NN & Regra dos “k-Vizinhos Mais Próximos" (k-Nearest-Neighbors) \\
MT & Média Tensão \\
NN-rule & Regra do "Vizinho Mais Próximo" (Nearest-Neighbor Rule) \\
NTL & Non-Technical Losses \\
p.u. & Por Unidade \\
PIB & Produto Interno Bruto \\
PNT & Perdas Não-Técnicas \\
PT & Perdas Técnicas \\
SEP & Sistema Elétrico de Potência \\
SMC & Sistema de Medição Centralizada \\
SV & Vetor de Suporte (Support Vector) \\
SVM & Máquina de Vetores de Suporte (Support Vector Machine) \\
Wh & Wora \\
\hline
\end{tabular}




\section{Capítulo 1 - Introdução}

Este capítulo apresenta uma visão geral sobre aspectos relacionados ao assunto de perdas não-técnicas/comerciais de energia elétrica, especialmente em sistemas de distribuição. Trata-se de um capítulo de caráter introdutório, com o objetivo de integralizar o trabalho em função do tema "perdas não-técnicas de energia elétrica".

As perdas não-técnicas (PNT) são originadas especialmente do furto de energia elétrica e demais irregularidades identificadas no sistema elétrico de potência ou no de medição, o que tornam-se problemas clássicos e crônicos para a indústria de suprimento de energia elétrica. Dentre as causas mais comuns de ocorrência de perdas não-técnicas destacam-se a falta ou adulteração de medição, mal-funcionamento da medição, conexões clandestinas ou ilegais, faturamentos irregulares ou errôneos e inadimplência de faturas - a qual, sua persistência, é um dos motivadores para os consumidores adentrarem ao mundo do consumo irregular [1].

Este problema não é exclusividade de países menos desenvolvidos como aqueles localizados nos continentes do Hemisfério Sul (especialmente América Latina, África e algumas regiões da Ásia), mas também identificado em países desenvolvidos como Estados Unidos da América e países do oeste europeu [2]. No cenário mundial, verificase que a América do Sul e América Central são as regiões nas quais é identificado o maior potencial de redução de perdas não-técnicas por apresentar as maiores taxas de PNT [3]. Inserido no mercado potencial, o Brasil, que servirá como alvo para o estudo, contribui com parcela significativa, devido ao seu porte e sua importância no ambiente energético latino-americano.

Neste contexto, a atuação e a prevenção de perdas não-técnicas são motivadas não somente pela busca por melhores resultados de qualidade de fornecimento ou econômico-financeiros das Empresas de prestação dos serviços de energia elétrica, mas também por fins de garantia de sustentabilidade, através da possibilidade de postergação de investimentos, uma vez que esses geralmente envolvem alto custo/impacto 
ambiental, além de contribuir para modicidade tarifária aos consumidores e representar senso de justiça, ordem e respeito, especialmente com a parcela idônea da sociedade.

\subsection{Objetivos}

O objetivo geral deste trabalho é apresentar uma proposta de metodologia para a investigação assertiva de perdas não-técnicas de energia elétrica em um ambiente de distribuição de energia elétrica em níveis de Baixa Tensão (BT), especialmente, considerando os aspectos específicos e regulatórios da região estudada, visando a atuação em unidades consumidoras potenciais destacadas e garantir a elevação dos níveis de sucesso em inspeções de consumo irregular com maior recuperação de receita com o menor esforço possível das equipes - esforço ótimo.

Os objetivos específicos são: (i) abordar o problema de detecção de clusters (aglomerados), tanto para dados de área quanto para dados de casos pontuais, utilizando um conjunto de dados espaciais de pontos potenciais de consumo de energia irregular em um sistema de distribuição de energia elétrica; (ii) propor metodologia eficiente de identificação de perdas não-técnicas, através de métodos de estatística espacial, classificação de padrões e otimização em engenharia; (iii) avaliar a viabilidade do modelo, aplicando-o em um cenário real.

\subsection{Estrutura do Trabalho}

O Capítulo 2 disserta sobre a caracterização das perdas elétricas em sistemas de potência, bem como seus tipos - técnicas e não-técnicas, sua distribuição no Brasil e no mundo. São também discutidas as implicações e considerações da matéria em âmbito tarifário, vinculado aos seus aspectos socioeconômicos.

O Capítulo 3 trata do estado da arte com relação às técnicas aplicadas por estudiosos para solução do problema de identificação e clusterização de pontos com perdas nãotécnicas. Esta seção também dispõe de metodologias de classificação de padrões e de análise e tratamento de imagens que são utilizadas neste trabalho. 
O Capítulo 4 trata da fundamentação teórica de métodos aplicáveis a Sistemas Elétricos de Potência - SEP no que tange a consumo de energia e suas perdas em equipamentos básicos do SEP, como transformadores e elementos de Iluminação Pública, além de técnicas clássicas de análise de circuitos e Fluxo de Potência.

O Capítulo 5 descreve, de forma detalhada, a metodologia proposta pelo trabalho, com suas respectivas etapas, implementadas por algoritmos computacionais, utilizando modelos matemáticos oriundos da Engenharia Elétrica e Otimização.

O Capítulo 6 relata os resultados obtidos com a aplicação de conjunto de dados à metodologia proposta, bem como seu estudo de caso e análises pontuais.

O Capítulo 7 apresenta as conclusões, desafios e recomendações para trabalhos futuros, que podem ser promovidos a partir deste. 


\section{Capítulo 2 - Perdas em sistemas de energia elétrica}

Este capítulo apresenta uma revisão literária de estudos realizados em vários países sobre os impactos das perdas de energia elétrica.

Nas primeiras seções, disserta-se a fundo os conceitos teóricos aplicados e divergências de metodologia de cálculo para Perdas Técnicas e Perdas Não-Técnicas - PNT, bem como a experiência dos operadores do sistema em caracterizar o tema e tipificação penal.

Em complemento, são destacados os diversos métodos empíricos encontrados de roubo ou consumo irregular de energia elétrica, como manipulação de equipamentos e a chamada "indústria da fraude".

A última seção apresenta uma visão geral de como as perdas de energia elétrica impactam negativamente a qualidade do sistema elétrico, a modelagem tarifária e quais os fatores considerados pelo órgão regulador brasileiro, a Agência Nacional de Energia Elétrica - ANEEL - na formulação do denominado "índice de complexidade" das áreas de concessão.

\subsection{O Consumo de Energia Elétrica e suas perdas}

A energia elétrica é uma das formas de energia mais utilizadas na atualidade, sendo essencial para grande parte da produção industrial, além do desempenho de atividades de agricultura, pecuária, comércio e serviços de uma população que depende diretamente da energia elétrica. A variação de consumo de energia reflete tanto no ritmo de atividade dos setores produtivos quanto no poder de compra da população e na aquisição bens ou serviços que necessitem acesso à rede elétrica que, por consequência, pressionam seu consumo.

Portanto, admitir que a produção e consumo de energia elétrica é um dos principais indicadores de desenvolvimento econômico de qualquer país e fatores contribuintes para 
variação do Produto Interno Bruto - PIB $^{1}$ de um país parece-nos deveras razoável, o que pode ser comprovado pelas informações da Figura 2-1.

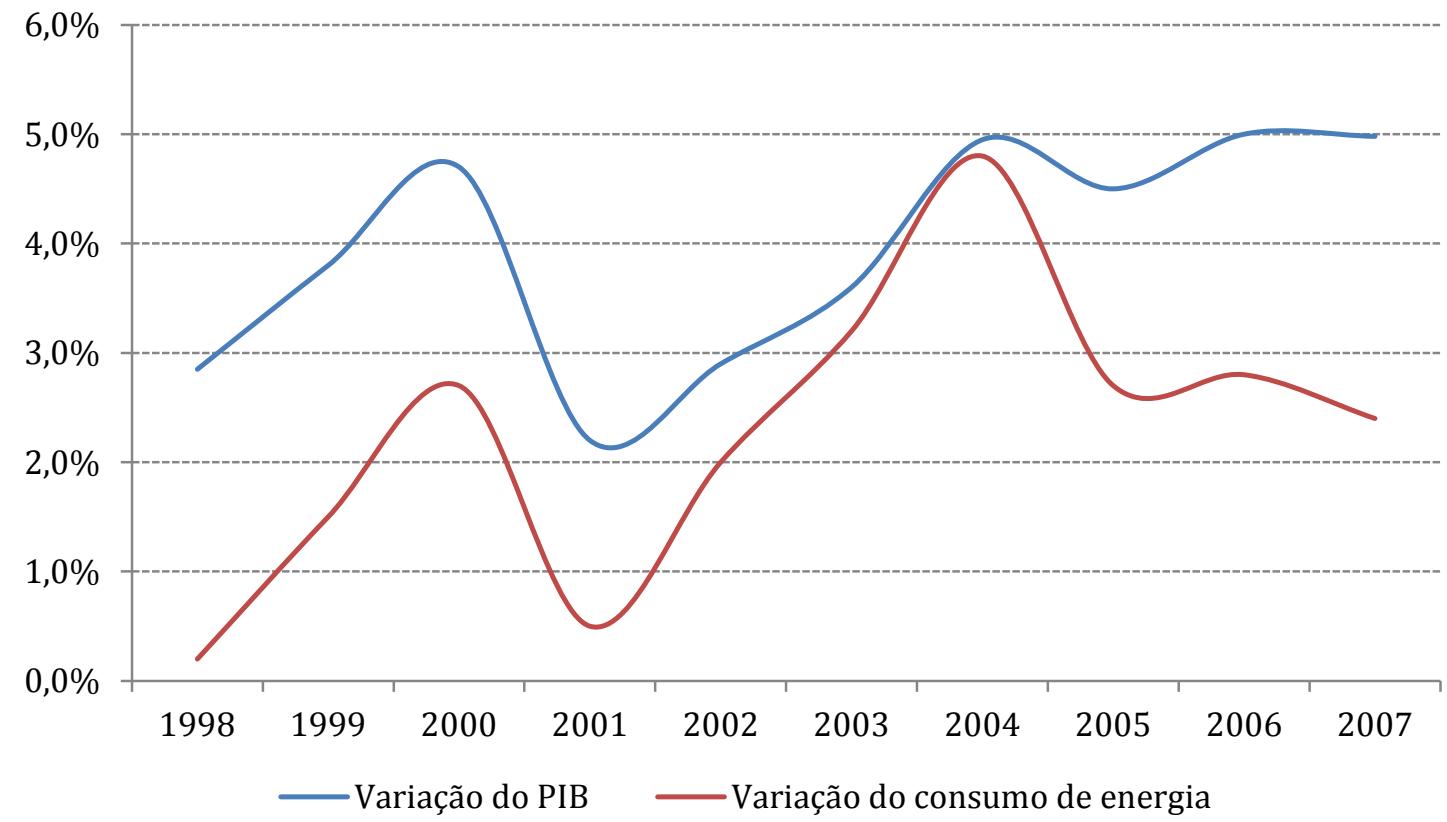

Figura 2-1 - Variação do Produto Interno Bruto (PIB) no Brasil em relação à variação de consumo de energia (1998-2007).

Fonte: Ipea, BP, 2008.

Interessante observar pela Figura 2-1 que, a partir do ando de 2005, ocorre um deslocamento entre as curvas de variação do PIB e de consumo de energia elétrica. $\mathrm{O}$ fato pode ser explicado pela maior consciência do consumidor para com a utilização da energia elétrica de forma eficiente, motivada pelo racionamento ocorrido no ciclo 20022003 no Brasil.

Mas não é somente nos setores produtivos que a energia elétrica desponta como vetor de elevada importância. Com o avanço da tecnologia e com o advento da modernidade, atualmente é inadmissível imaginar nossas vidas sem este bem, muitas vezes tido como serviços ou atividades essenciais à população [4] .

\footnotetext{
${ }^{1}$ Produto Interno Bruto (PIB): representa a soma, em valores monetários, de todos os bens e serviços finais produzidos numa determinada região (quer sejam países, estados ou municípios), durante um período determinado (mês, trimestre, ano). O PIB é um dos indicadores mais utilizados na macroeconomia com o objetivo de mensurar a atividade econômica de uma região [51].
} 


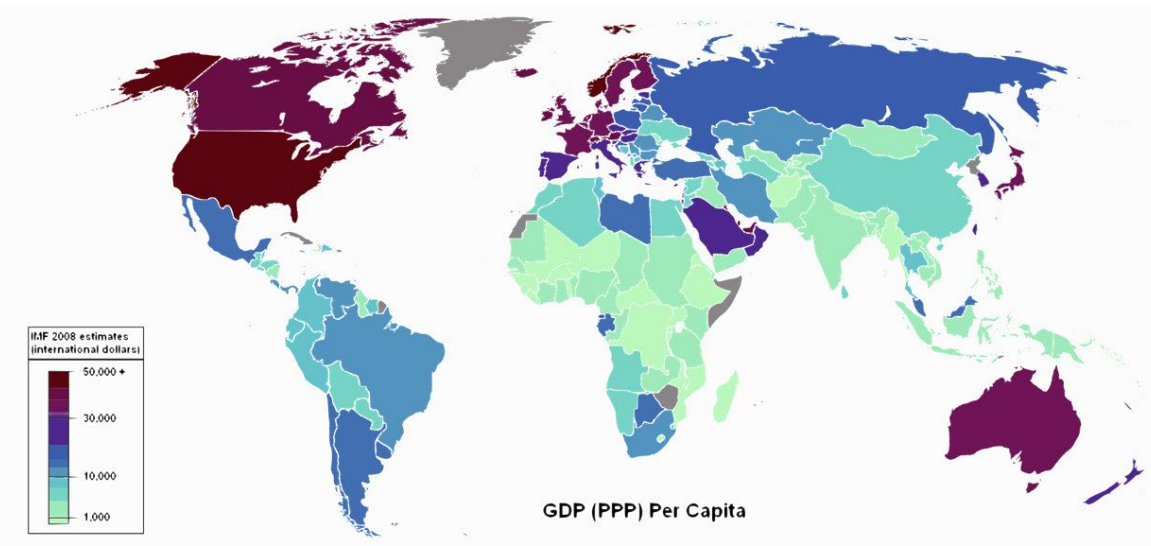

Figura 2-2 - Distribuição mundial do Produto Interno Bruto (PIB) em paridade com o poder aquisitivo (PPP) per capita.

Fonte: IMF, 2008.

Contudo, devido ao seu considerável custo de produção que envolve toda sua cadeia produtiva, desde a geração, transporte, comercialização e distribuição, além de, na maioria dos países, as atividades serem desempenhadas por meio de diversos players, concessionários de serviço público, uma vez que a intervenção única e exclusivamente estatal poderia não dar-se na mesma velocidade de desenvolvimento e crescimento que uma nação almeja, a energia elétrica é um bem precificado, ou melhor, tarifado aos consumidores finais, em contrapartida ao serviço prestado.

Ocorre que, especialmente em áreas de elevada complexidade sócio- econômica, no qual ainda há espaço para melhoria dos níveis de desigualdade, a contrapartida pelos serviços não é completa, considerando que parcela dos consumidores vale-se de práticas ilegais e artifícios técnicos para ludibriar o faturamento de consumo de energia elétrica das concessionárias.

Esta prática, no Brasil, é conhecida como o famigerado "gato" de energia e em algumas localidades e em determinados ciclo sociais é considera como comportamento normal e, até mesmo, aceitável, permitindo perpetrá-la, em virtude da discordância sobre o dever de aportar contrapartidas ou em ressentimento pela má prestação ou ausência de outros serviços públicos pelo Estado, sendo que o mesmo grupo poderia, conscientemente, estorvá-la (prestação do serviço). 
Cabe ressaltar que, valer-se da prática de procedimento irregular, como adulteração do sistema de medição ${ }^{2}$ de energia elétrica, em termos legais é qualificado como furto, definido como "Subtrair, para si ou para outrem, coisa alheia imóvel. Equipara-se à coisa móvel a energia elétrica ou qualquer outra que tenha valor econômico" [5]. Furtos ocorrem em todos os setores, geralmente vinculados a vantagem monetária, dentre os quais destacam-se: caixa bancários eletrônicos, transações de cartão de crédito, consumo vinculado aos serviços públicos como telecomunicações, de saneamento, água e esgoto e sistemas de distribuição de conteúdos audiovisuais e televisão (TV a Cabo).

Segundo o disposto em regulações do setor, perdas não técnicas correspondem à "parcela de energia consumida e não faturada por concessionária de distribuição, devido a irregularidades no cadastro de consumidores, na medição e nas instalações de consumo" [6].

Percebe-se que a relação entre o PIB e consumo, apresentada pela Figura 2-2, é inversamente proporcional ao nível de perdas não-técnicas. A Tabela 2-1 apresenta os níveis estimados de perdas elétricas em alguns países de todos os continentes, em função de seu respectivo PIB per capita.

\footnotetext{
${ }^{2}$ Sistema de Medição: conjunto de equipamentos, condutores, acessórios e chaves que efetivamente participam da realização da medição de faturamento [14].
} 


\begin{tabular}{|l|c|c|}
\hline \multicolumn{1}{|c|}{ País } & Perdas elétricas não-técnicas estimadas & PIB per capita \\
\hline Índia & 20 a 40\% & 2.700 \\
\hline Filipinas & No\% (Perdas Totais: 10\%) & 3.300 \\
\hline Indonésia & 3 a 5\% (Perdas Totais: 15\%) & 3.400 \\
\hline Jordânia & $13,2 \%$ (Perdas Totais: 23,2\%) & 4.700 \\
\hline Jamaica & $10 \%$ & 4.800 \\
\hline China & $0,32 \%$ (Perdas Totais: 5,69\%) & 5.300 \\
\hline Tailândia & 0,5 a 25\% & 8.000 \\
\hline Brasil & 6 a 64\% & 9.400 \\
\hline Turquia & $10 \%$ & 10.600 \\
\hline África do Sul & $12,74 \%$ & 12.800 \\
\hline Venezuela & acima de 10\% & 14.600 \\
\hline Rússia & Entre 0,2 a 1\% & $>30.000$ \\
\hline Reino Unido, Austrália e & & \\
Estados Unidos & Notas: & \\
\hline
\end{tabular}

Tabela 2-1 - Relação da distribuição de perdas não-técnicas em relação à prosperidade econômica. Fonte: Millard R. e Emmerton M., 2009.

\subsection{Perdas Elétricas}

De acordo com Alam et al. [2], as perdas que afetam os sistemas de distribuição de energia elétrica podem ser classificadas em duas grandes categorias: (i) perdas técnicas; e (ii) perdas não técnicas.

As perdas elétricas são definidas como sendo a diferença entre o montante de eletricidade entregue pela concessionária distribuidora de energia elétrica numa determinada região e a faturada como consumida pelas instalações dos consumidores.

Idealmente, toda a energia elétrica gerada poderia ser equivalente a toda energia registrada como consumida. Entretanto, em termos práticos, a situação difere da ideal uma vez que as perdas ocorrem como um resultado intrínseco do processo de transmissão e distribuição de energia elétrica. 
Davidson et al. [7] definiu que essas perdas de energia elétrica podem ser dadas segundo a seguinte equação:

$$
E_{\text {perdas }}=E_{\text {entregue }}-E_{\text {faturada }}
$$

Onde

$E_{\text {perdas }}$ expressa o montante de energia elétrica perdida,

$E_{\text {entregue }}$ expressa o montante de energia elétrica entregue pela concessionária, e

$E_{\text {faturada }}$ expressa o montante de energia elétrica faturado ou vendido/consumido.

\subsection{Perdas Elétricas Técnicas}

As perdas técnicas em sistemas de potência - como linhas de transmissão, alimentadores de distribuição, ramais e rede primária e secundária - são um fenômeno físico natural motivada pela dissipação de calor devido ao transpasse de corrente elétrica em um dado condutor em determinado período de tempo, fenômeno este conhecido no ambiente da Física como "Efeito Joule"3.

O nível de perdas técnicas de uma distribuidora depende diretamente do tipo de equipamento utilizado - tecnologia e tipologia da rede, basicamente - do comprimento e do carregamento dos circuitos mensurados, além da qualidade da manutenção do sistema elétrico em estudo, em consonância com a evolução do mercado consumidor.

Os patamares de perdas técnicas são passíveis de computação e controle, mesmo que estimados, ou seja, definidos por meio de parâmetros estocásticos, podendo ser definidas tanto por meio de simulações quanto através de medições ou avaliações do sistema elétrico estudado.

\footnotetext{
${ }^{3}$ Efeito Joule, também conhecido como "Lei de Joule" é uma lei física que expressa a relação entre o calor gerado e a corrente elétrica que percorre um condutor em determinado tempo. O nome é devido a James Prescott Joule (1818-1889) que estudou o fenômeno em 1840 [52].
} 
Valendo-se do avanço da tecnologia da informação e aquisição de dados, têm sido desenvolvidas, ao longo dos anos, ferramentas computacionais para cálculo de fluxo de potência, perdas e situação dos equipamentos em um sistema de potência, o que possibilitou que o cálculo das perdas técnicas se tornasse menos complexo e mais palpável. Na Figura 2-3 é possível observar a distribuição das perdas de energia elétrica no setor elétrico brasileiro.

A avaliação das perdas nas cargas do sistema, neste caso, não é incluída nos cálculos de perdas técnicas visto que, teoricamente, são susceptíveis a receber energia elétrica tanto quanto for possível [8].

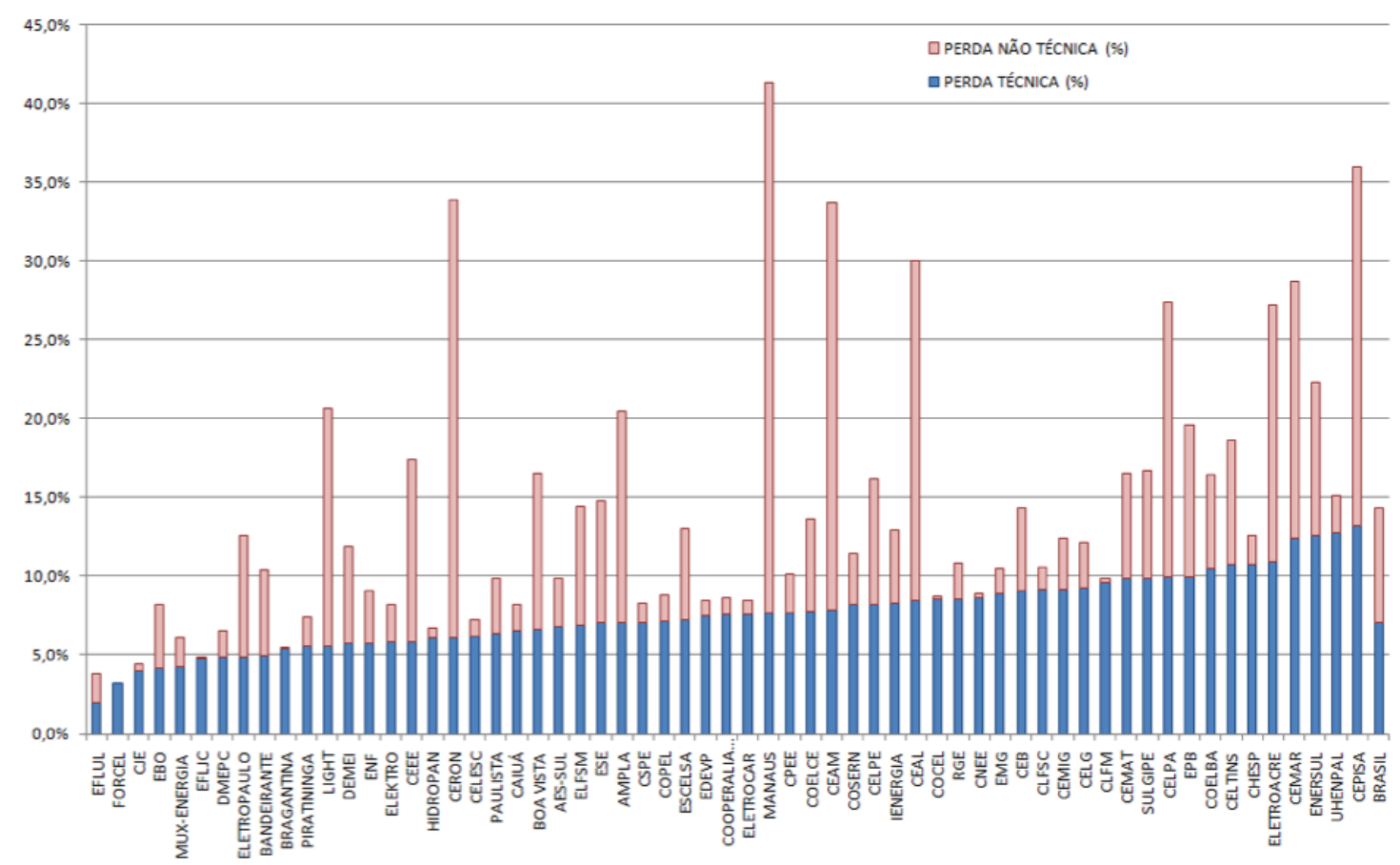

Figura 2-3 - Distribuição de perdas de energia elétrica, técnica e não-técnica, no segmento de distribuição de energia elétrica brasileiro.

Fonte: Aneel, 2010. 
Segundo Poveda et al. [9], geralmente, os cálculos de perdas técnicas incluem:

(i) as perdas resistivas em alimentadores primários (Alta Tensão - AT);

(ii) as perdas vinculadas aos equipamentos transformadores de distribuição perdas resistivas em seu núcleo e enrolamentos;

(iii) as perdas resistivas em alimentadores secundários (Média Tensão - MT e Baixa Tensão - BT)

(iv) as perdas resistivas em ramais de ligação - ligação entre distribuidora e consumidor e;

(v) as perdas nos equipamentos de medição.

Davidson et al. [7] definiu uma equação para calcular a receita financeira perdida devido à disposição de perdas técnicas de energia elétrica, conforme apresentado:

$$
C_{\text {perdido }}=U_{\text {custo }} \times E_{\text {Tperdida }}+M_{\text {custo }}
$$

Onde

$C_{\text {perdido }}$ expressa a receita financeira perdida devido à perdas técnicas ou adicionais ao sistema,

$U_{\text {custo }}$ expressa o custo unitário da energia elétrica - tarifa,

$E_{\text {Tperdida }}$ expressa o montante de energia elétrica perdida por deficiência técnica, $\mathrm{e}$

$M_{\text {custo }}$ expressa os custos operacionais adicionais ou para manutenção do sistema.

De acordo com os estudos de Dortolina \& Nadira et al. [10], as duas maiores fontes que contribuem para a elevação das perdas técnicas estão relacionadas a: (i) perdas de carregamentos, consistindo em componentes resistivos e reativos, de vários elementos do sistema; e (ii) perdas a vazio, independentes da carga real atendida pelo sistema elétrico de potência.

A maioria das perdas a vazio está vinculada ao núcleo dos equipamentos transformadores, resultado do fluxo elétrico de sua corrente de excitação. 


\subsection{Perdas Elétricas Não-Técnicas (Comerciais)}

As perdas não-técnicas - PNT, ou Non-Technical Losses - NTL, referem-se àquelas que têm ocorrência de forma independente e complementares às perdas técnicas nos sistemas de potência, compondo, junto ao último, o índice global de perdas em um sistema.

As PNT's estão localizadas, dominantemente, nas menores seções (BT) das redes de distribuição de energia elétrica, e são causadas por ações externas ao funcionamento nominal do sistema de potência, costumeiramente vinculadas a eventos observados nas cargas ou instalações de consumo e, indiretamente, por condições nas quais a metodologia de cálculo para estimação dos níveis de perdas técnicas não considerou.

No Brasil, o prejuízo com perdas não-técnicas ou consumo irregular de energia elétrica atingiu o patamar de $\mathrm{R} \$ 8,1$ bilhões ao ano, considerando o período de 2007 a 2010, conforme estudos da ANEEL. O valor inclui o custo da energia e os impostos que deixam de ser arrecadados aos cofres públicos. Em energia, o valor corresponde a mais de 27 mil Gigawatts-hora, aproximadamente $8 \%$ do consumo do mercado cativo elétrico brasileiro.

Esse montante seria suficiente, por exemplo, para abastecer anualmente os estados de Minas Gerais e Maranhão. 
Acredita-se que, atualmente, as formas mais notáveis de perdas não-técnicas estejam relacionadas ao furto de energia elétrica e à suspensão de fornecimento anterior a manipulação de consumo, devido à inadimplemento de faturas de energia elétrica, se não todas elas. Os fatores mais comuns que contribuem para a ocorrência de perdas nãotécnicas, indicadas na literatura [11], [12], [7] e [1], são os seguintes:

(i) Conexão ao sistema elétrico à revelia ou desautorizada pelos operadores do sistema de potência;

(ii) adulteração dos equipamentos de medição, visando o registro menor de consumo de energia elétrica;

(iii) desvios de energia elétrica desautorizados pelos operadores do sistema, através do by-pass dos equipamentos de medição ou qualquer outra forma de ligação clandestina;

(iv) imprecisões ou insuficiência de leitura dos medidores de energia;

(v) procedimentos de faturamento de consumo e base cadastral imprecisos;

(vi) procedimentos de recuperação de receita ineficientes;

(vii) irregularidades forjadas com o auxílio de funcionários corruptos do próprio operador do sistema, como adulterar os valores consumidos a serem faturados;

(viii) inadimplemento da(s) fatura(s) de energia elétrica;

(ix) perdas de energia elétrica devido a falhas de equipamentos de medição;

(x) considerável inexatidão da estimativa de cargas não medidas como, por exemplo, iluminação pública e tração elétrica;

(xi) ineficiência dos sistemas de gestão de negócios e tecnologia. 


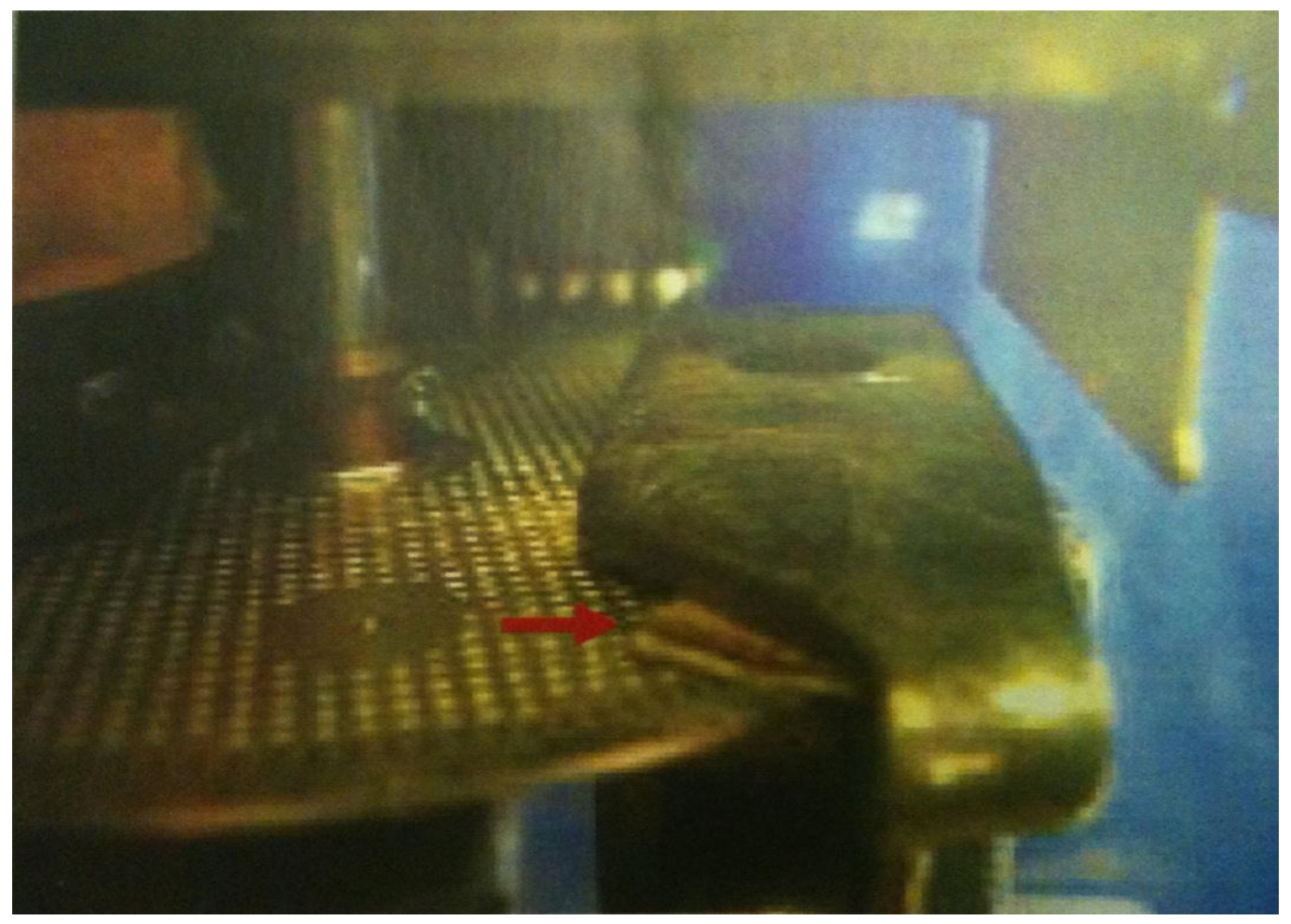

Figura 2-4 - Medidor convencional de energia elétrica manipulado, com o travamento do disco.

Fonte: Fábio Amorim da Rocha, 2011.

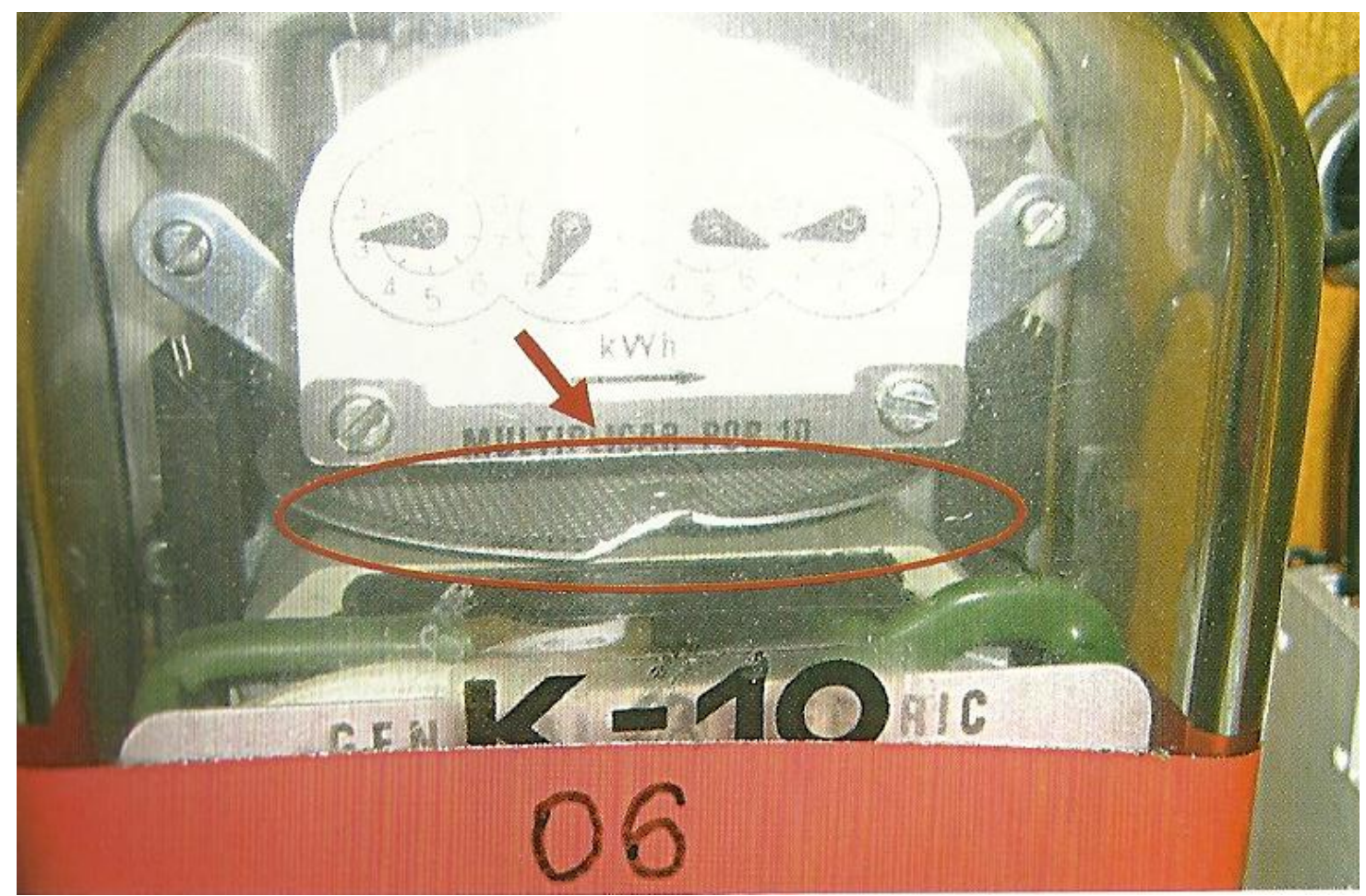

Figura 2-5 - Medidor convencional de energia elétrica manipulado, com o disco serrado, impossibilitando a medição correta.

Fonte: Fábio Amorim da Rocha, 2011. 


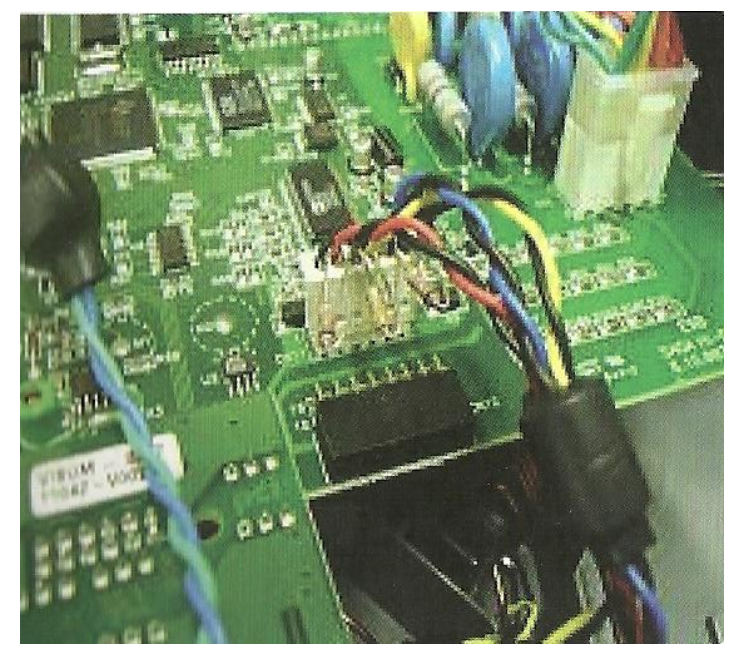

Figura 2-6 - Medidor eletrônico de energia elétrica manipulado, através de jumper.

Fonte: Fábio Amorim da Rocha, 2011.

Neste sentido, as Figuras Figura 2-4, Figura 2-5 e Figura 2-6 explicitam procedimentos irregulares em equipamentos de medição verificados em campo, tanto em medidores analógicos quanto digitais.

Além dos motivos listados, em um estudo realizado por [13] observou-se que distribuidoras em que há presença acentuada de instalações, cujos titulares solicitaram encerramento contratual, sem medição verifica-se também elevados níveis de perdas não-técnicas. Da mesma forma, aquelas empresas que se destacam no combate às perdas, mesmo atuando em regiões de elevada complexidade, a parcela de consumidores sem medidor é praticamente inexpressiva.

A correlação observada neste estudo entre as duas variáveis foi de $62 \%$, o que pode ser verificado na Figura 2-7. Esse é um resultado esperado, visto que o consumidor sem medição é faturado pelo mínimo ou por cálculos aproximados independente de seu consumo real, o que faz desse tipo de prática comercial um forte potencial para o surgimento de perdas não-técnicas.

A retirada dos equipamentos de medição, quando da solicitação de encerramento contratual por parte do consumidor, é prerrogativa da distribuidora gestora do sistema, conforme [14]. Esta prática é adotada por motivos diversos, sendo os principais 
relacionados à desativação contábil dos equipamentos ou, até mesmo, estoque e utilização dos mesmos em outro ponto de consumo. No caso de encerramento das relações contratuais, o ponto de consumo não mais pode ser faturado, apesar de o local existir fisicamente.

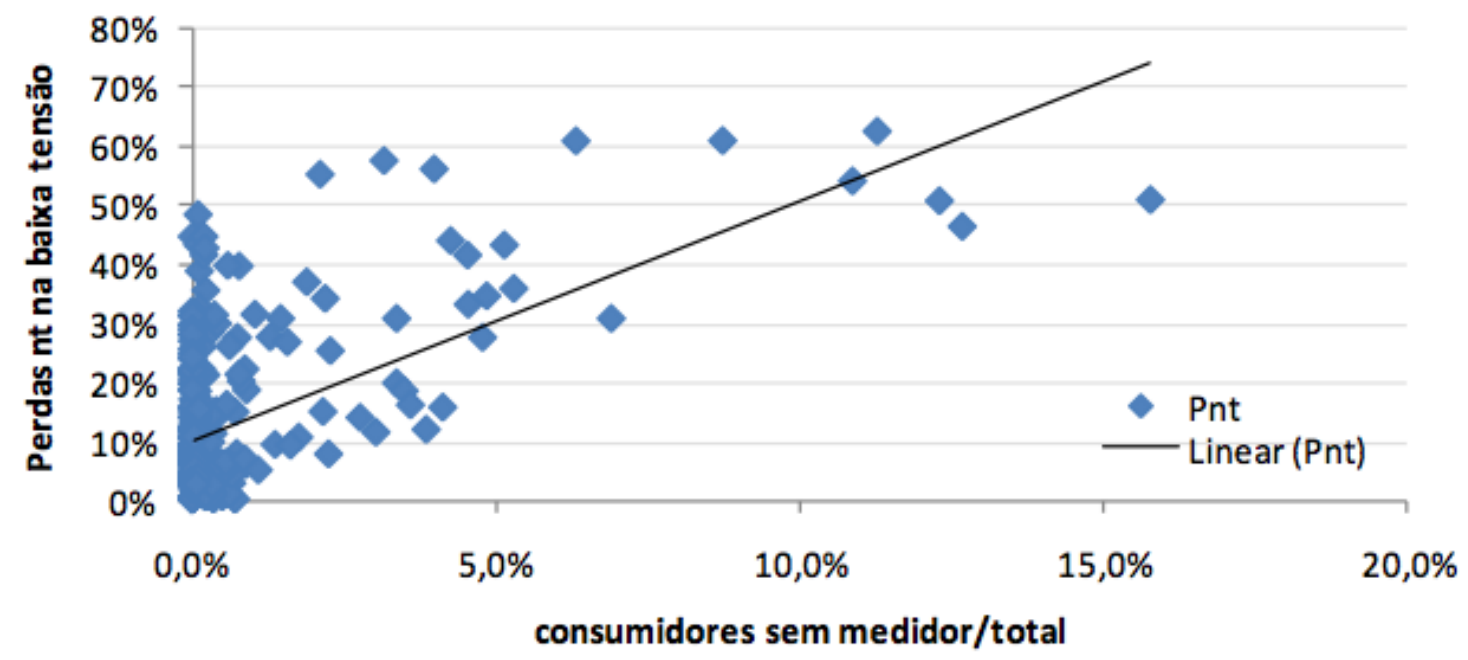

Figura 2-7 - Percentual de perdas não-técnicas vs percentual de consumidores sem medição. Fonte: ANEEL,2011.

Há ainda a chamada "indústria das irregularidades", ou seja, quem ofereça serviços de assistência jurídica aos clientes que cometem irregularidades no consumo de energia elétrica, visto que o entendimento sobre o período e o consumo retroativo à identificação da situação irregular ainda é deveras controverso na esfera judiciária que, em boa parcela dos julgamentos, entende ser indevida a cobrança dos valores não faturados ou arrecadados - popularmente denominados equivocadamente como "multa" - à época pelos operadores do sistema e, por essa razão, seria cabível, além do cancelamento dos valores retroativos cobrados, a indenização por danos morais.

Conforme observado na Figura 2-8, tais serviços são veiculados indiscriminadamente em jornais e outdoors espalhados em grandes centros urbanos e, pasmem, oferecidos em panfletos absurdamente entregues nas próprias agências de atendimento dos operadores do sistema onde, muitas vezes, os clientes são, também, abordados. 


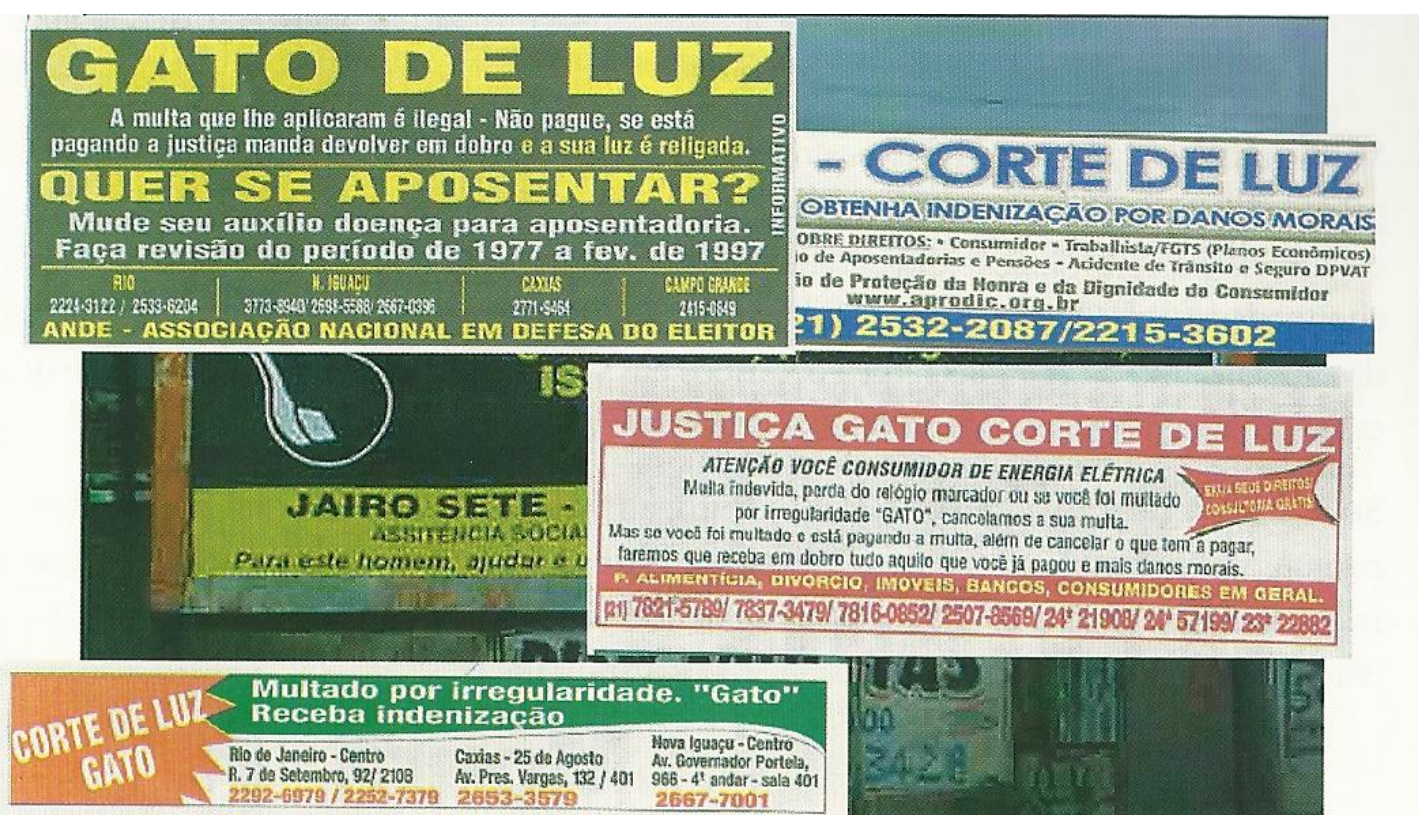

Figura 2-8 - Panfletos e chamadas veiculadas livremente na mídia com a promessa de reverter penalidades aos consumidores fraudadores.

Fonte: Compilação por Fábio Amorim da Rocha, 2011.

Segundo Vieiralves et al. [1], em comparação com o gerenciamento das perdas técnicas, a administração das perdas não-técnicas é de maior complexidade por depender de características socioeconômicas da região atendida pelo sistema de potência, especialmente no que diz respeito ao comportamento de consumo, pagamento e relacionamento dos consumidores, o qual é diretamente relacionado com o desenvolvimento social, econômico e educacional da população, o que pode ser observado na Figura 2-9. No setor elétrico brasileiro, muitos dos parâmetros supralistados, inclusive, compõem a metodologia de cálculo para definição de níveis regulatórios de perdas aceitáveis para cada operador de sistema elétrico, os quais são detalhados no item 2.5 deste trabalho. 


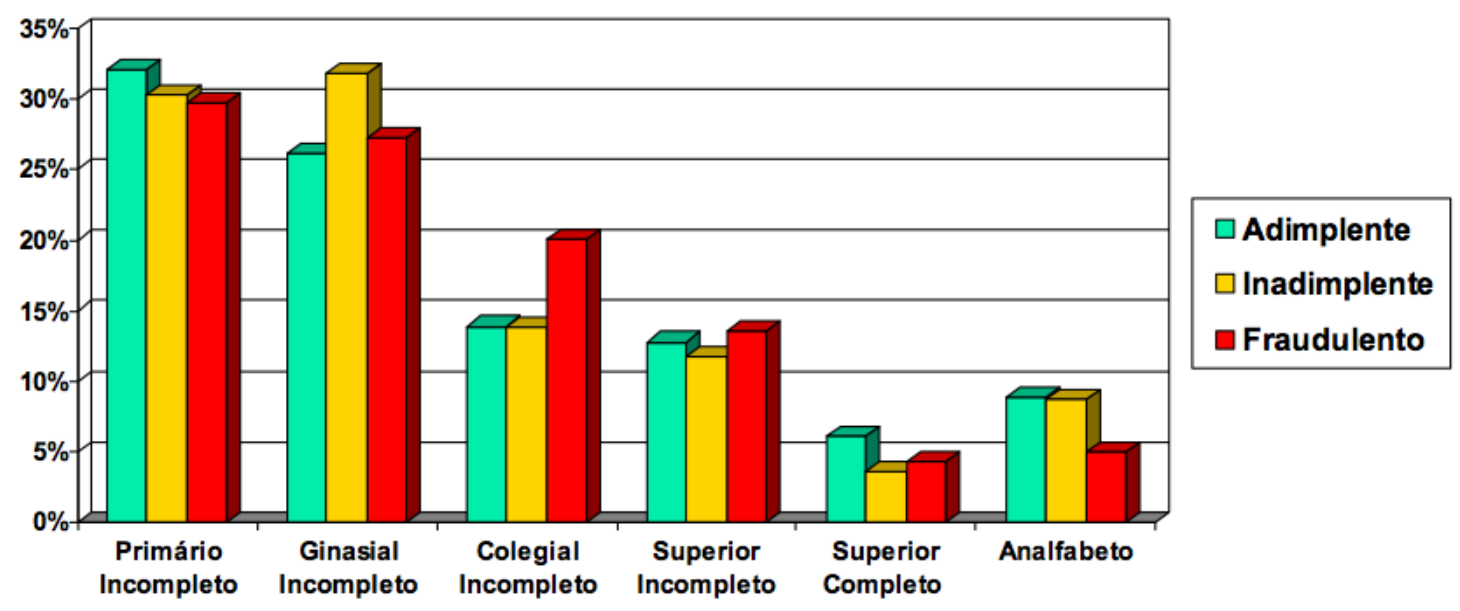

Figura 2-9 - Nível de escolaridade em comparação com perfil de consumo da população atendida pela distribuidora brasileira Elektro. A distribuidora atende municípios do interior do estado de São Paulo. Fonte: Elektro. Compilação: Gustavo Victor Chávez Ortega, 2008.

Os níveis de perdas não-técnicas são de complexa mensuração visto que, por estarem diretamente relacionadas a ocorrências ou intervenções humanas na rede elétrica, na maioria das oportunidades, os pontos nos quais o evento ocorre são desconhecidos pelos operadores do sistema, portanto, em via de regra não se detém nenhuma informação. Considerando essa restrição, Davidson \& Odubiyi et al. [15] sugerem que para estimação de perdas não-técnicas seja utilizada uma abordagem indireta, ponderada pela equação (2-1):

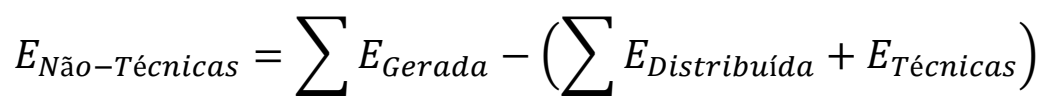

Onde

$E_{\text {Não-Técnicas }}$ expressa o montante de energia elétrica perdida de caráter nãotécnico,

$E_{\text {Gerada }}$ expressa o montante de energia elétrica gerada ou inserida em um dado sistema,

$E_{\text {Distribuida }}$ expressa o montante de energia elétrica entregue pela concessionária, e $E_{\text {Técnicas }}$ expressa o montante de energia elétrica perdida por deficiência técnica.

Uma das principais formas de combate às perdas comerciais é a execução, vinda dos responsáveis pela gestão dos ativos de distribuição, de inspeções nos equipamentos de 
medição das instalações consumidoras de energia elétrica. Esta atividade consiste na verificação in loco da existência de procedimentos irregularidades que comprovem a apuração de consumo não faturado ou faturado a menor e ocorrem, geralmente, na rede de distribuição, nos ramais de ligação entre sistema elétrico e instalação consumidora ou equipamentos de medição - ou nos próprios medidores - de consumo de energia elétrica.

Dependendo do modelo de composição tarifária adotado pelos gestores locais, a redução dos níveis de perdas não-técnicas pela operadora do sistema pode significar um benefício econômico direto declarado no custo unitário da energia elétrica arcado pelos consumidores, a postergação de investimentos em redes, que são dimensionadas pela demanda máxima, e geração e o incremento de receita da operadora, considerando que quanto mais as perdas de energia elétrica decrescem, mais energia elétrica poderá ser vendida ou faturada pelas instalações consumidores.

\subsection{Perdas Elétricas: Relação nas tarifas de energia elétrica}

Quando se permite o consumo de energia elétrica sem a respectiva contrapartida pecuniária, resultando na oneração dos custos, através de possível elevação da tarifa aos demais usuários do sistema que cumprem com sua contraprestação. Este fenômeno social é a tônica do famigerado ditado popular, advindo do setor econômico: "Não existe almoço grátis" (There ain't no such thing as a free lunch).

Em algum momento do marco regulatório, seja ele qual for, o custo operacional por práticas ilícitas serão repassadas aos demais clientes, em função da manutenção e prestação dos serviços ao inadimplente e/ou consumerista irregular.

No caso brasileiro, de acordo com a Lei Federal n ${ }^{\circ}$ 8.987/95, que dispõe sobre o regime de concessão e permissão da prestação de serviços públicos, no qual se enquadra a prestação de serviços de distribuição de energia elétrica, prevê que "as tarifas poderão ser diferenciadas em função das características técnicas e dos custos específicos provenientes do atendimento aos distintos segmentos de usuários" [16]. Neste sentido, percebe-se que os níveis de perdas não-técnicas contribuem negativamente - do ponto 
de vista do consumidor - e diretamente para a formação dos custos finais que compõe a tarifa de energia elétrica.

Fato é que, na última revisão do modelo tarifário homologado pela Agência Nacional de Energia Elétrica - ANEEL que visa o incentivo pela busca de benchmarking ${ }^{4}$ competitivo entre as empresas operadoras do setor, consta a fixação de níveis de perdas não-técnicas e suas trajetórias descendentes, a fim de assegurar que os ganhos de eficiência sejam repassados aos consumidores finais.

O desejo do órgão regular, conforme [13], é estimular os operadores a reduzir os atuais patamares de perdas a limites inferiores aos definidos na data-base da revisão tarifária na esperança de proporcionar elevação dos níveis de bem-estar global e, consequentemente, reduzir as perdas de receita da distribuidora. Ou seja, quanto mais eficiente for a empresa em termos de perdas, menos o consumidor será onerado no custeio da manutenção do serviço de energia elétrica.

Uma das premissas adotadas pela ANEEL na metodologia para definição dos níveis desejáveis de perdas não-técnicas é o fato de cada área de concessão possuir características distintas, o que influencia a gestão e o combate das PNT's. De acordo com o estudo da ANEEL et al. [13], dependendo da área de concessão, o poder de combate às perdas pelas distribuidoras é diferenciado devido a uma aparente indiferença do Estado, resultando em uma complexa cadeia de fatores socioeconômicos, distantes do controle do operador do sistema e que impactam no agravamento do problema, tais como a sensação de ausência de segurança pública, desorganização social, infraestrutura precária, informalidade social, dentre outros.

Como vínculo a este trabalho, é importante destacar que a metodologia, dado a diferenciação socioeconômica supracitada, busca desenvolver o denominado "índice de complexidade", considerando variáveis que representam fatores relevantes e, por estudos estocásticos, possuem relação de causalidade à disposição de perdas não-

\footnotetext{
${ }^{4}$ Processo sistemático e contínuo de avaliação dos produtos, serviços e processos de trabalho das organizações que são reconhecidas como representantes das melhores práticas com a finalidade de comparar desempenhos e identificar oportunidades de melhoria na organização que está realizando (ou monitorando).
} 
-técnicas, o que permitiu a comparação sobre as áreas de atuação de cada empresa. Estas variáveis auxiliam a compreensão dos motivos essenciais pelos quais os patamares de PNT's tendem a se elevar, forçando os operadores a ampliar seu esforço de combate.

O conjunto de variáveis pré-selecionadas no estudo [13], para a composição do índice de complexidade é apresentado na Tabela 2-2.

\begin{tabular}{|c|c|}
\hline Dimensão & Variável \\
\hline Violência & Óbitos por Agressão \\
\hline Escolaridade & $\begin{array}{l}\text { Taxa de Analfabetismo } \\
\text { Anos médios de estudo }\end{array}$ \\
\hline Renda & Renda média por habitante \\
\hline Desigualdade Social & $\begin{array}{l}\text { Percentual de pessoas abaixo da linha da pobreza } \\
\text { Percentual de chefes de família que recebem até três salários mínimos } \\
\text { Percentual de pessoas com renda domiciliar per capita inferior a meio salário } \\
\text { mínimo } \\
\text { Índice de Desenvolvimento Humano - IDH } \\
\text { Índice de Gini }\end{array}$ \\
\hline Infraestrutura & $\begin{array}{l}\text { Percentual de domicílios com água encanada } \\
\text { Percentual de domicílios com cobertura de Esgoto Sanitário } \\
\text { Percentual de domicílios sem coleta de lixo } \\
\text { Percentual de domicílios sem banheiro } \\
\text { Índice de cobertura da rede de água }\end{array}$ \\
\hline Demográfica & Número de consumidores \\
\hline Informalidade & $\begin{array}{l}\text { Percentual de pessoas que vivem em domicílios subnormais } \\
\text { Percentual de pessoas que vivem em domicílios "precários" } \\
\text { Percentual de domicílios cuja classificação de posse do terreno foi enquadrada } \\
\text { como "outra condição" }\end{array}$ \\
\hline $\begin{array}{l}\text { Comprometimento da } \\
\text { renda }\end{array}$ & $\begin{array}{l}\text { Inadimplência no setor de crédito do Sistema Financeiro Nacional } \\
\text { Inadimplência no setor elétrico } \\
\text { Inadimplência no setor de água \& esgoto }\end{array}$ \\
\hline Outras variáveis & Perdas no setor de água \& esgoto \\
\hline
\end{tabular}

Tabela 2-2 - Resumo das variáveis analisadas na metodologia de tratamento regulatório para perdas não técnicas de energia elétrica.

Fonte: ANEEL,2011.

A partir das variáveis pré-selecionadas, conforme [13], a metodologia buscou melhorar a inferência estatística, identificando e disponibilizando somente aquelas que apresentarem maior relevância, observando: 
(i) a justificativa conceitual para o uso da variável e sua relação de causalidade com o fenômeno, perdas não-técnicas;

(ii) a coerência do resultado com as hipóteses que embasaram a introdução da variável no modelo, ou seja, uma variável selecionada para representar desarranjo social, por exemplo, não será selecionada se a sua relação com as perdas não-técnicas se mostrar negativa;

(iii) a significância estatística da variável no modelo.

Levando em consideração os parâmetros definidos, a metodologia definitiva considerou três modelos-base resultantes da simulação das variáveis, dados valores específicos de perdas não-técnicas, para os quais, na definição do indicador de complexidade global, considerou-se a média aritmética simples dos resultados obtidos em cada modelo.

As Tabela 2-3, Tabela 2-4 e Tabela 2-5 resumem os modelos resultantes.

\begin{tabular}{|c|c|c|c|c|}
\hline Conceitos & Variáveis representativas & $\begin{array}{l}\text { Coeficiente } \\
\text { Estimado }\end{array}$ & $\begin{array}{c}\mathrm{T} \\
\text { Estatístico }\end{array}$ & $\begin{array}{c}P \\
\text { Valor }\end{array}$ \\
\hline & Constante & 0,159 & 1,77 & $7,76 \%$ \\
\hline Violência & Óbitos por agressão & 0,20 & 3,99 & $<1 \%$ \\
\hline Desigualdade & $\begin{array}{l}\text { Percentual de chefes de família que recebem } \\
\text { até } 3 \text { salários mínimos }\end{array}$ & 0,193 & 3,14 & $<1 \%$ \\
\hline Precariedade & $\begin{array}{l}\text { Percentual de domicílios subnormais mais } \\
\text { precários }(\mathrm{MC})\end{array}$ & 1,253 & 3,31 & $<1 \%$ \\
\hline Infraestrutura & Cobertura de abastecimento de água & $-0,304$ & $-3,92$ & $<1 \%$ \\
\hline $\begin{array}{l}\text { Comprometimento } \\
\text { da renda }\end{array}$ & Inadimplência no setor de crédito & 0,914 & 2,63 & $<1 \%$ \\
\hline \multicolumn{5}{|c|}{ Estatística do Modelo } \\
\hline $\begin{array}{l}\text { Wald chi }^{2}=72,48 \\
\text { F-statistic }=14,38 \\
R^{2} \text { within }=0,053 \\
R^{2} \text { between }=0,053 \\
R^{2} \text { overall }=0,053\end{array}$ & $\begin{array}{l}\text { Sigma } \mu=0,12594976 \\
\text { Sigma } e=0,03216057 \\
\text { Rho fov }=0,93879014\end{array}$ & & & \\
\hline
\end{tabular}

Tabela 2-3 - Modelo "A" para cálculo do índice de complexidade da área de concessão de cada distribuidora nacional.

Fonte: ANEEL, 2011. 


\begin{tabular}{|c|c|c|c|c|}
\hline Conceitos & Variáveis representativas & $\begin{array}{l}\text { Coeficiente } \\
\text { Estimado }\end{array}$ & $\begin{array}{c}\mathbf{T} \\
\text { Estatístico }\end{array}$ & P Valor \\
\hline \multicolumn{2}{|r|}{ Constante } & 0,145 & 1,42 & $15,40 \%$ \\
\hline Violência & Óbitos por agressão & 0,155 & 3,10 & $<1 \%$ \\
\hline Desigualdade & $\begin{array}{l}\text { Percentual de pessoas com renda per capita } \\
\text { inferior a meio salário mínimo }\end{array}$ & 0,279 & 3,58 & $<1 \%$ \\
\hline Precariedade & $\begin{array}{l}\text { Percentual de domicílios subnormais mais } \\
\text { precários (MC) }\end{array}$ & 1,350 & 3,72 & $<1 \%$ \\
\hline Infraestrutura & Cobertura de coleta de lixo & $-0,202$ & $-1,99$ & $4,70 \%$ \\
\hline $\begin{array}{c}\text { Comprometimento } \\
\text { da renda }\end{array}$ & Inadimplência no setor de crédito & 0,834 & 2,32 & $2,15 \%$ \\
\hline \multicolumn{5}{|c|}{ Estatística do Modelo } \\
\hline $\begin{array}{l}\text { Wald chi }^{2}=67,25 \\
\text { F-statistic }=13,41 \\
R^{2} \text { within }=0,0314 \\
R^{2} \text { between }=0,5159 \\
R^{2} \text { overall }=0,5080\end{array}$ & $\begin{array}{l}\text { Sigma } \mu=0,11794146 \\
\text { Sigma e }=0,03243441 \\
\text { Rho fov }=0,92969001\end{array}$ & & & \\
\hline
\end{tabular}

Tabela 2-4 - Modelo "B" para cálculo do índice de complexidade da área de concessão de cada distribuidora nacional.

Fonte: ANEEL, 2011.

\begin{tabular}{|c|c|c|c|c|}
\hline Conceitos & Variáveis representativas & $\begin{array}{l}\text { Coeficiente } \\
\text { Estimado }\end{array}$ & $\begin{array}{c}\mathrm{T} \\
\text { Estatístico }\end{array}$ & P Valor \\
\hline & Constante & 0,06 & 0,43 & $66,50 \%$ \\
\hline Violência & Óbitos por agressão & 0,1623 & 3,23 & $<1 \%$ \\
\hline Desigualdade & Índice de Gini & 0,52 & 2,94 & $<1 \%$ \\
\hline Precariedade & $\begin{array}{l}\text { Percentual de domicílios subnormais mais } \\
\text { precários (MC) }\end{array}$ & 1,171 & 3,10 & $<1 \%$ \\
\hline Infraestrutura & Cobertura de abastecimento de água & $-0,388$ & $-4,73$ & $<1 \%$ \\
\hline $\begin{array}{l}\text { Comprometimento } \\
\text { da renda }\end{array}$ & Inadimplência no setor de crédito & 1,070 & 3,10 & $<1 \%$ \\
\hline \multicolumn{2}{|l|}{ Tendência } & 0,008 & 4,48 & $<1 \%$ \\
\hline \multicolumn{5}{|c|}{ Estatística do Modelo } \\
\hline Wald chi $^{2}=83,54$ & Sigma $\mu=0,12693949$ & & & \\
\hline F-statistic $=13,85$ & Sigma e $=0,03184557$ & & & \\
\hline $\begin{array}{l}R^{2} \text { within }=0,0910 \\
R^{2} \text { between }=0,5371 \\
R^{2} \text { overall }=0,5290\end{array}$ & Rho fov $=0,9407897$ & & & \\
\hline
\end{tabular}

Tabela 2-5 - Modelo "C" para cálculo do índice de complexidade da área de concessão de cada distribuidora nacional.

Fonte: ANEEL, 2011.

Os modelos resultantes foram formados considerando a busca pela melhor inferência estatística - observadas pelas informações "Coeficiente Estimado", "T Estatístico" e "P Valor" -, aderência à realidade e a capacidade explicativa do modelo para com a evolução de PNT's em áreas de características semelhantes, através de combinações e seleção das variáveis dispostas na Tabela 2-2. Percebe-se também que a aplicação das variáveis "Violência", "Desigualdade", "Precariedade", "Infraestrutura" e "Comprometimento de Renda" ocorreu em todos os três modelos, o que nos comprova a contribuição destas para entendermos o fenômeno da proliferação de PNT's. 
Por, comparativamente, apresentar resultados semelhantes para cada modelo aplicado, o órgão regulador classificou a metodologia como positiva, visto evidenciar que independente das variabilidades individuais das variáveis e apesar das diferentes formas de mensurar cada dimensão, o cálculo da "complexidade socioeconômica", de uma forma geral, converge para um mesmo padrão de distribuição.

Ademais, percebe-se que os fatores estudados constantes em qualquer dos modelos para cálculo do índice de complexidade, aplicados à áreas semelhantes neste quesito, que mais se correlacionam com o agravamento das perdas comerciais - como desigualdade social, violência e precariedade - foram praticamente os mesmos identificados por empirismo e apresentados no item 2.5 deste trabalho. 


\section{Capítulo 3 - Metodologias de classificação por técnicas inteligentes/agrupamento}

Este capítulo apresenta técnicas e metodologias utilizadas das mais variadas formas para solução do problema clássico de identificação de perdas de energia elétrica em sistemas de potência. Nesta seção, observa-se uma revisão da literatura referente a técnicas nãoparamétricas, como a regra do "Vizinho Mais Próximo" e suas variantes, metodologia de decomposição de objetos espaciais, como o "Diagrama de Voronoi" e também técnicas de aprendizagem de máquina e classificação de padrões, como a "Máquina de Vetores de Suporte" - SVM. Na sequência, disponibiliza-se uma visão geral sobre técnicas de análise gráfica e visual, como as transformadas wavelet em sua forma discreta e continua, bem como uma noção sobre o sistema de cor RGB, utilizado em sistemas de informação. No final desta seção, é apresentada uma revisão sobre técnicas de interpolação, em especial o método "Polinômios de Lagrange".

\subsection{Metodologias utilizadas para identificação de focos de consumo irregular}

$\mathrm{Na}$ literatura, são utilizadas diversas técnicas, seja de classificação de padrões ou estatísticas, para solução do problema de identificação de consumidores com indício de perdas não-técnicas, a Tabela 3-1 apresenta algumas delas:

\begin{tabular}{|l|l|}
\hline \multicolumn{1}{|c|}{ País e/ou Autor } & \multicolumn{1}{c|}{ Técnica/Metodologia utilizada } \\
\hline Brasil (Campinas) & - Análise de Fluxo de Potência \\
Eduardo de Xerez Vieiralves [1] & - C4.5 \\
Hamilton Melo Ferreira [17] & -Redes Neurais Artificiais \\
Leonardo Mendonça Oliveira de Queiroz [18] & - Naive Bayes \\
& - Máquina de Vetores de Suporte (SVM) \\
& - Sistemas Neuro-Fuzzy (NEFCLASS, NFHB- \\
& Invertido) \\
& - Clusterização Fuzzy C-Means (FCM) \\
Brasil (Rio de Janeiro) & - Redes Neurais Artificiais \\
Gustavo Victor Chávez Ortega [19] & - Sistemas Neuro-Fuzzy \\
& - Algoritmos Genéticos \\
\hline
\end{tabular}




\begin{tabular}{|c|c|}
\hline $\begin{array}{l}\text { Brasil (São Paulo) } \\
\text { Carlos Alexandre de Sousa Penin [20] }\end{array}$ & $\begin{array}{l}\text { - Redes Neurais Artificiais } \\
\text { - Análise Discriminante Ficher } \\
\text {-Regressão Logística }\end{array}$ \\
\hline Eslovênia [21] & $\begin{array}{l}\text { - Clusterização Hierárquica } \\
\text { - Clusterização Fuzzy C-Means (FCM) }\end{array}$ \\
\hline $\begin{array}{l}\text { Malásia } \\
\text { Tenaga Nasional Berhad [22] }\end{array}$ & $\begin{array}{l}\text { - Clusterização Fuzzy C-Means (FCM) } \\
\text { - Redes Neurais Artificiais (ANN) } \\
\text { - Classificação Fuzzy }\end{array}$ \\
\hline $\begin{array}{l}\text { Portugal } \\
\text { Companhia de Distribuição Portuguesa [23] }\end{array}$ & $\begin{array}{l}\text { - Clusterização por k-Médias } \\
\text { - Mapeamento de auto-organização (SOM) } \\
\text { - Aproximação de Dois Níveis }\end{array}$ \\
\hline Reino Unido [21] & - Classificação Fuzzy \\
\hline Romênia [21] & $\begin{array}{l}\text {-Clusterização Hierárquica } \\
\text { - Clusterização por k-Médias }\end{array}$ \\
\hline $\begin{array}{l}\text { Rússia } \\
\text { Johannes Wilhelmus Fourie [24] }\end{array}$ & $\begin{array}{l}\text { - Técnicas Estatísticas (P-Valores, Teste T, } \\
\text { Teste F) }\end{array}$ \\
\hline $\begin{array}{l}\text { Tailândia } \\
\text { Jawad Nagi [21] }\end{array}$ & $\begin{array}{l}\text { - Máquina de Vetores de Suporte (SVM) } \\
\text { - Sistema de Inferência Fuzzy (FIS) }\end{array}$ \\
\hline $\begin{array}{l}\text { Taiwan } \\
\text { Taiwan Power Company [25] }\end{array}$ & - Técnicas estatísticas \\
\hline
\end{tabular}

Tabela 3-1 - Metodologias e técnicas utilizadas para identificação de indícios de consumo irregular.

\subsection{Técnicas não-paramétricas}

Neste capítulo são examinados os procedimentos não-paramétricos disponíveis na literatura que podem ser utilizados para distribuições espaciais arbitrárias.

Existem vários métodos não-paramétricos de interesse no reconhecimento de padrões, no qual um dos mais utilizados é a regra do "Vizinho Mais Próximo" - NearestNeighbor Rule - o qual não se atém somente à estimação probabilística.

\subsubsection{Regra do "Vizinho Mais Próximo"}

Conforme descreve Duda, Hart \& Stock et al. [26], a regra do "Vizinho Mais Próximo" - NN-rule trata-se de um procedimento sub-ótimo, ou seja, sua utilização converterá 
normalmente a uma taxa de erro maior que a mínima possível, a taxa de Bayes ${ }^{5}$. No entanto, com um número ilimitado de protótipos, a taxa de erro nunca é pior do que duas vezes a taxa de Bayes.

Algoritmos que utilizam a regra do "Vizinho Mais Próximo" tendem a apresentar simplicidade conceitual e computacional.

Para compreender o objetivo do procedimento, supõe-se que o único conhecimento que dispomos é um conjunto de $i$ pontos corretamente classificados em categorias $\theta:\left(x_{i}, \theta_{i}\right)$. Intuitivamente, é razoável supor que as observações que são mais próximas uma das outras, por alguma métrica de distância definida e adequada ao problema, possuirão a mesma classificação. Dessa forma, ao classificar um elemento desconhecido $x$, seria apropriado pesar as evidências dos $x_{i}$ 's vizinhos.

Um processo de decisão simples e não-paramétrico que age desta forma é a regra do "Vizinho Mais Próximo" ou NN-rule, que classifica o elemento $x$ na categoria de seu Vizinho Mais Próximo.

Mais precisamente, pode-se dizer que $x_{n}^{\prime} \in\left(x_{1}, x_{2}, \ldots, x_{n}\right)$ é um vizinho próximo de $x$ se a medida de distância entre os pontos for a mínima dentre as demais, ou seja, se $\min \left[d\left(x_{i}, x\right)\right]=d\left(x_{n}^{\prime}, x\right)$, onde $i=1,2, \ldots, n$.

A regra do "Vizinho Mais Próximo" escolhe classificar $x$ à categoria $\theta_{n}$ se $x_{n}$ é o Vizinho Mais Próximo de $x$ e pertence à classe $\theta_{n}$.

Há a possibilidade de se cometer um engano caso $\theta_{n}$ não possua a mesma categoria/classe que $\theta$. Além disso, observa-se que a NN-rule apenas utiliza o Vizinho Mais Próximo como um classificador, ignorando os pontos de dados pré-classificados restantes.

\footnotetext{
${ }^{5}$ Taxa de Erro de Bayes: Em Classificação Estatística, a taxa de Erro de Bayes (Bayes Error Rate) é a mais baixa taxa de erro possível para uma dada classe de classificador.

É necessário um número de abordagens para que a estimativa da taxa de erro de Bayes exista.

A taxa de erro de Bayes se dispõe como de importante utilização nos estudos de padrões e técnicas de aprendizagem de máquina [26].
} 


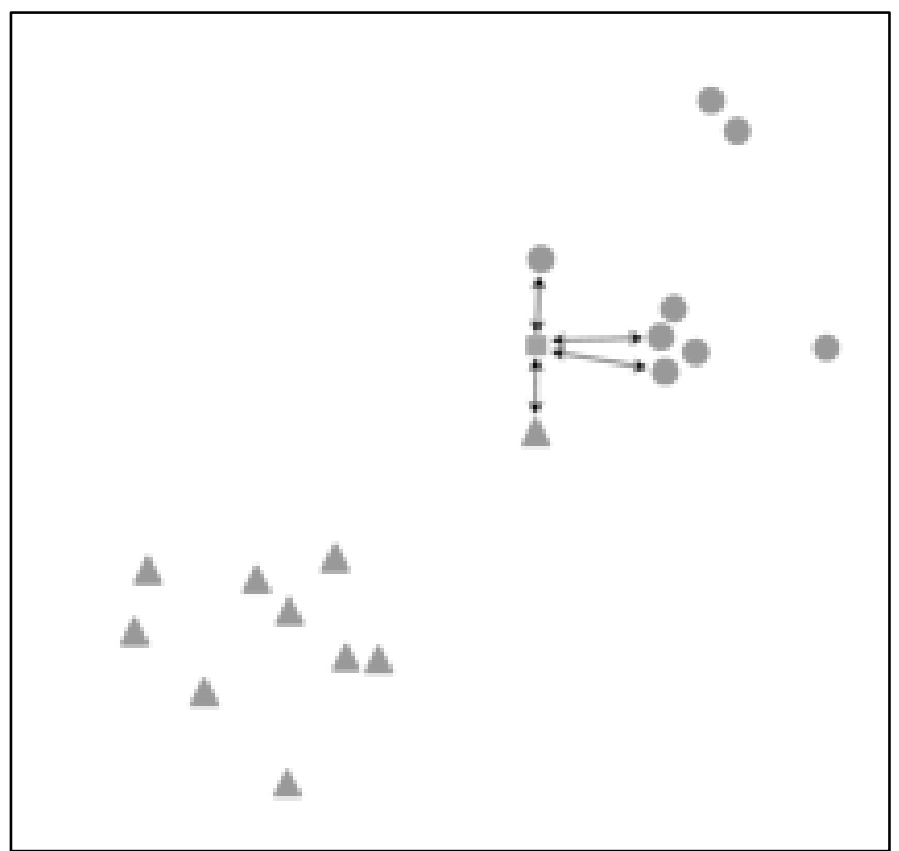

Figura 3-1 - Demonstração gráfica sobre a regra do "Vizinho Mais Próximo".

Fonte: Leif E. Peterson, 2009.

A Figura 3-1 apresenta um exemplo da aplicação da regra do "Vizinho Mais Próximo". Nesse problema, existem duas categorias/classes: $\theta_{1}$ (triângulos) e $\theta_{2}$ (círculos). $\mathrm{O}$ quadrado verde representa o elemento desconhecido $x$ e, como seu Vizinho Mais Próximo vem de classe $\theta_{1}$, o elemento será rotulado como sendo da mesma classe.

\subsubsection{A regra dos "k-Vizinhos Mais Próximos"}

Uma óbvia extensão da regra do "Vizinho Mais Próximo" é a regra dos "k-Vizinhos Mais Próximos", $k$-Nearest-Neighbors Rule - kNN. Como seria de se esperar a partir de sua nomenclatura, tal regra classifica $x$ atribuindo-o a categoria/classe mais frequentemente representada dentre as demais $k$ amostras mais próximas, em outras palavras, a decisão é realizada através da análise democrática das classes dos $k$ vizinhos mais próximos, assim como demonstrado na Figura 3-2. 


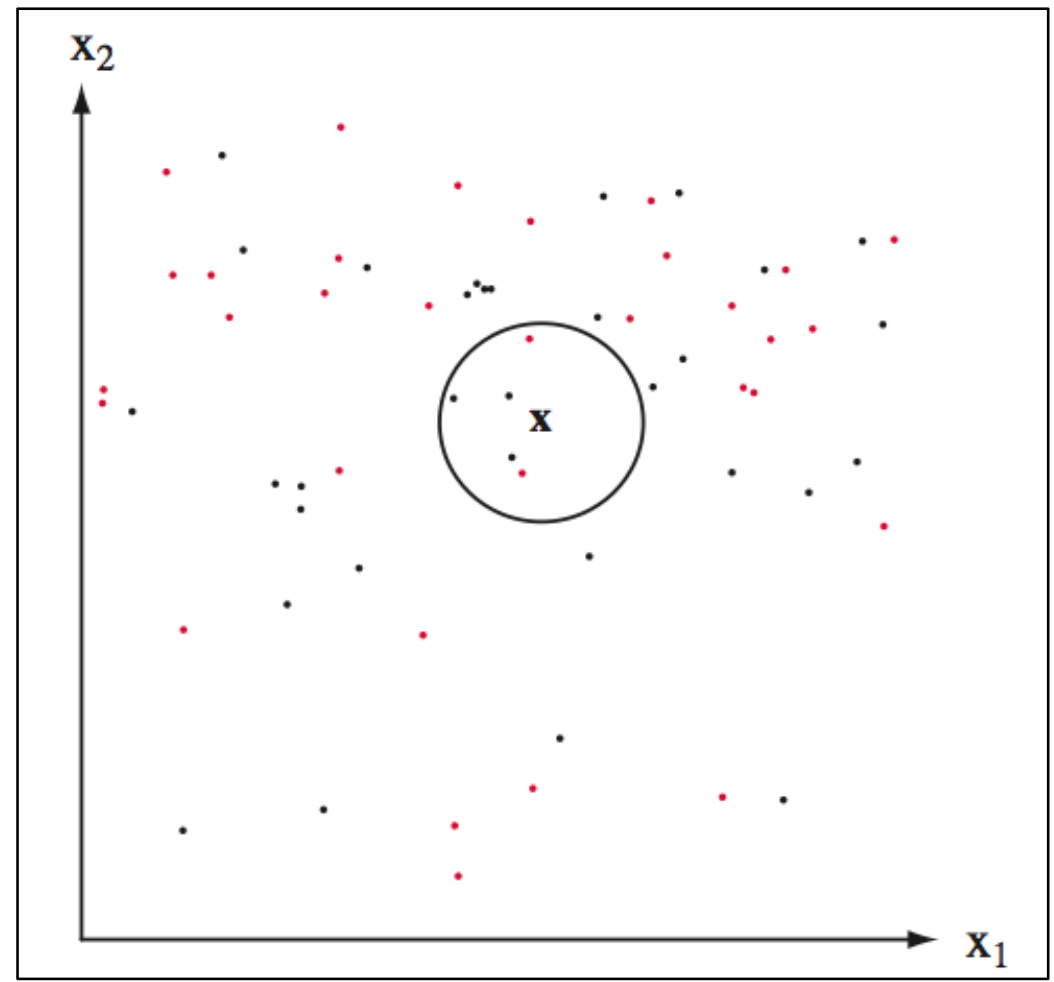

Figura 3-2 - A busca pelos $k$-vizinhos mais próximos inicia-se a partir do ponto de teste $\boldsymbol{x}$. Deste, cresce uma região esférica até que a mesma englobe $k$ amostras pré-classificadas. Assim, a classificação do ponto de teste $\boldsymbol{x}$ é dada pela maioria dos votos (classificações) dessas amostras. No caso de $k=5$, o ponto de teste $\boldsymbol{x}$ seria classificado na categoria de pontos pretos.

Fonte: Duda, Hart \& Stock, 2006.

Nesse exemplo, considerando o caso de duas classes com $k$ ímpar (para evitar empates na análise democrática), pode-se obter alguns esclarecimentos adicionais sobre esses procedimentos.

\subsubsection{Diagrama de Voronoi}

O Diagrama de Voronoi apresenta a decomposição de um plano com $n$ pontos em polígonos, cada qual contendo exatamente um ponto gerador e cada ponto em um determinado polígono está mais próximo ao ponto gerador do que qualquer outro. Em síntese é realizado o particionamento de um determinado plano dimensional, semelhante a área de abrangência do ponto em estudo, através da distância entre determinada classe ou subconjuntos neste plano.

Aurenhammer et al. [27] descreve que os chamados Diagramas de Voronoi são formados a partir de um conjunto de pontos em um determinado plano, no qual cada 
diagramação no plano é desenvolvida aplicando a regra do "Vizinho Mais Próximo", onde cada ponto é associado com a região do plano mais próximo a este, o que pode ser observado na Figura 3-3.

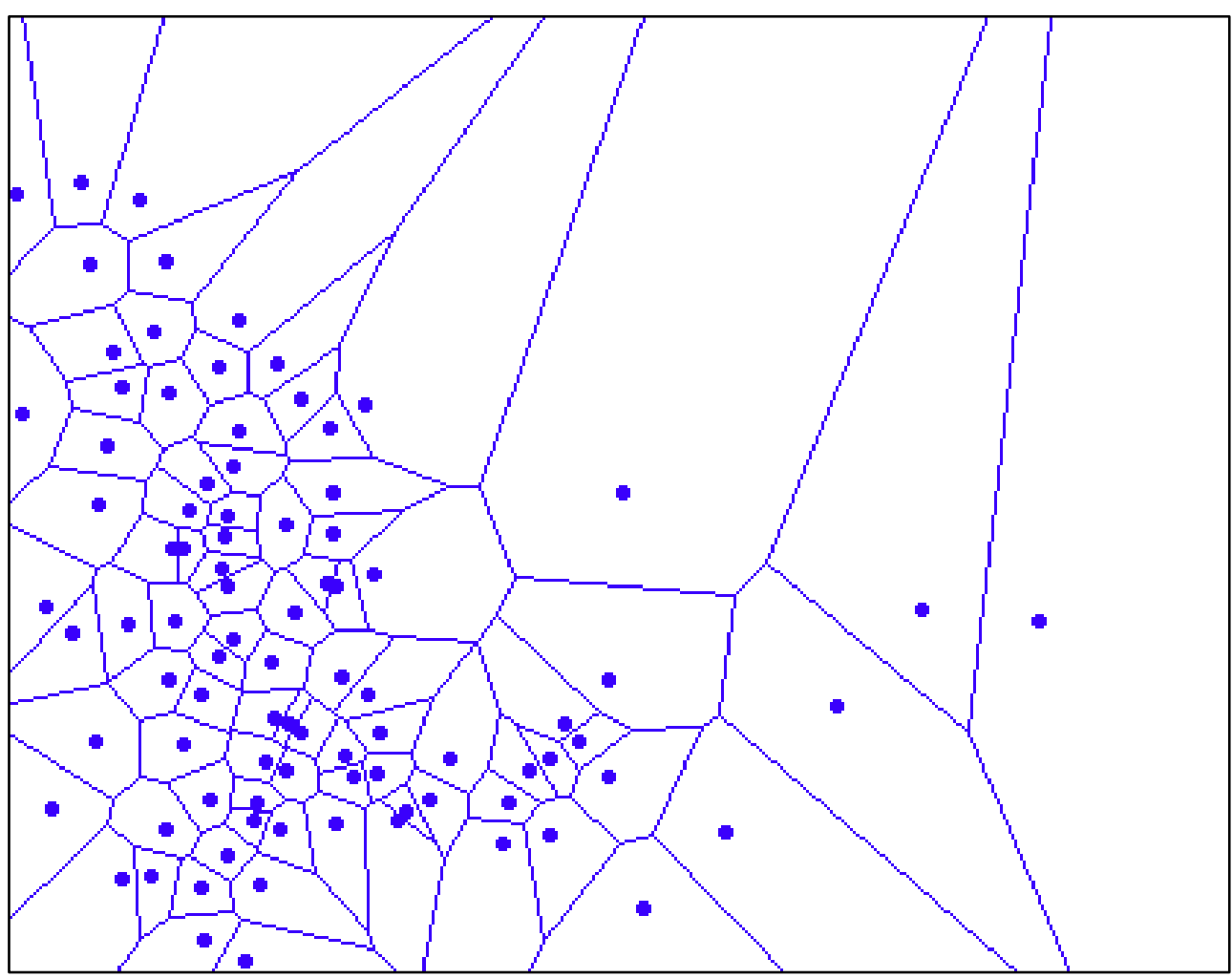

Figura 3-3 - Exemplo de um Diagrama de Voronoi de $n$ pontos em um plano. Nesse caso, os pontos são as instalações, objeto de análise deste trabalho.

Segundo Duda, Hart \& Stock et al. [26], baseando no conceito da regra do "Vizinho Mais Próximo", a classe $\theta^{\prime}$ associada a um Vizinho Mais Próximo é uma variável aleatória, e a probabilidade de $\theta^{\prime}=\omega_{i}$ é meramente a probabilidade a posteriori $P\left(\omega_{i} \mid \boldsymbol{x}^{\prime}\right)$.

Assim, quando o número de amostras é muito grande, é razoável assumir que $\boldsymbol{x}$ ' é suficientemente próximo a $\boldsymbol{x}$, tanto que $P\left(\omega_{i} \mid \boldsymbol{x}^{\prime}\right) \simeq P\left(\omega_{i} \mid \boldsymbol{x}\right)$. Uma vez que esta é exatamente a probabilidade que estará vinculada ao estado $\omega_{i}$, a regra do "Vizinho Mais Próximo" corresponderá efetivamente às probabilidades desta natureza. 
Se definir-se $\omega_{m}(\mathbf{x})$ como:

$$
P\left(\omega_{m} \mid \boldsymbol{x}\right)=\max _{i} P\left(\omega_{i} \mid \boldsymbol{x}\right)
$$

Então a regra de decisão de Bayes sempre selecionará $\omega_{m}$. Dessa forma, a regra permite particionar o espaço de características em células consistindo de todos os pontos mais próximos a um dado ponto de treinamento $\boldsymbol{x}^{\prime}$ do que quaisquer outros pontos de treinamento.

Todos os pontos de tal célula são então classificados pela categoria do ponto de treinamento, assim chamada como Diagrama Voronoi, - Voronoi Tesselation conforme demonstrado na Figura 3-4.
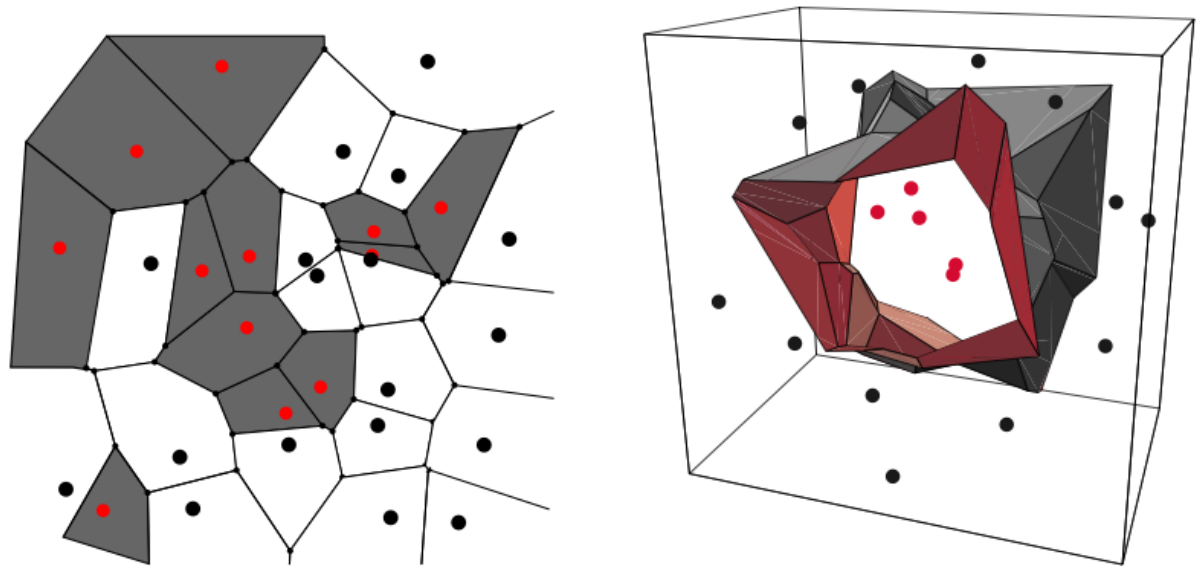

Figura 3-4 -Em duas dimensões (lado esquerdo da figura), o algoritmo do "Vizinho Mais Próximo" leva a uma partição do espaço de entrada em células Voronoi, cada qual classificada pela categoria do ponto de treinamento. Em três dimensões (lado direito da figura), as células Voronoi são tridimensionais e as fronteiras de decisão são semelhantes à superfície de um cristal.

Fonte: Duda, Hart \& Stock, 2006.

\subsection{Máquina de Vetores de Suporte - Support Vector Machine (SVM)}

Trata-se de uma técnica de aprendizagem de máquina fundamentada em métodos que permitem a máquina aperfeiçoar, por si só, seu desempenho em uma determinada tarefa, neste caso a análise de informação para o reconhecimento e classificação de padrões, usando filosofia de regressão e discriminante linear. 
Porém, diferentemente das demais técnicas de aprendizado linear de máquinas, algoritmos SVM dependem de pré-processamento das informações para representar padrões em dimensões elevadas, geralmente muito maiores do que o espaço de características originais.

De acordo com Vapnik et al. [28], a técnica "Máquina de Vetores de Suporte" implementa a seguinte ideia: mapear os vetores de entrada $\boldsymbol{x}$ em um espaço de características/classes de elevada dimensão $\boldsymbol{Z}$ através de mapeamento linear ou nãolinear dos pontos em comum, onde, neste espaço multidimensional, uma separação hiperplana ótima é construída. As Figura 3-5 e Figura 3-6 apresentam tipos de classificadores que utilizaram a ferramenta SVM.
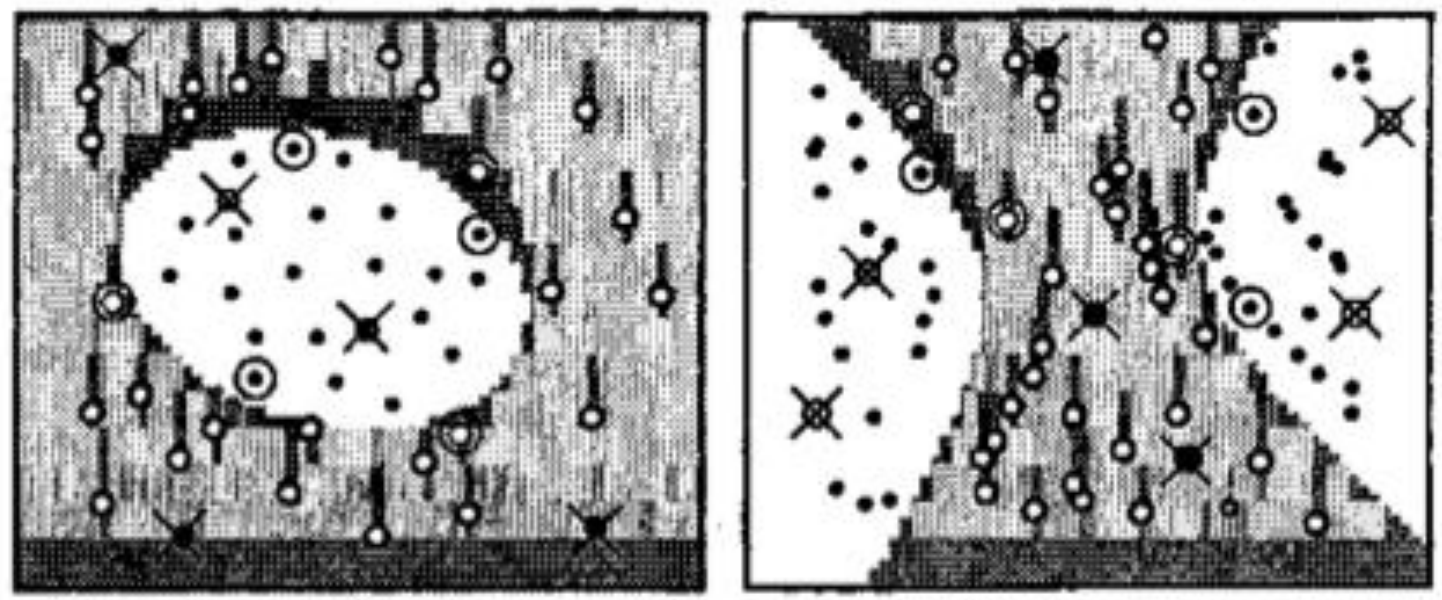

Figura 3-5 - Duas classes de vetores são representadas pelos círculos pretos e brancos. Nos exemplos, as imagens não podem ser separados com erros, os quais são indicados por cruzes, e os vetores de suporte por círculos duplos.

Fonte: Vapnik, 1999.

Os ilustres mestres Duda, Hart \& Stock se posicionaram sobre o tema em [26], dispondo que o objetivo principal de um algoritmo baseado em Support Vector Machine é encontrar o hiperplano com a maior margem de separação, no qual espera-se que quanto maior a margem, melhor seja a generalização do classificador. 


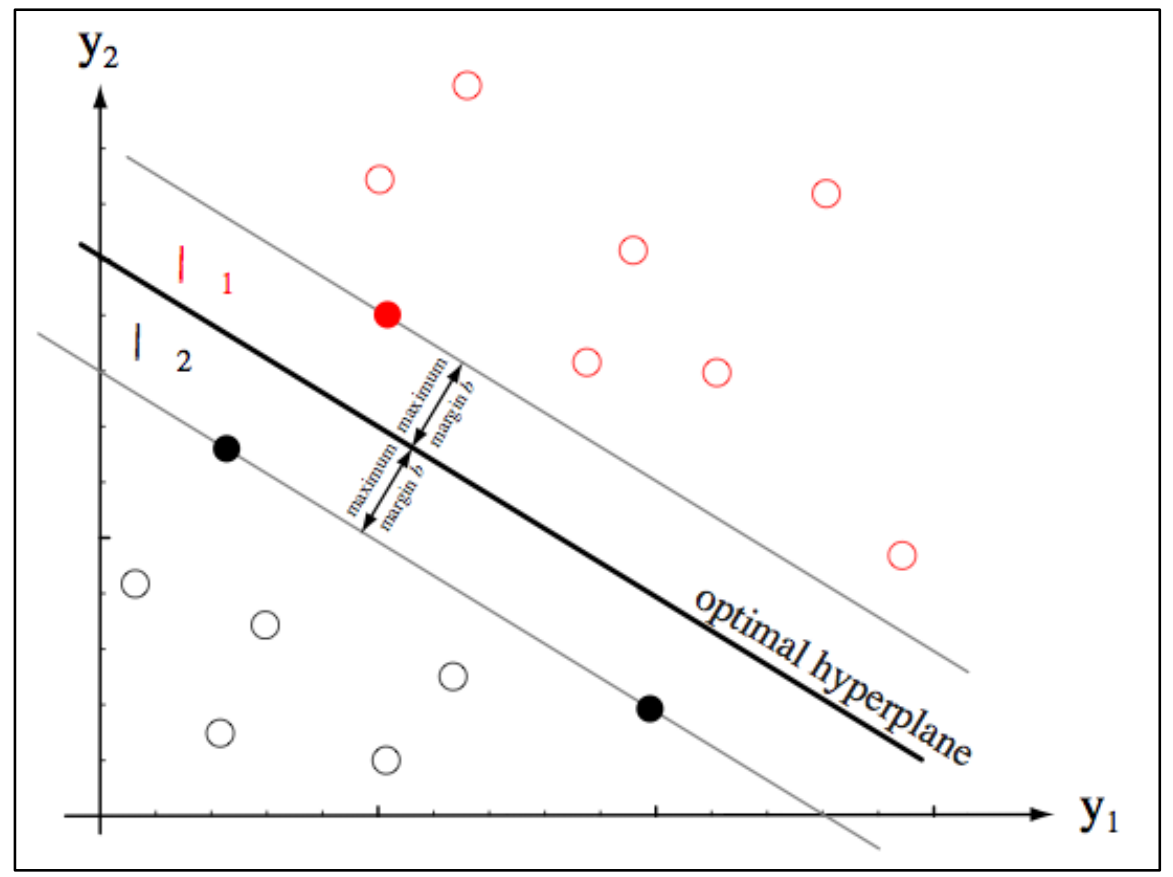

Figura 3-6 - O treinamento de uma máquina de vetores de suporte - SVM consiste em encontrar o hiperplano ótimo, ou seja, com a distância máxima a partir dos padrões, apurados no treinamento, mais próximas. Os vetores de suporte são os padrões (mais próximos), ou distância b do hiperplano. Os três vetores de suporte são representados como pontos sólidos.

Fonte: Duda, Hart \& Stock, 2006.

Apesar de sua forma básica e original proposta por Vapnik, se fosse considerar a separação das classes (classificação) de forma linear, em alguns problemas, tal forma de separação seria inócua, visto que os erros inerentes à classificação poderiam ser maiores que os esperados, motivados pelo fato de que a grande maioria dos problemas reais não são separáveis linearmente.

A abordagem utilizada para as técnicas SVM, a fim de resolver esse efeito, consiste no mapeamento ou conversão dos dados para um espaço de dimensão maior.

O primeiro passo para a formação de uma máquina de vetores de suporte não-linear é a seleção das funções não-lineares (funções de kernel, dispostas na Tabela 3-2) que projetarão os dados de características/classes de entrada a um espaço de dimensão superior, para permitir a classificação dos dados de entrada, que se encontram em espaços não linearmente separáveis. 
Frequentemente a seleção da função kernel dependerá especialmente do conhecimento do analista sobre a característica do problema. Na ausência deste conhecimento, há a possibilidade de se utilizar funções pré-determinadas como as polinomiais, Gaussianas, sigmoidais ou ainda outras funções básicas.

\begin{tabular}{ll}
\hline \multicolumn{1}{c}{ Função Kernel - Descrição } & \multicolumn{1}{c}{ Função $\boldsymbol{\phi}\left(\boldsymbol{x}_{\boldsymbol{i}}, \boldsymbol{x}_{\boldsymbol{j}}\right)$} \\
\hline Polinomial & $\left(\delta\left(x_{i} \cdot x_{j}\right)+k\right)^{d}$ \\
Gaussiano & $\exp \left(-\sigma\left\|x_{i}-x_{j}\right\|^{2}\right)$ \\
Sigmoidal & $\tanh \left(\delta\left(x_{i} \cdot x_{j}\right)+k\right)$ \\
\hline
\end{tabular}

Tabela 3-2 - Funções kernel mais utilizadas.

Para a formação de máquina de SV não-linear e pela sua característica, os hiperplanos no espaço de dimensão superior são definidos como o conjunto de pontos cujo produto escalar com um vetor naquele espaço é constante. De maneira análoga, os vetores que definem os hiperplanos podem ser escolhidos através da combinação linear com parâmetros $\alpha_{i}$ dos vetores de classes/características disponíveis na base de dados. Com a escolha de um hiperplano, os pontos $\boldsymbol{x}$ no espaço de características são definidos pela seguinte relação:

$$
\sum_{i} \alpha_{i} K\left(x_{i}, x\right)=\text { constante }
$$

A partir da equação ( 3-2), a convolução do produto escalar permite a construção das funções de decisão que são não-lineares no espaço de entrada,

$$
f(x)=\operatorname{sign}\left(\sum_{\text {vet suporte }} y_{i} \alpha_{i} K\left(x_{i}, x\right)-b\right)
$$

Onde

$K\left(x_{i}, x\right)$ expressa a função de kernel selecionada para separação do hiperplano, $\alpha_{i}$ são os multiplicadores de Lagrange

$y_{i}$ são os pesos definidos para cada vetor 
e que são equivalentes às funções de decisão lineares no espaço de características de dimensão superior $\psi_{i}(x), \ldots, \psi_{N}(x)-K\left(x_{i}, x\right)$ é a convolução do produto escalar para este espaço de características.

Para determinar os coeficientes $\boldsymbol{\alpha}_{\boldsymbol{i}}$, no caso separável é necessário encontrar a maximização da equação ( 3-4), na forma clássica de um problema de otimização:

$$
W(\alpha)=\sum_{i=1}^{n} \alpha_{i}-\frac{1}{2} \sum_{i, j}^{n} \alpha_{i} \alpha_{j} y_{i} y_{j} K\left(x_{i}, x_{j}\right)
$$

sujeita às seguintes restrições

$$
\sum_{i=1}^{n} \alpha_{i} y_{i}=0 \quad \alpha_{i} \geq 0 \quad i=1,2, \ldots, n
$$

Onde

$K\left(x_{i}, x_{j}\right)$ expressa a função de kernel selecionada para separação do hiperplano, $\alpha_{n}$ são os multiplicadores de Lagrange $y_{n}$ são os pesos definidos para cada vetor.

\subsection{Análise ou transformada Wavelet}

O termo wavelet vem da palavra francesa "ondelette" que em português significa "pequena onda".

As transformadas wavelet podem ser consideradas como formas de representação de informações no domínio da frequência para sinais no domínio do tempo contínuo (analógico) e, desta forma, relacionados a uma análise harmônica dos sinais.

As funções wavelet são análogas às funções de escalonamento, estas últimas expressas por: 


$$
\varphi_{i, k}(x)=2^{\frac{j}{2}} \varphi\left(2^{j} x-k\right)
$$

Onde

$\varphi_{i, k}(x)$ é a função de escalonamento, em relação a uma dada posição $\boldsymbol{x}$,

$k$ é um parâmetro determinado pela posição da função de escalonamento ao longo do eixo $\boldsymbol{x}$,

$j$ é um parâmetro determinado pela largura da função ao longo do eixo $\boldsymbol{x}$.

As funções de escalonamento são utilizadas comumente para aproximar uma função ou imagem em diferentes níveis, cuja característica é semelhante ao de uma função de expansão, porém com a incorporação de conversões de inteiros e escalonamento binário. Cada aproximação é diferida por um fator (de base 2) de aproximação ao nível do vizinho mais próximo.

No caso de funções wavelet, a função $\psi(x)$ é definida como sendo a função de escalonamento descrita em ( 3-6) para todo $k \in \mathbf{Z}$ que se estende pelo espaço $W_{j}$ onde:

$$
\begin{aligned}
\operatorname{span}(S)= & \left\{\sum_{i=1}^{n} \lambda_{i} v_{i} \mid k \in \mathbb{N}, v_{i} \in S, \lambda_{i} \in \boldsymbol{K}\right\} \\
& W_{j}=\operatorname{span}\left\{\varphi_{i, k}(x)\right\}
\end{aligned}
$$

A função wavelet abrange a diferença entre quaisquer dois subespaços adjacentes $V_{j} \mathrm{e}$ $V_{j+1}$ conforme demonstrado na Figura 3-7.

Segundo Gonzalez \& Woods et al. [29], a função de escalonamento em seu nível de resolução mais baixo, $V_{0}$, fornece uma aproximação da função original e wavelets $W_{0}$, codificando a diferença entre tal aproximação e a função original. Dessa forma, qualquer função wavelet pode ser expressa como a soma ponderada das variações:

$$
\varphi(x)=\sqrt{2} \sum_{n} h_{\varphi}(n) \varphi(2 x-n)
$$


Onde

$h_{\varphi}(n)$ são os coeficientes da(s) função(ões) wavelet, para ponderação.

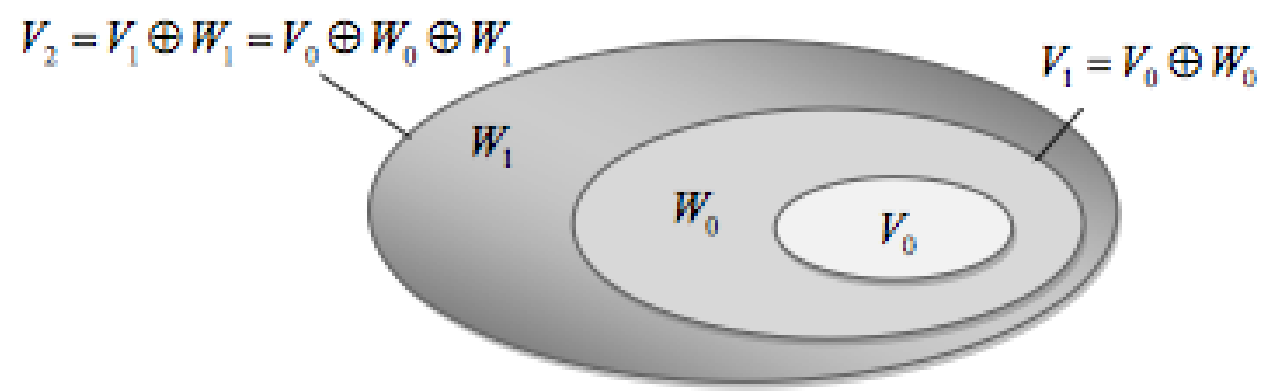

Figura 3-7 - Relação especial entre os conjuntos/espaços de escalonamento e função wavelet. Fonte: Henry Lee T.-H..

\subsubsection{A transformada Wavelet contínua}

Segundo Kovačević, Goyal \& Vetterli et al. [30], a transformada wavelet contínua utiliza uma função $\varphi(t)$ e todas as suas respectivas versões de deslocamento e escalonamento para realizar a análise da função original ou imagem a ser estudada.

Considerando uma wavelet real $\varphi(t) \in \mathcal{L}^{2}(\mathbb{R})$ centralizada em $t=0$ e possuindo, no mínimo, um momento zero (ou seja, $\int \varphi(t) d t=0$ ) e todos os seus deslocamentos e escalonamentos, a forma geral da transformada wavelet contínua pode ser expressa como:

$$
W_{\varphi}(a, b)=\int_{-\infty}^{\infty} f(x) \varphi_{a, b}(x) d x
$$

Sendo a chamada "wavelet-mãe" (mother wavelet) expressa por:

$$
\varphi_{a, b}(t)=\frac{1}{\sqrt{|a|}} \varphi\left(\frac{t-b}{a}\right), a \in \mathbb{R}^{+}, b \in \mathbb{R}
$$


Onde $\varphi_{a, b}(t)$, variáveis denominadas wavelets, dispõem de centralização em torno de $b$ (fator de deslocamento/translação - localização da janela) e escalonada pelo fator $a$ (fator de escalonamento). $\mathrm{O}$ fator de escalonamento $\frac{1}{\sqrt{|a|}}$ garante que a norma da dimensão $\mathcal{L}^{2}$ estará preservada, sem perda de generalidade.

\subsubsection{A transformada discreta Wavelet (Discrete Wavelet Transform)}

Uma forma de se expressar os parâmetros de conversão $a$ e $b$ em termos de valores discretos foi fruto dos estudos de Acharya e Ray et al. [31]. Nestes estudos, os parâmetros, apresentados na forma geral da mother wavelet, em ( 3-10) e que representam escalonamento e deslocamento, respectivamente, podem ser expressos da seguinte forma:

$$
a=a_{o}^{j}, \quad b=k b_{0} a_{0}^{j}
$$

Onde:

$j$ é o parâmetro que contribui para o escalonamento/dimensionamento da transformada wavelet $\mathrm{e}$,

$k$ é o parâmetro relacionado com a conversão da função wavelet.

Ainda de acordo com Acharya e Ray et al. [31], à medida em que a distância de conversão varia em relação ao escalonamento da função wavelet, o fator $b$ deve levar esta característica de escalonamento em consideração, no domínio contínuo. Dessa forma, $a_{0}^{j}$ é multiplicado por $k b_{0}$, concluindo a discretrização do fator $b$.

Substituindo os fatores $a$ e $b$ na equação ( 3-10), a função "wavelet-mãe", a função wavelet global pode então ser expressa como:

$$
\varphi_{a, b}(t)=\frac{1}{\sqrt{a_{o}^{j}}} \varphi\left(\frac{t}{a_{o}^{j}}-k b_{0}\right)
$$


Aplicando o método de amostragem díade ${ }^{6}$ na equação (3-12), e definindo valores dos fatores $a_{0}$ e $b_{0}$ como sendo 2 e 1 , respectivamente, temos: $a=2^{j}$ e $b=k 2^{j}$. Assim, aplicando os fatores na equação ( 3-12), a função wavelet pode ser definida como:

$$
\varphi_{j, k}(t)=\frac{1}{\sqrt{2^{j}}} \varphi\left(\frac{t}{2^{j}}-k\right)
$$

Conforme Gonzalez e Woods et al. [29], os coeficientes da função discreta wavelet pode ser obtida através da expansão matemática de $f(x)$ como uma sequência de números. Considerando este conceito e aplicando o princípio das séries de expansão, os coeficientes da transformada discreta wavelet pode ser definidos como:

$$
\begin{aligned}
& W_{\varphi}\left(j_{0}, k\right)=\frac{1}{\sqrt{M}} \sum_{t=0}^{M-1} f(t) \varphi_{j_{0}, k}(t) \\
& W_{\psi}(j, k)=\frac{1}{\sqrt{M}} \sum_{t=0}^{M-1} f(t) \psi_{j, k}(t)
\end{aligned}
$$

Onde

$W_{\varphi}\left(j_{0}, k\right)$ é o coeficiente de aproximação da função e,

$W_{\psi}(j, k)$ é o coeficiente de detalhamento da função a ser estudada.

$M$ é o parâmetro referendado a uma potência de 2 que varia entre 0 e $J-1$

As equações ( 3-14) e ( 3-15) são válidas para $j \geq j_{0}$ e, a partir destes coeficientes, é possível a reconstrução do sinal $f(t)$ como sendo:

$$
f(t)=\frac{1}{\sqrt{M}}\left(\sum_{k} W_{\varphi}\left(j_{0}, k\right) \varphi_{j_{0}, k}(t)+\sum_{j=j_{0}}^{\infty} \sum_{k} W_{\psi}(j, k) \psi_{j, k}(t)\right)
$$

Em comparação com a utilização da transformada clássica de Fourier, a Transformada Wavelet Discreta - DWT apresenta melhor desempenho devido à sua capacidade em

\footnotetext{
${ }^{6}$ Díade: conjunto ou grupo de dois elementos.
} 
localizar tempo e frequência, simultaneamente, o que simplifica consideravelmente a manipulação e compressão de imagens.

\subsubsection{A transformada rápida Wavelet (Fast Wavelet Transform)}

Em 1988, um algoritmo chamado de "Transformada Rápida Wavelet", Fast Wavelet Transform - FWT, que realiza a decomposição e reconstrução wavelet rápida foi desenvolvido por Stéphane G. Mallat [32] com o objetivo de disponibilizar uma maneira eficiente e rápida de se aplicar a Transformada Wavelet Discreta - DWT.

A ideia original é a expansão da imagem para que tenha número de colunas e de linhas múltiplos de $2^{j}$, sem que haja a ampliação da imagem, apenas sua expansão, criando o efeito de "bordas".

O estudioso Lee et al. [33] aborda o tema considerando a equação wavelet de multiresolução, através da equação ( 3-8), para realização da expansão de $\boldsymbol{x}$ por $2^{j}$. Convertendo assim $\boldsymbol{x}$ em unidades de $\boldsymbol{k}$ e fazendo $m=2 k+n$, tem-se:

$$
\begin{gathered}
\varphi\left(2^{j} x-k\right)=\sqrt{2} \sum_{n} h_{\varphi}(n) \varphi\left(2\left(2^{j} x-k\right)-n\right) \\
=\sqrt{2} \sum_{m} h_{\varphi}(m-2 k) \varphi\left(2^{j+1} x-m\right)
\end{gathered}
$$

Partindo da equação ( 3-9) e considerando a definição da Transformada Wavelet Discreta, conforme equações ( 3-14) e (3-15), pode-se encontrar uma propriedade da FWT que envolve a convolução da função de escalonamento e coeficientes wavelet. Substituindo a equação ( 3-6) em ( 3-23) - função básica da DWT, tem-se:

$$
W_{\varphi}(j, k)=\frac{1}{\sqrt{M}} \sum_{x} f(x) 2^{\frac{j}{2}} \varphi\left(2^{j} x-k\right)
$$

Realizando a substituição de $\varphi\left(2^{j} x-k\right)$ no lado direito da equação ( 3-9), tem-se: 


$$
W_{\varphi}(j, k)=\frac{1}{\sqrt{M}} \sum_{x} f(x) 2^{\frac{j}{2}}\left[\sqrt{2} \sum_{m} h_{\varphi}(m-2 k) \varphi\left(2^{j+1} x-m\right)\right]
$$

Redistribuindo e organizando a parte somatória da equação ( 3-19):

$$
W_{\varphi}(j, k)=\sum_{m} h_{\varphi}(m-2 k)\left[\frac{1}{\sqrt{M}} \sum_{x} f(x) 2^{(j+1) / 2} \varphi\left(2^{j+1} x-m\right)\right]
$$

Pode-se observar que a parcela da equação ( 3-12) entre colchetes é semelhante à equação ( $3-18$ ), considerando a variável $j$ defasada, $j_{0}=j+1$. Dessa forma, podemos reescrevê-la como:

$$
W_{\varphi}(j, k)=\sum_{m} h_{\varphi}(m-2 k) W_{\varphi}(j+1, m)
$$

E, similarmente (e finalmente), o coeficiente de aproximação DWT, defasado em $\mathrm{j}+1$ pode ser expresso como:

$$
W_{\psi}(j, k)=\sum_{m} h_{\psi}(m-2 k) W_{\psi}(j+1, m)
$$

As equações ( 3-13) e ( 3-14) apontam que tanto a aproximação quanto os coeficientes $W_{\varphi}(j, k)$ e $W_{\psi}(j, k)$ defasados em $\mathrm{j}+1$ podem ser obtidos através da convolução $W_{\varphi}(j+1, k)$.

Considerando este fato, as equações ( 3-13) e ( 3-14) podem então ser expressas nas formas das seguintes convoluções:

$$
\begin{aligned}
& W_{\psi}(j, k)=\left.h_{\psi}(-n) * W_{\varphi}(j+1, n)\right|_{n=2 k, k \geq 0} \\
& W_{\varphi}(j, k)=\left.h_{\varphi}(-n) * W_{\psi}(j+1, n)\right|_{n=2 k, k \geq 0}
\end{aligned}
$$

Observando a Figura 3-8, percebe-se que os filtros de análise FWT são $h_{0}(n)=$ $h_{\varphi}(-n)$ e $h_{1}(n)=h_{\psi}(-n)$, e que os filtros requeridos para FWT inversa são $g_{0}(n)=$ $h_{0}(-n)=h_{\varphi}(n)$ e $g_{1}(n)=h_{1}(-n)=h_{\psi}(n)$. 


$$
W_{\varphi}(j+1, n)-W_{\psi}(j, n)
$$

Figura 3-8 - Análise do banco de filtros da transformada rápida wavelet e sua inversa. Fonte: Henry Lee T.-H..

A reconstrução da função/imagem original $f(x)$ pode ser realizada aplicando a transformada rápida inversa wavelet, como pode ser verificado pela Figura 3-9, que utiliza o escalonamento e vetores wavelet utilizados na FWT, gerando os coeficientes de aproximação de níveis defasados em $j+1$. 

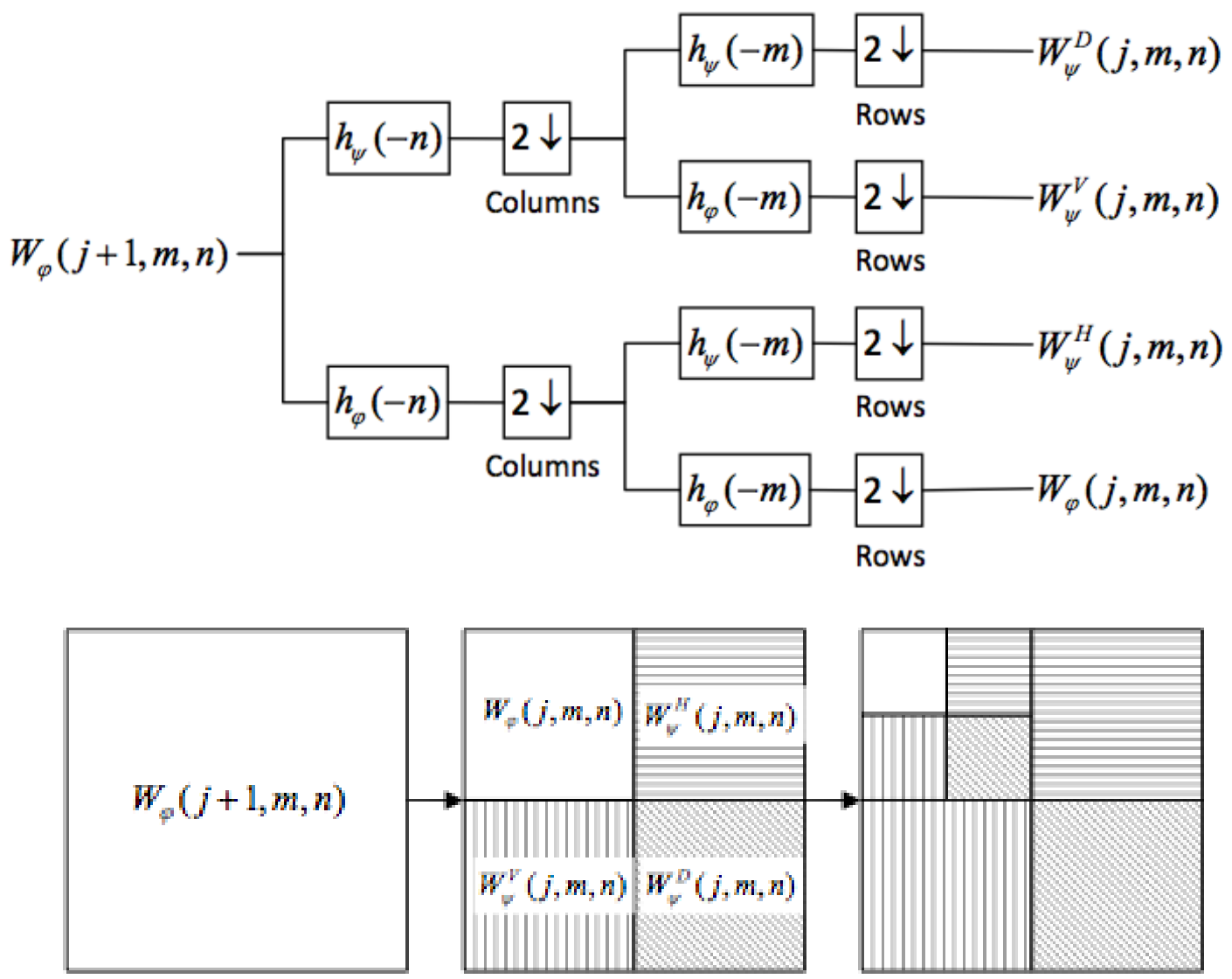

Figura 3-9 - Análise do banco de filtros da transformada rápida wavelet para duas dimensões e exemplo de decomposição.

Fonte: Henry Lee T.-H..

\subsection{O sistema de cor RGB (Red/Green/Blue)}

De acordo com Lima et al. [34], existem diversos sistemas e formas matemáticas para se representar uma imagem.

No sistema de cores aditivas RGB, formado pelas cores Vermelho (Red), Verde (Green,) e Azul (Blue) e cujo objetivo essencial é a codificação e a reprodução de cores em dispositivos eletrônicos, uma imagem digital é formada atribuindo-se a cada pixel $^{7}$ um vetor com três componentes, cada um dos quais representando as intensidades das cores do sistema RGB: vermelho, verde e azul, respectivamente.

\footnotetext{
${ }^{7}$ Pixel é a aglutinação de Picture e Element, ou seja, elemento de imagem. Trata-se do menor elemento num dispositivo de exibição, como um monitor de vídeo, por exemplo, ao qual é possível atribuir-se uma determinada cor. De uma forma simples, um pixel é o menor ponto que forma uma imagem digital, sendo que o conjunto de pixels, geralmente em ordem superior a milhares, formam uma imagem inteira [53].
} 
No caso original/padrão, quando a imagem é colorida, o valor de cada componente é um número inteiro entre 0 e 255 . Se a imagem for em preto e branco, as três componentes são idênticas, sendo a imagem caracterizada completamente pelo seu escalar em cada linha, ou seja, o valor comum das três intensidades. A Figura 3-10 apresenta, de forma sucinta, a combinação de cores do sistema RGB.

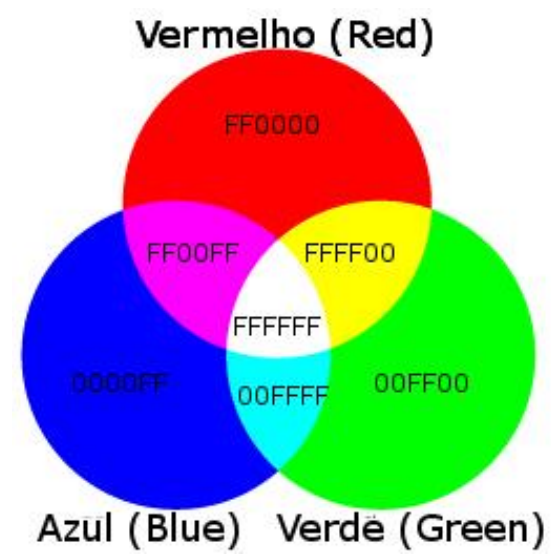

Figura 3-10 - Diagrama de Venn representando as três cores básicas do sistema RGB (Red/Blue/Green ou Vermelho/Azul/Verde) e algumas de suas possíveis combinações. Os valores dos vetores RGB, na figura, estão representados em hexadecimal.

Na Tabela 3-2 são dispostos exemplos de codificação de cores utilizando o sistema RGB:

\begin{tabular}{|c|c|c|c|c|}
\hline Descrição & $\begin{array}{l}\text { R-Vermelho } \\
\text { (Hexadecimal) }\end{array}$ & $\begin{array}{c}\text { G - Verde } \\
\text { (Hexadecimal) }\end{array}$ & $\begin{array}{c}\text { B - Azul } \\
\text { (Hexadecimal) }\end{array}$ & Cor \\
\hline Vermelho (Red) & 255 (\#FF) & $0(\# 00)$ & $0(\# 00)$ & \\
\hline Verde (Green) & $0(\# 00)$ & 255 (\#FF) & $0(\# 00)$ & \\
\hline Azul (Blue) & $0(\# 00)$ & $0(\# 00)$ & 255 (\#FF) & \\
\hline Ouro (Gold) & 255 (\#FF) & 215 (\#D7) & $0(\# 00)$ & \\
\hline Rosa Claro (Light Pink) & 255 (\#FF) & 182 (\#B6) & 193 (\#C1) & \\
\hline Céu Azul (Sky Blue) & 135 (\#87) & 206 (\#CE) & 235 (\#EB) & \\
\hline Roxo (Purple) & $128(\# 80)$ & $0(\# 00)$ & $128(\# 80)$ & \\
\hline Marrom (Brown) & 165 (\#A5) & $42(\# 2 A)$ & $42(\# 2 A)$ & \\
\hline Prata (Silver) & 192 (\#CO) & 192 (\#CO) & 192 (\#CO) & \\
\hline Laranja (Orange) & 255 (\#FF) & 165 (\#A5) & $0(\# 00)$ & \\
\hline Fúcsia (Fuchsia) & 255 (\#FF) & $0(\# 00)$ & 255 (\#FF) & \\
\hline
\end{tabular}

Tabela 3-3 - Exemplo de cores utilizando a escala RGB. Entre parênteses, a codificação em escala hexadecimal. 


\subsection{Síntese do Capítulo}

Este capítulo analisou a fundo os conceitos teóricos das técnicas aplicadas para solução da problemática de identificação de focos de consumo irregular. Foi apresentada uma visão geral das técnicas costumeiramente utilizadas para o tema, aplicadas em diversos mercados de energia elétrica no mundo, como algoritmos de Inteligência Artificial populares: Máquina de Vetores de Suporte (SVM), Lógica Fuzzy (FL) e Redes Neuras Artificiais (ANN).

Com o objetivo de conceder base teórica aos interessados e como revisão da literatura, na sequência houve o detalhamento das ferramentas que, de certa forma, contribuíram para os resultados deste trabalho, sendo utilizadas fortemente nas etapas da metodologia descrita no Capítulo 5 - , como: as técnicas paramétricas de classificação, onde se destacam a regra dos "k-Vizinhos Mais Próximos" e o Diagrama de Voronoi; o sistema de distribuição de cores utilizando vetores - Sistema RGB e; técnicas para compressão e análise de sinais/imagens, como a Transformada Rápida Wavelet. 


\section{Capítulo 4 - Fundamentos aplicados em Sistemas de Energia Elétrica}

Este capítulo aborda fundamentos de Engenharia Elétrica que, de certa forma, foram utilizados ou possuem relação direta com os objetivos deste trabalho. A introdução inicia com as discussões preliminares sobre equipamentos transformadores de potência, incluindo sua terminologia, distribuição nas redes das maiores concessionárias de energia elétrica brasileira, a apresentação de seu circuito equivalente e, finalmente, a relação do equipamento com perdas elétricas - em vazio e totais. Na mesma linha de raciocínio, é discutido o tempo de vida (ou vida útil) dos equipamentos transformadores em relação ao aumento de perdas elétricas, especialmente motivado por agentes externos e desgaste natural, e como este fato pode contribuir negativamente para a elevação das perdas no sistema. A distribuição e cálculo das perdas elétricas em equipamentos de Iluminação Pública - IP são discutidos em sequência, considerando conceitos teóricos, legais e regulatórios que regem sobre a matéria, bem como sua utilização em sistemas de IP, em termos de tipificação da lâmpada - potência e perdas. A derradeira parte do capítulo apresenta metodologia clássica de cálculo de Fluxo de Potência, teorizada por Newton-Raphson, algoritmo utilizado no trabalho para identificação primária de "pontos-quentes" de perdas.

\subsection{Transformadores de Potência}

Os transformadores elétricos são equipamentos de fundamental importância no sistema elétrico que, por indução eletromagnética, convertem as grandezas elétricas primordiais, tensão e corrente alternada, entre determinado número de enrolamentos - geralmente, dois - com a mesma frequência, porém valores distintos de tensão e corrente.

A terminologia aplicada em normas técnicas brasileiras [35] define o equipamento como sendo "Um dispositivo que por meio da indução eletromagnética, transfere energia elétrica de um ou mais circuitos (primário) para outro ou outros circuitos (secundário), usando a mesma frequência, mas, geralmente, com tensões e intensidades de correntes diferentes". 
Em média, no sistema elétrico nacional, cada equipamento de transformação instalado na rede de Baixa Tensão suporta o consumo equivalente a cerca de 17,2 unidades consumidoras, conforme compilação apresentada pela Tabela 4-1:

\begin{tabular}{|l|c|c|c|c|c|c|}
\cline { 2 - 7 } \multicolumn{1}{c|}{} & CPFL & CEMIG & Coelba & AES SUL & CEEE & DME-PC \\
\hline $\begin{array}{l}\text { Região da } \\
\text { Área de Concessão }\end{array}$ & São Paulo & $\begin{array}{l}\text { Minas } \\
\text { Gerais }\end{array}$ & Bahia & $\begin{array}{l}\text { Rio Grande } \\
\text { do Sul }\end{array}$ & $\begin{array}{l}\text { Rio Grande } \\
\text { do Sul }\end{array}$ & $\begin{array}{l}\text { Minas } \\
\text { Gerais }\end{array}$ \\
\hline Consumidores & 3.813 .597 & 7.424 .052 & 5.169 .237 & 1.236 .043 & 1.513 .711 & 67.296 \\
\hline Transformadores & 156.878 & 768.060 & 193.298 & 56.285 & 54.024 & 2.405 \\
\hline $\begin{array}{l}\text { Média de consumidores } \\
\text { por transformador }\end{array}$ & 24,3 & 9,7 & 26,7 & 22,0 & 28,0 & 28,0 \\
\hline
\end{tabular}

\begin{tabular}{|l|c|c|c|c|c|c|}
\cline { 2 - 7 } \multicolumn{1}{c|}{} & Bandeirante & CEB & Celesc & Elektro & Eletropaulo & Copel \\
\hline $\begin{array}{l}\text { Região da } \\
\text { Área de Concessão }\end{array}$ & São Paulo & $\begin{array}{l}\text { Distrito } \\
\text { Federal }\end{array}$ & $\begin{array}{l}\text { Santa } \\
\text { Catarina }\end{array}$ & São Paulo & São Paulo & Paraná \\
\hline Consumidores & 1.513 .357 & 882.718 & 2.431 .092 & 2.198 .932 & 6.102 .463 & 3.932 .563 \\
\hline Transformadores & 58.128 & 22.561 & 153.556 & 156.246 & 116.200 & 363.631 \\
\hline $\begin{array}{l}\text { Média de consumidores } \\
\text { por transformador }\end{array}$ & 26,0 & 39,1 & 15,8 & 14,1 & 52,5 & 10,8 \\
\hline \multicolumn{2}{|l|}{ Média Geral de consumidores por transformador } & \multicolumn{4}{c|}{$\mathbf{1 7 , 2}$} \\
\hline
\end{tabular}

Tabela 4-1 - Relação de transformadores em comparação com o número de instalações consumidoras por empresa distribuidora de energia elétrica do sistema nacional.

Fonte: Compilação de notas técnicas ANEEL sobre o $3^{\circ}$ Ciclo de Revisão Tarifária Periódica das distribuidoras.

Apesar de sua complexidade elétrica e estrutural, é possível simular o funcionamento de um transformador através de modelagem matemática que representa seu circuito equivalente, conforme apresentado pela Figura 4-1.

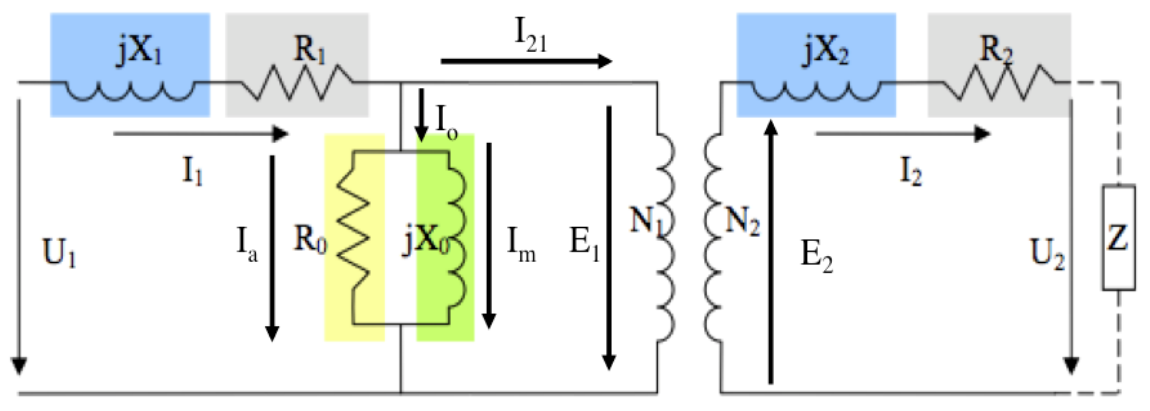

Figura 4-1 - Circuito equivalente completo de um equipamento transformador, com carga.

Fonte: Araújo Sá, C.M.,2002. 
No modelo apresentado pela Figura 4-1, são representadas:

(i)

as perdas elétricas por efeito térmico dos enrolamentos do transformado são representadas pelas resistências - partes destacadas em cinza;

(ii) as correntes parasitas de Foucault e de histerese, por serem provocadas no núcleo do equipamento, são representadas pela resistência $R_{0}$;

(iii) por ser um equipamento eletromagnético, os fluxos de fuga provocam uma defasagem de cerca de $90^{\circ}$ na tensão em relação à corrente, sendo assim representadas por elementos indutores;

(iv) a reatância $X_{0}$ representa a corrente magnetizante.

Considerando o modelo canônico de um transformador, visto pela Figura 4-1, pode-se expressar as relações das grandezas entre o circuito primário e secundário pelo seguinte conjunto de equações:

$$
\begin{gathered}
\overrightarrow{I_{1}}=\vec{I}_{21}+\vec{I}_{0} \\
\vec{U}_{1}=-\vec{E}_{1}+\left(R_{1}+j X_{1}\right) \cdot \vec{I}_{1} \\
\vec{I}_{2}=-a \vec{I}_{21} \\
\vec{U}_{2}=\vec{E}_{2}-\left(R_{2}+j X_{2}\right) \cdot \vec{I}_{2} \\
-\vec{E}_{1}=j \omega N_{1} \vec{\phi} \\
\vec{E}_{2}=-j \omega N_{2} \vec{\phi}
\end{gathered}
$$

Onde

$\omega$ representa a frequência angular do elemento;

$N$ representa o enrolamento (primário ou secundário) estudado;

$\phi$ representa o fluxo magnético mútuo aos dois enrolamentos.

Neste exemplo, no qual são verificadas perdas elétricas também no circuito secundário, provocando queda de tensão, pode-se notar que:

$$
a=\frac{N_{1}}{N_{2}}=\frac{E_{1}}{E_{2}}=\frac{I_{2}}{I_{21}} \neq \frac{U_{1}}{U_{2}} \neq \frac{I_{2}}{I_{1}}
$$


Como todo equipamento elétrico, os transformadores, intrinsicamente, apresentam perdas de energia elétrica quando em funcionamento que dependem de suas caraterísticas e material de fabricação, disposição no sistema, temperatura entre outros.

Consideráveis parcelas das perdas elétricas nestes equipamentos são comumente relacionadas ao efeito físico da histerese ${ }^{8}$ e térmicas - correntes parasitas de Foucault $^{9}$.

Segundo a Norma Técnica 5380 - Transformadores de Potência, em [36], formatada pela Associação Brasileira de Normas Técnicas - ABNT que prescreve os métodos de ensaio referentes a transformadores de potência, as perdas elétricas por:

(i) histerese são função do valor máximo da densidade de fluxo, a qual é função do valor médio da tensão;

(ii) correntes de Foucault são função do valor eficaz da tensão de alimentação.

As perdas elétricas esperadas por equipamento transformador, em função de sua capacidade de potência, são apresentadas na Norma Técnica 5440 - Transformadores para redes aéreas de distribuição - Padronização, em [35], conforme disponível na Tabela 4-2. Os valores apresentados foram fruto de estudo de padronização das características elétricas e mecânicas dos equipamentos transformadores, realizado através de ensaios com materiais que atendam aos valores admitidos e esperados de qualidade para o bom funcionamento das redes de distribuição de energia elétrica.

\footnotetext{
${ }^{8}$ Histerese é a tendência de um material ou sistema de conservar suas propriedades na ausência de um estímulo que as gerou.

${ }^{9}$ Correntes parasitas de Foucault são correntes elétricas induzidas, de níveis consideráveis/elevados, oriundas de fluxo variável transpassando por um condutor - em transformadores, geralmente material ferromagnético. O fenômeno é caracterizado por dissipação térmica de considerável montante de energia.
} 


\begin{tabular}{|c|c|c|c|}
\hline $\begin{array}{c}\text { Potência do } \\
\text { transformador (KVA) }\end{array}$ & $\begin{array}{c}\text { Perda em vazio } \\
\text { (W) }\end{array}$ & $\begin{array}{c}\text { Perda Total } \\
\text { (W) }\end{array}$ & $\begin{array}{c}\text { Perda Total / Potência } \\
\text { do transformador (\%) }\end{array}$ \\
\hline 15 & 65 & 330 & $2,4 \%$ \\
\hline 30 & 150 & 695 & $2,5 \%$ \\
\hline 45 & 195 & 945 & $2,3 \%$ \\
\hline 75 & 295 & 1395 & $1,8 \%$ \\
\hline 112,5 & 390 & 1890 & $1,7 \%$ \\
\hline 150 & 485 & 2335 & $1,6 \%$ \\
\hline 225 & 650 & 3260 & $1,5 \%$ \\
\hline 300 & 810 & 4060 & \\
\hline
\end{tabular}

Tabela 4-2 - Valores garantidos de perdas para transformadores trifásicos com tensão máxima de $15 \mathrm{kV}$. Para o cálculo da coluna "Perda Total/Potência do transformador", foi considerado o fator de potência (FP) equivalente a $92 \%$.

Fonte: ABNT, 2011.

Considerando um ensaio de equipamento transformador de energia elétrica e os valores de perdas elétricas dispostos na Tabela 4-2, a correção a ser realizada nos valores apurados de perdas com o equipamento em vazio (sem carga), definida por [36], pode ser expressa como sendo:

$$
\begin{gathered}
W_{0}=W_{m} \cdot \frac{100}{W_{h} \%+k W_{f} \%} \\
k=\left(\frac{V_{e f}}{1,11 . V_{\text {méd }}}\right)^{2}
\end{gathered}
$$

Onde

$W_{0}$ equivale às perdas em vazio para tensão senoidal pura, em $\mathrm{W}$;

$W_{m}$ equivale às perdas em vazio medidas;

$W_{h}$ equivale às perdas por histerese, em $\%$, relativas às perdas em vazio medidas;

$W_{f}$ equivale às perdas por correntes parasitas de Foucault, em \%, relativas às perdas em vazio medidas;

$V_{e f}$ equivale ao valor eficaz da tensão de alimentação, verificada em equipamento de medição (voltímetro $\mathrm{V}_{1}$ ), conforme Figura 4-2 e Figura 4-3;

$V_{\text {méd }}$ equivale ao valor médio da tensão de alimentação, verificada em equipamento de medição (voltímetro $V_{2}$ ), conforme Figura 4-2 e Figura 4-3. 


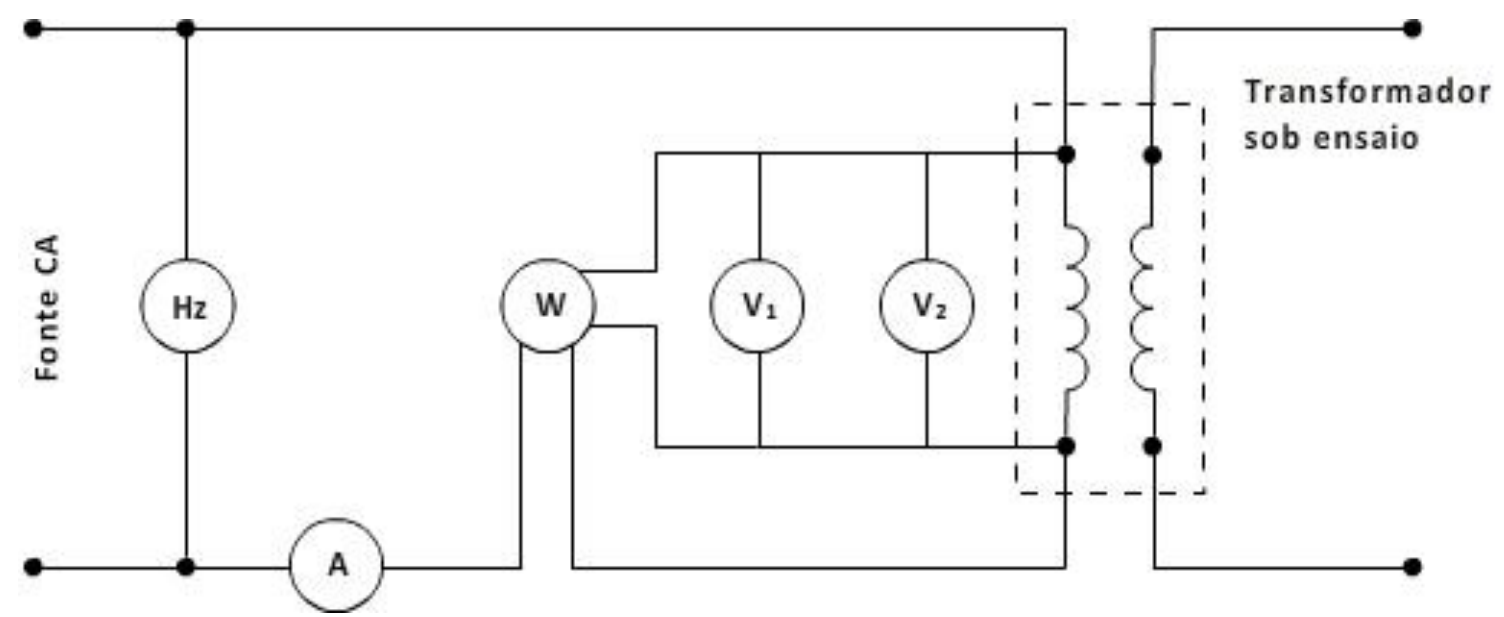

Figura 4-2 - Diagrama de ligações para ensaio de perdas em vazio e corrente de excitação em transformadores, sem transformadores para instrumentos.

Fonte: ABNT, 2011.

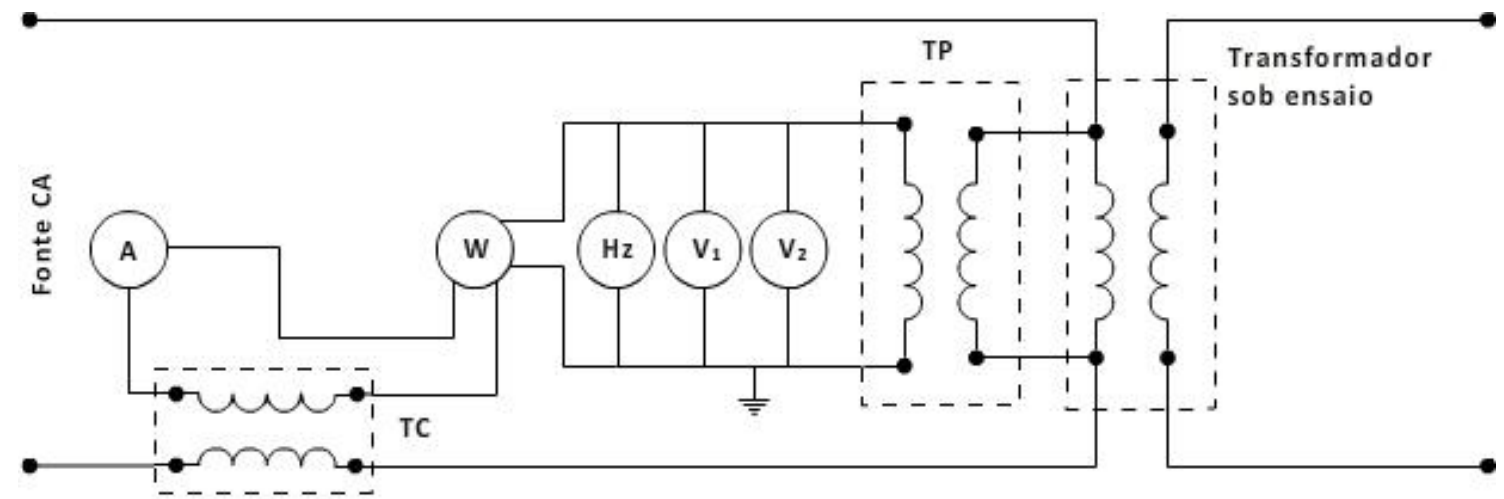

Figura 4-3 - Diagrama de ligações para ensaio de perdas em vazio e corrente de excitação em transformadores, com transformadores para instrumentos.

Fonte: ABNT, 2011.

Os valores das perdas por histerese e correntes parasitas de Foucault $-W_{h}$ e $W_{f}$, respectivamente - a serem substituídas na equação ( 4-3) devem ser grandezas medidas, contudo, na impossibilidade de se realizarem as medições necessárias, os valores típicos apresentados na Tabela 4-3 podem ser adotados, caso os materiais utilizados na fabricação do equipamento transformador considerarem chapas laminadas a frio de grão orientado. 


\begin{tabular}{|l|c|}
\hline \multicolumn{1}{|c|}{ Tipo de Perdas elétricas } & Valor Percentual Típico \\
\hline Perdas por histerese $\left(W_{h}\right)$ & $50 \%$ \\
\hline Perdas por correntes parasitas de Foucault $\left(W_{f}\right)$ & $50 \%$ \\
\hline
\end{tabular}

Tabela 4-3 - Valores percentuais típicos a serem utilizados nas variáveis $\boldsymbol{W}_{\boldsymbol{h}}$ ou $\boldsymbol{W}_{\boldsymbol{f}}$, caso haja impossibilidade de medição de tais grandezas.

Fonte: ABNT, 1993.

\subsubsection{Tempo de vida de um transformador de potência em relação às perdas}

É convencional que o desgaste natural dos equipamentos transformadores, somados a fatores externos, como exposição ao tempo (sol e chuva) e carregamento superior aos limites esperados ao funcionamento nominal, bem como a presença de harmônicos, contribuam diretamente para a redução de sua vida útil.

Neste intuito, Gouda, Amer, Salem et al. [37] desenvolveram um método analítico para predição da elevação de temperatura e redução de vida útil dos equipamentos transformadores em função da presença de correntes harmônicas. Neste trabalho, verificou-se que o nível de perdas elétricas se eleva em períodos intermediários de sua vida útil e, ao final do período, apresenta certa saturação em valores equivalentes a 2,2 p.u. (por unidade) de perdas elétricas, conforme verificado pela Figura 4-4.

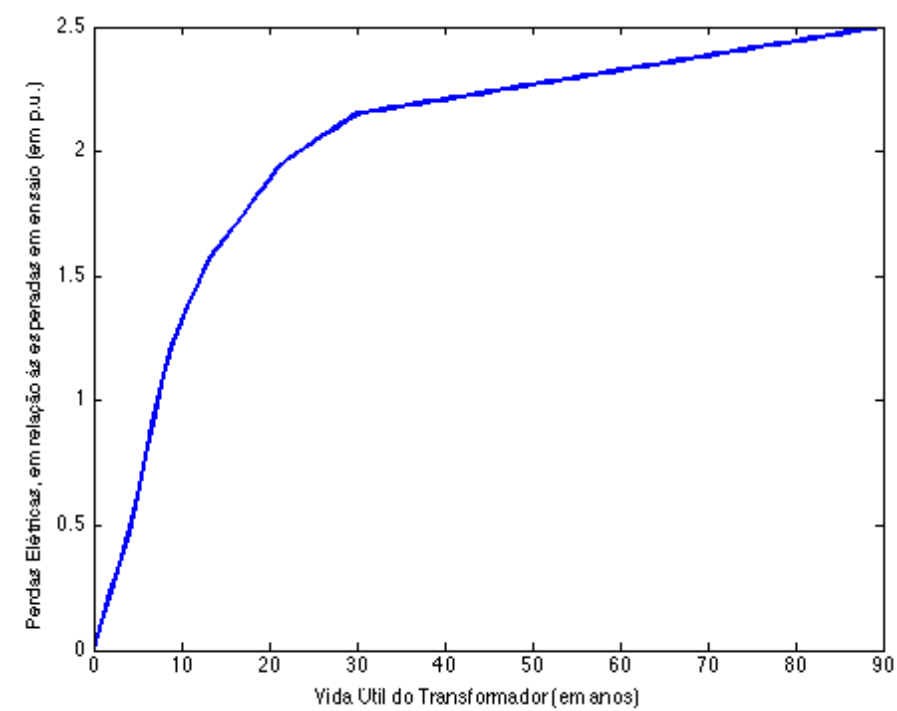

Figura 4-5 - Relação entre vida útil do transformador e perdas elétricas , em p.u., estimada para até quatro vezes o período de vida útil nominal do equipamento. 
Para o mercado brasileiro, de acordo com o manual de controle patrimonial do setor elétrico et al. [38], os equipamentos "Transformadores de Distribuição" possuem taxa de depreciação anual equivalente a 5\%, ou seja, espera-se que sua vida útil, contabilmente, seja alcançada em até 20 anos, o que, utilizando a curva relacional apresentada pela Figura 4-5, para este período, espera-se que a elevação das perdas elétricas seja próxima 1,8 vezes as perdas nominais e intrínsecas do equipamento - por histerese e por correntes de Foucault.

\subsection{Distribuição e cálculo das perdas em Iluminação Pública}

Segundo normas técnicas de uma conceituada distribuidora de energia elétrica [39], a distribuição de iluminação pública tem como "objetivo prover de luz, através de claridade artificial, os logradouros públicos no período noturno ou nos escurecimentos diurnos ocasionais, inclusive aqueles que necessitam de iluminação permanente no período diurno”. Porém, a terminologia aplicada no cenário regulatório dá definição simplificada ao serviço. Conforme a ANEEL [14], a iluminação pública trata-se de "serviço público que tem por objetivo exclusivo prover de claridade os logradouros públicos, de forma periódica, contínua ou eventual".

Fato é que o serviço propicia: (i) conforto e mobilidade pública em períodos vespertinos, (ii) segurança à população, uma vez que pode prevenir a criminalidade, (iii) a realização de espetáculos e eventos e (iv) é parte integrante e contribui para o cenário deslumbrante das cidades, especialmente em monumentos, obras, fontes e praças.

Apesar de a responsabilidade pela distribuição do serviço ser do Poder Municipal, incluindo, em exclusivo o Distrito Federal - de acordo com a Constituição da República Federativa do Brasil [40], por consumir energia elétrica, o sistema de IP é faturado pelas distribuidoras, utilizando critérios definidos na regulação, no qual considera que o tempo para consumo diário é de 11 horas e 52 minutos [14]. Sobre a capilaridade do serviço, segundo estudo do IBGE [41], em cerca de 95,5\% dos logradouros brasileiros existe a distribuição de iluminação pública. 
Diante de sua tamanha importância, e considerando que a capacidade de luminosidade das lâmpadas instaladas tem alcance limitado, a distribuição do serviço de IP possui grande capilaridade em sistemas de potência, configurando-se como o conjunto de equipamentos mais comum neste contexto. E, como todo equipamento elétrico, o conjunto também apresenta perdas elétricas quando em funcionamento o que, com a agregação dos fatores "capilaridade" e "limitação de horas para faturamento do serviço" supracitado, depreciam ainda mais o sistema elétrico em termos de perdas. Estudos do Programa Nacional de Conservação de Energia Elétrica - Procel [42], apontam que, no Brasil, a iluminação pública corresponde a aproximadamente $4,5 \%$ da demanda nacional e 3,4\% do consumo total de energia elétrica no país, o que reforça ainda mais a necessidade de se considerar o fator IP nos cálculos de perdas de um sistema de distribuição de energia elétrica.

Para determinação das cargas das lâmpadas e reatores, bem como a relação de perdas para cada equipamento, para efeitos dos cálculos de carregamento do sistema e queda de tensão na rede - fluxo de potência - são utilizados os seguintes padrões de potência, conforme apresentado na Tabela 4-4, distribuídos de forma uniforme e de acordo com a carga apresentada em cada trecho do alimentador, considerando que se utiliza maior iluminação em áreas com maior densidade.

\begin{tabular}{|c|c|c|c|c|}
\hline $\begin{array}{l}\text { Carga Trecho } \\
\text { (kVA) }\end{array}$ & Tipo de Lâmpada & $\begin{array}{c}\text { Potência } \\
\text { (W) }\end{array}$ & $\begin{array}{l}\text { Perdas no Reator } \\
\text { (W) }\end{array}$ & $\begin{array}{l}\text { Lâmpada e } \\
\text { Reator (W) }\end{array}$ \\
\hline Entre 0 a 50 & \multirow{3}{*}{ Vapor de Sódio } & 100 & 18 & 118 \\
\hline Entre 50 a 110 & & 150 & 26 & 176 \\
\hline Acima de 110 & & 250 & 37 & 287 \\
\hline
\end{tabular}

Tabela 4-4 - Dados de carga para Iluminação Pública, considerando valores médios de fabricantes e fator de potência $92 \%$.

Fonte: Cemig, 2012.

As lâmpadas de "Vapor de Sódio" e "Vapor de Mercúrio" são as mais utilizadas em sistema de iluminação pública, conforme verificado em estudos Procel [42], representado pela Figura 4-6. 


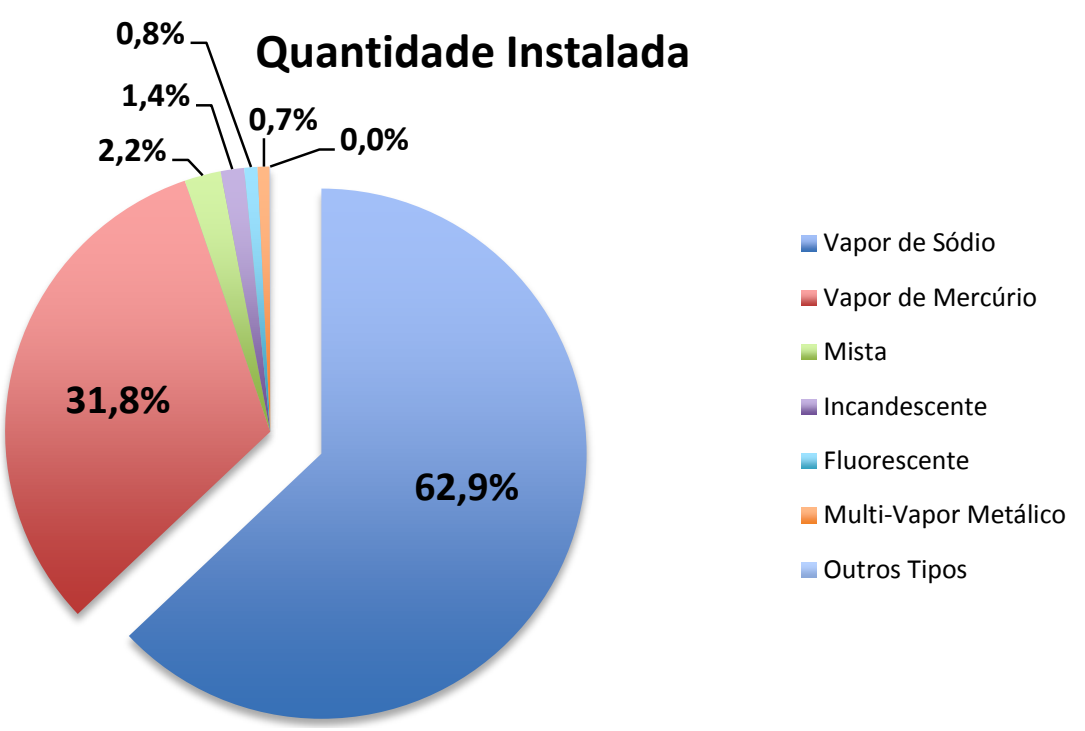

Figura 4-6 - Relação de tipos e quantidades percentuais de lâmpadas instaladas no Brasil. Fonte: Procel, 2008.

O sistema de iluminação unilateral, demonstrado pela Figura 4-7 e que será considerado neste estudo, é o mais comumente utilizado nos diversos municípios tendo em vista sua satisfatória eficiência luminosa e relativo baixo custo em comparação aos demais sistemas comuns disponíveis - (i) alternado, (ii) oposto, (iii) canteiro central e (iv) tirante/suspensão central. Normalmente as distâncias utilizadas para a instalação de iluminação segue a disposição dos postes, no qual a distância entre testadas é de até 15 metros ou de 10 metros entre guias.

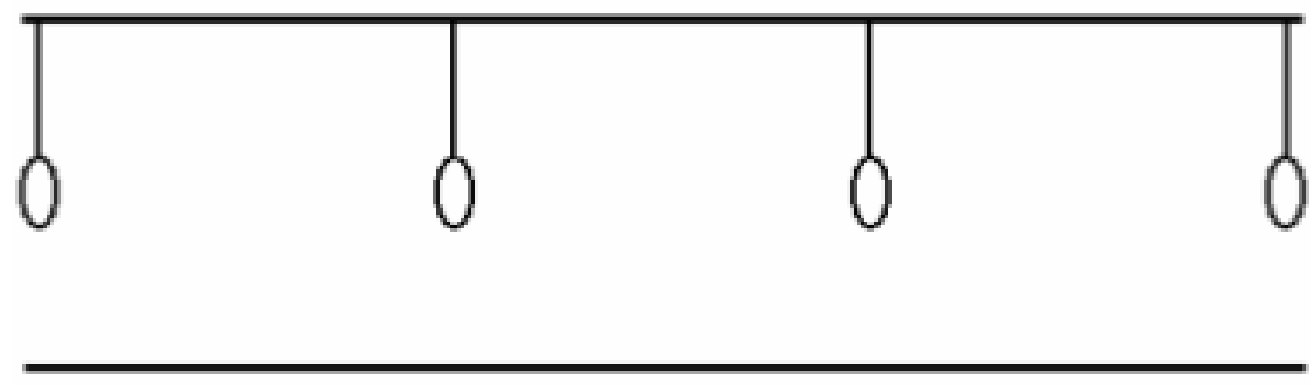

Figura 4-7 - Esquemático simplificado de um sistema de iluminação Unilateral - visão aérea. Fonte: CPFL, 2006.

A distribuição de postes, dessa forma, pode ser realizada pela divisão simples entre o comprimento do trecho do alimentador e distância entre as testadas, em consonância com a equação ( 4-5): 


$$
\operatorname{carga}_{\text {iluminação }}=\frac{d_{\text {trecho }}}{d_{\text {min_testada }_{\text {L }}}} \cdot P_{\text {Lâmpada }}
$$

onde

carga $a_{\text {iluminação }}$ representa a carga utilizada por instalação de equipamentos de iluminação pública;

$d_{\text {trecho }}$ representa a distância do trecho do alimentador no qual será instalado o sistema de iluminação pública;

$d_{\text {min_testada }}$ representa a distância mínima entre a testada ou guias definidas para distribuição do sistema de IP;

$P_{\text {Lâmpada }}$ representa a potência do tipo de lâmpada selecionado para o trecho. Esta definição depende, geralmente, da carga instalada ou quantidade de instalações consumidoras do trecho.

\subsection{Cálculo de Fluxo de Potência}

Segundo [43], o método de cálculo de fluxo de potência Newton-Raphson consiste na aproximação de um conjunto de equações não-lineares em equações lineares usando expansão por séries de Taylor, com os termos de ordem superior ignorados, baseado na solução da equação Jacobiana ( 4-6):

$$
J^{-1}\left[\begin{array}{l}
\Delta P \\
\Delta Q
\end{array}\right]=-\left[\begin{array}{c}
\Delta \theta \\
\Delta|V|
\end{array}\right]
$$

onde $\Delta \theta$ é a matriz de mudanças incrementais dos ângulos de tensões; $\Delta|V|$ é a matriz dos módulos de tensões; $\Delta P$ representa a matriz dos resíduos de potência ativa e $\Delta Q$ representa a matriz dos resíduos de potência reativa.

As equações $\Delta \mathrm{P}$ e $\Delta \mathrm{Q}$ são denominadas equações de incompatibilidade e podem ser representadas como:

$$
\Delta P_{i}=-P_{i}+\sum_{k=1}^{N}\left|V_{i}\right|\left|V_{k}\right|\left(G_{i k} \cos \theta_{i k}+B_{i k} \sin \theta_{i k}\right)
$$




$$
\Delta \mathrm{Q}_{\mathrm{i}}=-\mathrm{Q}_{\mathrm{i}}+\sum_{\mathrm{k}=1}^{\mathrm{N}}\left|\mathrm{V}_{\mathrm{i}}\right|\left|\mathrm{V}_{\mathrm{k}}\right|\left(\mathrm{G}_{\mathrm{ik}} \sin \theta_{\mathrm{ik}}+\mathrm{B}_{\mathrm{ik}} \cos \theta_{\mathrm{ik}}\right)
$$

Onde

$N$ representa o número de barras do sistema estudado.

De maneira análoga, a matriz Jacobiana pode ser representada como:

$$
J=\left[\begin{array}{ll}
\frac{\partial \Delta P}{\partial \theta} & \frac{\partial \Delta P}{\partial|V|} \\
\frac{\partial \Delta Q}{\partial \theta} & \frac{\partial \Delta Q}{\partial|V|}
\end{array}\right]
$$

Todos os termos das matrizes Jacobiana e de incompatibilidade ( $\Delta P$ e $\Delta Q$ ) são avaliadas usando os valores atuais (referentes a cada iteração) de $\mathrm{V}$ e $\theta$, de forma a resolver as matrizes $\Delta|V|$ e $\Delta \theta$, respectivamente. Normalmente, considerando que a matriz Jacobiana apresente vários elementos nulos, a equação ( 4-8) pode ser resolvida utilizando algum tipo fatoração LU - Lower/Upper.

Os valores de V e $\theta$, utilizados na presente iteração, são, posteriormente, atualizados, conforme a equação ( 4-9):

$$
\left[\begin{array}{c}
\theta \\
|V|
\end{array}\right]^{m+1}=\left[\begin{array}{c}
\theta \\
|V|
\end{array}\right]^{m}+\left[\begin{array}{c}
\Delta \theta \\
\Delta|V|
\end{array}\right]^{m}
$$

Onde

$m$ representa o número de iterações do algoritmo.

O processo de iteração continuará até que uma condição de parada seja satisfeita ou ocorra uma convergência. A condição mais comum para se mensurar a convergência é a verificação da norma das matrizes de incompatibilidade em comparação com níveis de tolerância específicos. 


\section{Capítulo 5 - Descrição da Metodologia Proposta}

Este capítulo descreve a metodologia proposta para identificação e clusterização espacial de perdas não-técnicas em sistemas de distribuição de energia elétrica, dispondo da implementação dos algoritmos necessários para sua realização. Inicialmente apresenta-se uma visão geral do projeto e sua respectiva metodologia de pesquisa. A metodologia prevê a disposição das atividades em 11 etapas, sendo que a fase inicial do projeto consiste na análise e tratamento do conjunto de dados de entrada, incluindo três etapas: (i) pré-processamento das informações, (ii) qualificação e (iii) enriquecimento ou pós-processamento das informações. As três etapas seguintes tratam da estruturação do problema e estimação das perdas elétricas do sistema, e considera: (i) a distribuição da iluminação pública, bem como o cálculo de perdas técnicas associadas, (ii) a identificação da localização dos agrupamentos ou instalações e transformadores no trecho do alimentador e (iii) cálculo das perdas técnicas dos transformadores. As etapas seguintes referem-se efetivamente à identificação de pontos de consumo irregulares, sendo: (i) análise de consumo atual da instalação em relação ao consumo nominal, (ii) execução de análise de Fluxo de Potência, (iii) análise combinatória, via transformada wavelet das imagens históricas, (iv) seleção das regiões e agrupamentos mais críticos, em termos de consumo irregular e, finalmente, (v) análise comparativa e pontual dos maiores alvos. Este capítulo ainda discute sobre a disponibilização de perfis típicos de consumo irregular, visando à avaliação do modelo.

\subsection{Metodologia Proposta}

As metodologias atualmente aplicadas para identificação de perdas não-técnicas apresentam espaços para melhorias, especialmente no que tange ao índice de sucesso das inspeções in loco, aplicadas ao público-alvo sugerido pelo algoritmo utilizado.

É perceptível que o processo de seleção de alvos de consumo irregular, na prática, é realizado utilizando informações e análise de consumo individual das instalações, vinculadas ás informações sobre ações/serviços realizados naquele ponto, bem como denúncia de terceiros, informações estas distribuídas por meio de banco de dados 
personalizados ou planilhas de apoio. O maior motivador de inspeções, ainda, são denúncias da equipe de campo da própria concessionária, realizadas quando da visita às instalações para execução de qualquer tipo de serviço -não somente inspeções.

Para contribuir com os modelos utilizados, a fim de promover a identificação de pontos críticos de consumo irregular, a metodologia pretende abordar o problema de detecção de clusters (aglomerados) tanto para dados de área quanto para dados de casos pontuais, utilizando um conjunto de dados espaciais de pontos potenciais de consumo de energia irregular em um sistema de distribuição de energia elétrica.

Nestas abordagens, propomos um algoritmo eficiente de identificação de perdas nãotécnicas, através de métodos de estatística espacial e otimização em engenharia para detecção de clusters espaciais, visando à atuação em unidades consumidoras potenciais destacadas pelo mesmo, a fim de garantir a elevação dos níveis de sucesso em inspeções de consumo irregular e maior recuperação de receita com o menor esforço possível das equipes (esforço ótimo).

A Figura 5-1 demonstra a representação geral da metodologia proposta neste trabalho para identificação de perdas não- técnicas em sistemas de distribuição de energia elétrica. 


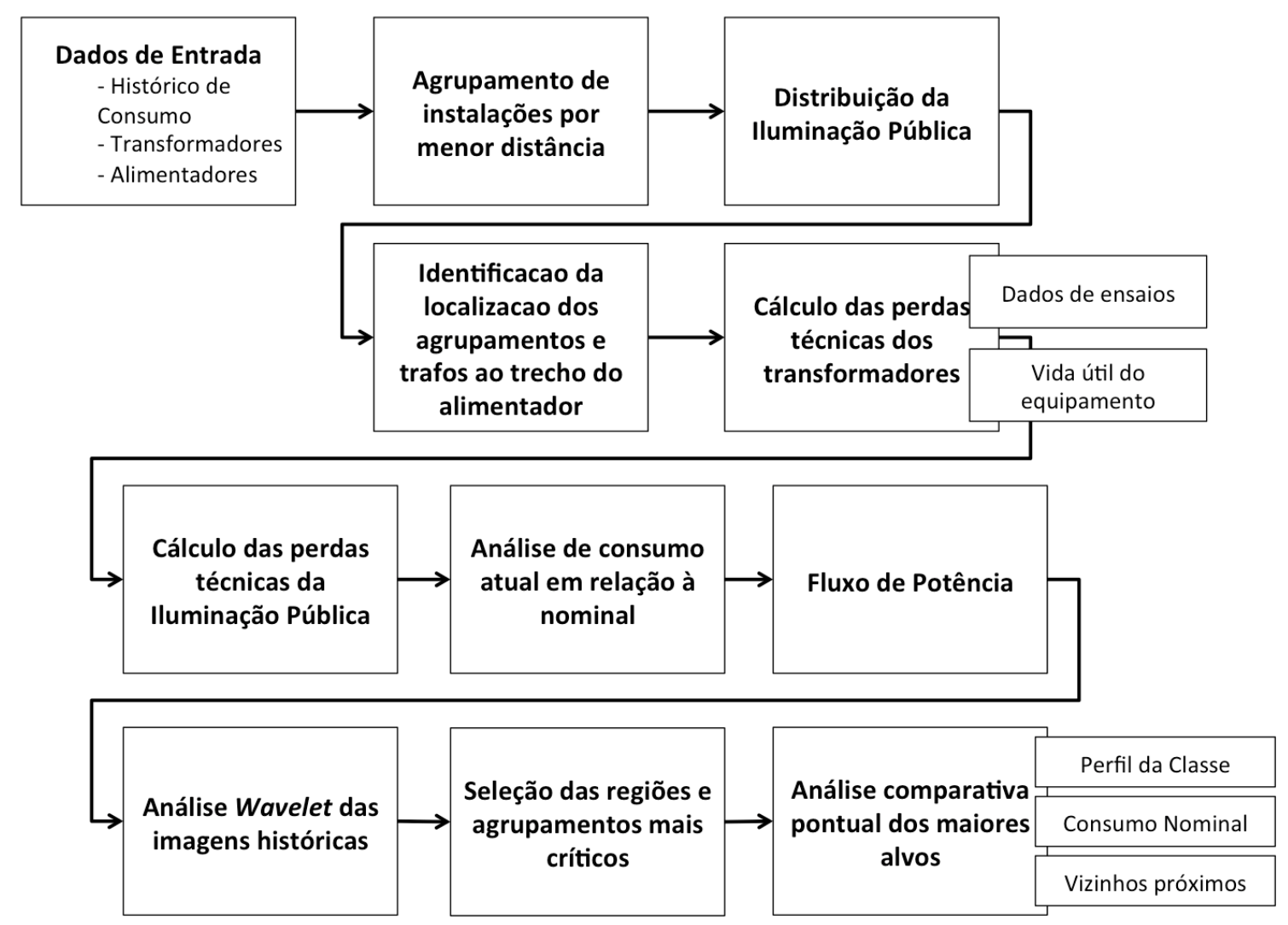

Figura 5-1 - Representação da metodologia para identificação e clusterização espacial de perdas nãotécnicas em sistemas de distribuição de energia elétrica.

As etapas são especificadas com maior ênfase nos tópicos seguintes.

\subsection{Tratamento do conjunto de dados de entrada}

A solução do problema inicia-se com o tratamento de conjunto de dados virtuais ou reais, complexo e extenso de um sistema de distribuição de energia elétrica, contendo informações ditas básicas - como pontos de consumo, histórico de consumo de energia elétrica e localização geodesia, latitude e longitude - e de suporte, - como atividade desenvolvida no ponto de consumo e dados de denúncias e suspeitas de condição irregular.

Nesta fase, é proposta a atividade de qualificação e enriquecimento da base de informações básicas de casos potenciais, esta última dada pela intersecção com dados de suporte. A atividade prevê a seleção e extração de características de comportamento dos consumidores, no qual os resultados adquiridos permitem verificarmos, por exemplo, se 
a incidência do mesmo comportamento em um definido subconjunto espacial é particular ou comum a outras regiões do conjunto ou se motivada por influência de atitudes tomadas por pontos individuais diante de fatores externos - como o famigerado "Efeito Boca-a-Boca" 10 elevando a probabilidade de sucesso em futuros casos de inspeção.

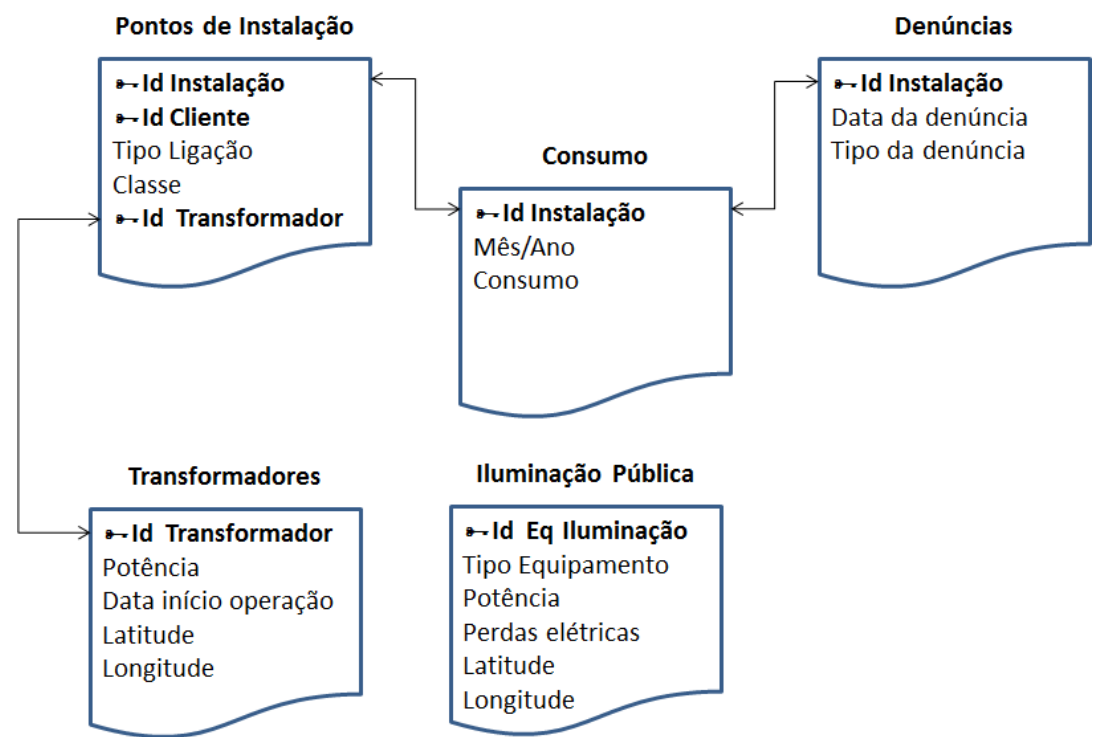

Figura 5-2 - Diagrama Entidade Relacionamento (DER) simplificado dos conjuntos de dados de entrada utilizados.

Insta ressaltar que as relações entre as bases de dados, demonstrada pela Figura 5-2, não são exaustivas, pois depende de como a empresa interessada disponibiliza os dados necessários. Podem também ser adequadas aos interesses e necessidades da companhia de distribuição de energia elétrica na qual a metodologia será aplicada.

\section{Conjunto de dados "Pontos de Instalação":}

Os dados básicos sugeridos pelo modelo para este conjunto de dados são:

(i) Identificação do consumidor/cliente responsável pela titularidade do ponto de consumo à época;

(ii) Identificação do ponto de consumo/instalação;

(iii) Tipo de ligação do ponto de consumo (Monofásico, Bifásico ou Trifásico);

\footnotetext{
${ }^{10}$ Forma gratuita de promover, de forma oral ou escrita, experiências, produtos, serviços, empresas ou eventos, e é principal e geralmente utilizada pelos seus consumidores, que relatam a outras pessoas a sua experiência pessoal com os mesmos.
} 
(iv) Classe (Residencial, Industrial, Comercial, Rural, Poder Público, Iluminação Pública, Serviços Públicos ou Consumo Próprio) e subclasse de consumo;

(v) Ramo de atividade desenvolvida no ponto de consumo, conforme definido na Classificação Nacional de Atividades Econômicas - CNAE;

(vi) Média de consumo de energia elétrica da instalação;

(vii) Último consumo de energia elétrica apurado;

(viii) Montante atual em dívida;

(ix) Quantidade de faturas inadimplentes;

(x) Transformador vinculado;

(xi) Trecho do alimentador vinculado;

(xii) Latitude;

(xiii) Longitude.

\section{Conjunto de dados "Consumo":}

Os dados básicos sugeridos pelo modelo para este conjunto de dados são:

(i) Identificação do consumidor/cliente responsável pela titularidade do ponto de consumo à época;

(ii) Identificação do ponto de consumo/instalação;

(iii) Grupo de classe de consumo;

(iv) Mês/Ano de faturamento;

(v) Consumo de energia elétrica apurado no período.

\section{Conjunto de dados "Transformadores":}

Os dados básicos sugeridos pelo modelo para este conjunto de dados são:

(i) Identificação do equipamento transformador;

(ii) Potência do transformador;

(iii) Data da instalação do equipamento transformador na rede;

(iv) Número de fases do equipamento transformador;

(v) Fator de Carga - FC;

(vi) Carregamento do equipamento;

(vii) Demanda $(\mathrm{kW})$;

(viii) Trecho do alimentador vinculado; 
(ix) Latitude;

(x) Longitude.

\section{Conjunto de dados "Denúncias":}

Os dados básicos sugeridos pelo modelo para este conjunto de dados são:

(i) Identificação do ponto de consumo/instalação;

(ii) Data da denúncia;

(iii) Tipo de denúncia realizada.

\section{Conjunto de dados "Iluminação Pública":}

Os dados básicos sugeridos pelo modelo para este conjunto de dados são:

(i) Tipo do equipamento/lâmpada (Vapor de Sódio, Vapor de Mercúrio, entre outras);

(ii) Potência da Lâmpada;

(iii) Perdas elétricas estimadas pelo fabricante;

(iv) Quantidade de denúncias com o motivo "Lâmpadas acessas durante o dia" apuradas no período;

(v) Latitude do poste no qual o equipamento está instalado;

(vi) Longitude do poste no qual o equipamento está instalado;

\subsection{Distribuição da Iluminação Pública e respectivo cálculo das perdas técnicas}

A distribuição da Iluminação Pública ocorre de duas principais: (i) através da consideração da base de dados de Iluminação Pública do(s) município(s) base do estudo, conforme descrito no item 5.2 deste Capítulo ou (ii) através de estimativa dos pontos de IP considerando a distribuição de carga do sistema elétrico e do comprimento do trecho do alimentador, dentre outros critérios, de acordo com o apresentado pelo item 4.2 desta dissertação.

Caso seja disponível a base de dados dos equipamentos de Iluminação Pública, a utilização da abordagem (i) supracitada é recomendada, tendo em vista que, geralmente, possibilita maior acurácia ao modelo, dependendo da qualidade desta base. Neste caso, 
por inexistir equipamentos de medição para tal, o cálculo de faturamento do consumo de energia elétrica da Iluminação Pública é estimado, considerando restrições regulatórias quanto ao horário diário de utilização, fator também definido no item 4.2.

\subsection{Identificação da localização dos agrupamentos e transformadores ao trecho do alimentador}

Caso sejam indisponíveis as informações que vinculam os elementos ativos do estudo ao respectivo trecho do alimentador, a metodologia prevê a identificação da localização dos pontos de instalação, agrupamentos (os pontos de instalação) - se for o caso - e de elementos da rede, como transformadores ao trecho mais próximo.

Por ser uma estimativa da identificação real dos elementos, a previsão da localização reduz a acurácia do modelo, porém traduz-se como uma solução bastante viável na ausência da original.

A identificação ocorre através da busca do trecho mais próximo à coordenada geodesia do elemento estudado, utilizando a técnica de classificação de padrões não-paramétrica “Regra do Vizinho Mais Próximo", especificada no item 3.2.1 deste trabalho.

O objetivo deste módulo é subsidiar a etapa "Execução de análise de fluxo de potência", possibilitando a inicialização da identificação dos focos de perdas não-técnicas.

\subsection{Cálculo das perdas técnicas dos transformadores}

Nesta etapa, para efeito de cálculo das perdas elétricas esperadas por equipamento transformador, em função de sua capacidade de potência, são utilizados os valores estimados disponíveis na Tabela 4-2. Os valores apresentados tratam-se do resultado de estudo de padronização das características elétricas e mecânicas dos equipamentos transformadores, realizado através de ensaios com materiais que atendam aos valores admitidos e esperados de qualidade para o bom funcionamento das redes de distribuição de energia elétrica. 
Considerando os valores adquiridos por ensaio de equipamento transformador de energia elétrica e os respectivos valores de perdas elétricas, disponíveis na Tabela 4-2, a correção a ser realizada nos valores apurados de perdas com o equipamento em vazio (sem carga) segue o objetivo dispostos pelas equações ( 4-3) e (4-4), parametrizadas pelas informações constantes da Tabela 4-3, apresentadas no item 4.1 desta dissertação.

Além da consideração das perdas elétricas em equipamentos transformadores, a presença de harmônicos contribui diretamente para sua redução da vida útil, conforme observado e descrito no item 4.1.1. Neste sentido, o modelo também dispõe deste critério para estimação das perdas elétricas do equipamento de transformação. Para tanto, é utilizada a disposição experimental de perdas elétricas com relação à vida útil do equipamento, verificada nos estudos de Gouda, Amer, Salem et al. [37].

\subsection{Análise de consumo atual em relação ao nominal}

Neste módulo, o consumo dos agrupamentos ou instalações é comparado aos seus respectivos consumos esperados, baseado no perfil de consumo regular, se houver, ou por distribuição de probabilidade característica.

Para cada período de análise, que depende diretamente do volume de informações disponíveis em histórico, é calculada a relação entre os consumos de energia elétrica verificado e esperado - que serão dados de entrada para as próximas etapas da metodologia.

A análise considera intervalos fixos e/ou sazonais pré-determinados para o estudo do comportamento de consumo das instalações, porém, dependendo da característica do mercado e da disposição da base de dados que será estudada, intervalos mais justos ou espaçados podem ser utilizados. Cada análise considera como período inicial - ou período-base - aquele: (i) em que se iniciou o processo de fornecimento de energia elétrica para o ponto de consumo ou (ii) que seja o mais antigo, disponível na base de dados, para a instalação em estudo ou ainda (iii) que o analista do processo de consumo irregular de energia elétrica julgar ser o nominal, por decisão suportada por limitação regulatória, determinação administrativa (ouvidoria) ou jurídica, eventos ocorridos ao 
ponto de consumo ao longo do período - como serviços comerciais suspeitos e denúncias - ou por empirismo.

A partir da comparação, são formados os mapas históricos, formados pela análise de consumo entre o período $n$ e $n$ - 1 , distribuídos por temperatura de coloração (do alvo "mais frio" para o "mais quente") e comparativos que servirão como subsídio para análise visual inicial e grosseira das regiões com maior indício de consumo irregular, além de insumo básico para as etapas finais da metodologia: "Análise Wavelet das imagens históricas", "Seleção das regiões e agrupamentos mais críticos" e, finalmente, “Análise comparativa pontual dos maiores alvos".

\subsection{Execução de análise de fluxo de potência}

Para aplicação da análise do sistema de potência estudado, é utilizado o método de Newton-Raphson, apresentado no item 4.3, o qual tenta buscar a solução em um menor número de iterações possível, facilitando a resolução deste tipo de problema.

Nesta etapa, o resultado principal é a disposição de perdas elétricas globais, ativas e reativas, bem como a queda de tensão em cada trecho do alimentador. Os resultados servirão como valor-base para comparação com os valores de consumo medidos, identificando, assim, trechos no qual há maior propensão de existência de foco de consumo irregular de energia.

\subsection{Análise combinatória Wavelet das imagens históricas}

Apos a execução da análise de fluxo de potência, é possível identificar com maior clareza a distinção entre as perdas elétricas técnicas e não-técnicas do sistema, permitindo assim uma macro visão do problema.

Para identificação dos maiores focos de perdas não-técnicas, de maneira grosseira, porém eficiente, a metodologia prevê a utilização de transformadas wavelet aplicada aos mapas históricos do sistema, adquiridos por período definido. 
As transformadas wavelet, conforme apresentado no Capítulo 3, são formas de representação de informações no domínio da frequência para sinais no domínio do tempo contínuo (analógico) e, desta forma, relacionados a uma análise harmônica dos sinais. Dessa maneira, para os mapas históricos adquiridos na etapa "Análise de consumo atual em relação ao nominal" são aplicadas transformadas wavelet e, com o resultado da transformação, cruzados um a um, por comparação por diferença. Este processo disponibiliza informações sobre a evolução das áreas em termos de consumo decadente, - que é um forte indício de existência de perdas não-técnicas - originando um novo mapa, com as respectivas áreas de mancha.

Ainda nesta fase, a análise grosseira dos focos de perdas não-técnicas dá-se pela comparação combinatória das imagens históricas de cada iteração, definidas em 5.6, conforme sugerido pela equação ( 5-1):

$$
\left[\begin{array}{cccc}
a_{12} & a_{13} & \cdots & a_{1 n} \\
& a_{23} & \cdots & a_{2 n} \\
& & \ddots & \vdots \\
& & & a_{m n}
\end{array}\right]
$$

onde $n$ equivale ao número de diagramas históricos analisados (ou iterações) e $m$ ao número de diagramas históricos menos 1 , ou seja, n-1.

Percebe-se que as diagonais da equação ( 5-1), especialmente as extremas, por hipótese, apresentarão os resultados mais relevantes para análise de evolução dos focos, tendo em vista serem componentes principais do estudo: os demais elementos são complementos auxiliares, ou seja:

$$
\begin{aligned}
& a_{1 n}=a_{12}+a_{23}+\cdots+a_{m n} \\
& a_{2 n}=a_{23}+a_{34}+\cdots+a_{m n}
\end{aligned}
$$




\subsection{Seleção das regiões e agrupamentos mais críticos}

A seleção das regiões e agrupamentos mais críticos, em termos de consumo de energia elétrica não-faturada, inicia-se através da análise dos diagramas combinatórios resultantes da etapa anterior, "Análise combinatório Wavelet das imagens históricas", especialmente das diagonais de ordem mais elevada verificadas na equação ( 5-1). Devido serem resultado da combinação das imagens históricas, para os diagramas citados, os pontos críticos serão aqueles em que a tonalidade de cor (se houver - visto a possibilidade de serem transcritos em "Preto e Branco" também) apresentar maior intensidade, propositalmente, visando identificação visual e simples das regiões.

A etapa seguinte à identificação das regiões é a classificação dos agrupamentos, componentes da região selecionada, para fins de priorização de atuação. Para tanto, cada ponto de instalação potencial - ou todo o conjunto de instalações da região - é analisado pontualmente seu perfil de consumo, exemplificado pela Figura 5-3 e considerando os seguintes critérios:

(i) Taxa de consumo menor que a média dos maiores consumos verificados;

(ii) Percentual do período em que serão identificadas as médias dos consumos de energia elétrica máximos e mínimos;

(iii) Média dos maiores consumos verificados, considerando parte do período, conforme definido em (ii);

(iv) Média dos menores consumos verificados, considerando parte do período, conforme definido em (ii);

(v) Percentagem do período global do histórico em que o consumo da instalação apresentou-se menor que a taxa de consumo, definida em (i).

A metodologia dispõe das variáveis (i) e (ii) para ajustes do melhor modelo de seleção dos alvos, no qual seus parâmetros dependerão da característica do mercado e do apetite de atuação da empresa gestora, estimado pela disponibilização de equipes para inspeção. 


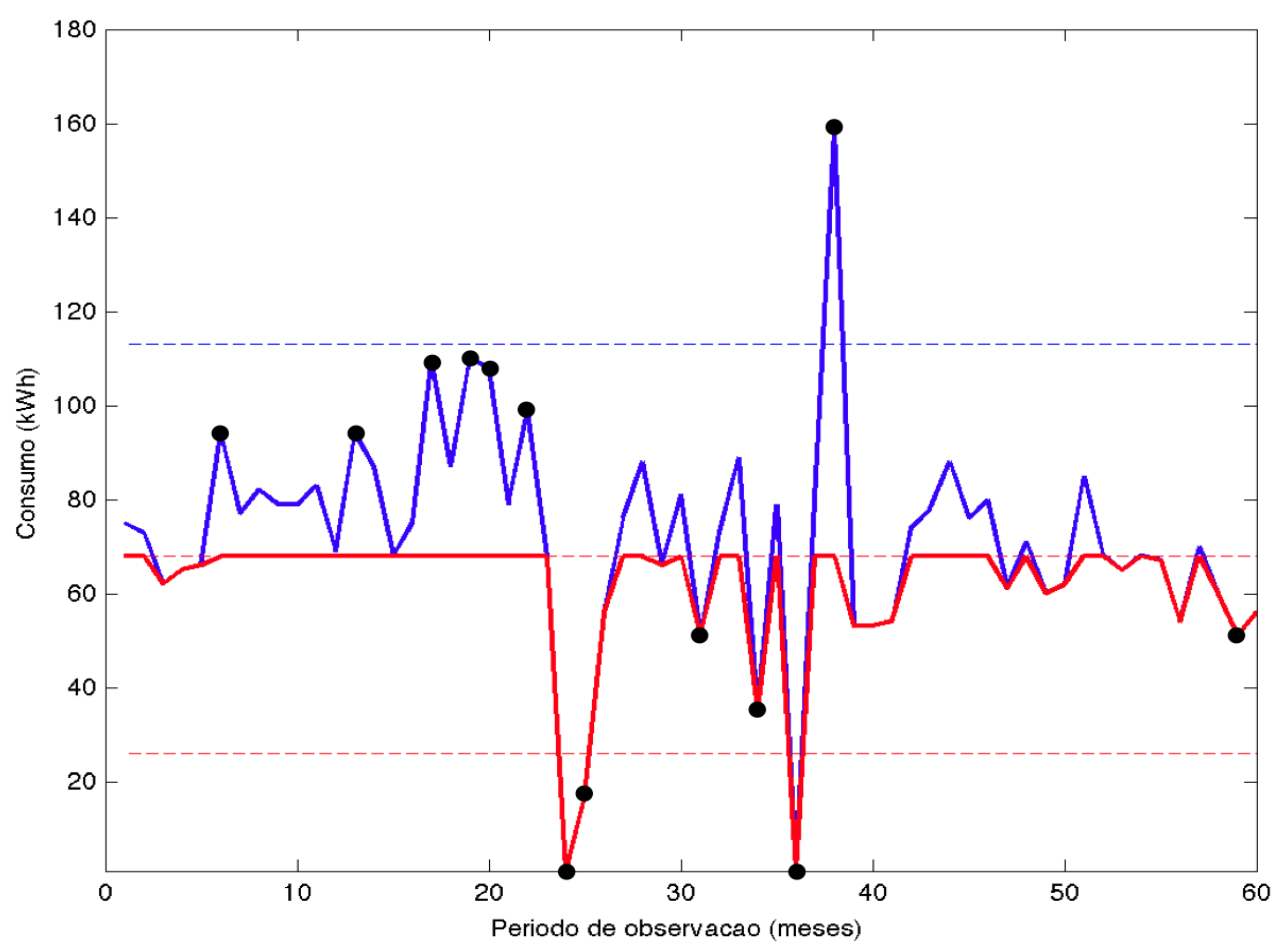

Figura 5-3 - Modelo analítico para definição de consumo crítico. Neste caso, o percentual do período para determinação das médias max/min foi de $10 \%$ (ou 6 períodos). Em azul, os consumos de energia acima do nominal/esperado. Em vermelho, os consumos de energia que se lograram abaixo do nominal/esperado. As linhas pontilhadas representam os valores médios dos maiores e menores consumos verificados. Os pontos destacados em negrito representam os valores de consumo de energia máximos e mínimos considerados para determinação das médias (linhas pontilhadas).

Considerando a relação entre os períodos em que o consumo de energia elétrica apresentou-se menor que o nominal ou esperado, em relação ao número total de períodos, identificam-se os principais focos de atuação em cada região. Os pontos de consumo são apresentados na forma decrescente de criticidade.

A metodologia também permite a aplicação de modelos (conjunto de critérios) utilizados pelas distribuidoras, formados por empirismo ou característica de mercado.

\subsection{Análise comparativa e pontual dos maiores alvos}

Nesta etapa, a metodologia busca identificar de forma pontual, a partir dos focos selecionados pela etapa anterior, os locais críticos de consumo irregular, ordenados por critério decrescente de criticidade. 
Para cada local identificado, é realizada a comparação do consumo histórico do alvo com:

o perfil de consumo da classe do ponto de consumo - Residencial, Industrial, Comercial ou Rural, por exemplo;

(ii) o consumo dos pontos de consumo vizinhos lógicos mais próximos, da mesma classe e;

(iii) o consumo nominal/esperado do alvo.

Com a disponibilidade dos melhores alvos, a próxima etapa sugerida é a efetiva execução de inspeção in loco nos pontos de consumo identificados a fim de caracterizar o indício de procedimento irregular, visando a sua regularização, se for o caso.

\subsection{Perfis de Consumo Irregular Típicos}

Para avaliação da efetividade da metodologia na identificação de instalações com este tipo de consumo, o modelo dispõe de cinco curvas típicas de consumo irregular.

Os perfis de consumo típicos foram formados através de compilação de dados apurados de uma amostra de 50 instalações, disponíveis no Apêndice A - , no qual foram verificados e confirmados algum tipo de procedimento irregular, perdurando por 49 meses, em média, nos mais diversos períodos e cenários.

Para que houvesse equalização nas comparações e agrupamentos das curvas históricas verificadas, os perfis de consumo da amostragem foram devidamente normalizados ${ }^{11}$, com a aplicação da seguinte equação:

$$
Z=\frac{X-\mu}{\sigma}
$$

\footnotetext{
${ }^{11}$ Normalização de informações remete a ajustar valores observados em escalas diferentes para uma escala teoricamente comum, permitindo a comparação dos valores normalizados para diferentes conjuntos de dados, buscando eliminar os efeitos de determinadas influências na base de dados.
} 
Onde

$\mathrm{Z}$ representa o valor normalizado de uma distribuição;

$\mathrm{X}$ representa o valor que se pretende normalizar;

$\mu$ representa a média aritmética da distribuição;

$\sigma$ representa o desvio-padrão da distribuição;

A partir da normalização das curvas específicas de consumo de energia elétrica de cada uma das instalações, realizou-se a análise estatística de correlação e relevância entre as curvas. Para cada distribuição de consumo, foram selecionadas cinco distribuições que apresentaram maior correlação com a primeira, dentre as demais 49 , formando um grupo que apresente perfis similares, e assim sucessivamente, até que tivéssemos 50 grupos, com 5 distribuições cada, conforme apresentado pela equação ( 5-4).

Para a identificação das curvas que possuíam a maior correlação, foi utilizado o "coeficiente de correlação de Pearson" [44].

$\operatorname{Max}\left(\left|\frac{\sum_{i=1}^{n}\left(y_{k, i}-\overline{y_{k}}\right)\left(y_{j, i}-\overline{y_{J}}\right)}{\sqrt{\sum_{i=1}^{n}\left(y_{k, i}-\overline{y_{k}}\right)^{2}} \cdot \sqrt{\sum_{i=1}^{n}\left(y_{j, i}-\overline{y_{j}}\right)^{2}}}\right|\right) \quad j=1,2, \cdots, m \quad \forall j \neq k$

Onde

$\overline{y_{k}}$ representa a média aritmética da distribuição normalizada principal;

$\overline{y_{J}}$ representa as médias aritméticas das distribuições normalizadas secundárias;

A Tabela 5-1 exemplifica a aplicação da análise de correlação entre as distribuições, através da aplicação da equação ( 5-4):

\begin{tabular}{|l|c|c|c|c|c|}
\cline { 2 - 6 } \multicolumn{1}{c|}{} & \multicolumn{5}{c|}{ Codificação da Distribuição } \\
\hline Distribuição Principal & 9 & 21 & 23 & 36 & 42 \\
\hline Distribuição Secundária com melhor correlação & 18 & 24 & 29 & 30 & 36 \\
\hline Distribuição Secundária com 2 a melhor correlação & 23 & 25 & 11 & 46 & 9 \\
\hline Distribuição Secundária com 3 a melhor correlação & 29 & 11 & 37 & 26 & 32 \\
\hline Distribuição Secundária com 4 melhor correlação & 14 & 22 & 50 & 48 & 7 \\
\hline Distribuição Secundária com 5 melhor correlação & 24 & 47 & 25 & 19 & 37 \\
\hline
\end{tabular}

Tabela 5-1 - Análise de correlação entre as curvas de consumo irregular e formação de grupos das instalações de amostragem. 
Os cinco grupos selecionados foram definidos considerando as distribuições principais que apresentaram maior frequência figurando como a distribuição de melhor correlação, dentre os demais 49 grupos construídos, exemplificado pela Tabela 5-2.

\begin{tabular}{|c|c|c|}
\hline $\begin{array}{c}\text { Codificação da } \\
\text { Distribuição }\end{array}$ & $\begin{array}{c}\text { Frequência em que a distribuição } \\
\text { figurou-dentre as 5 que apresentaram } \\
\text { melhor correlação }\end{array}$ & $\begin{array}{c}\text { Frequência em que a distribuição } \\
\text { figurou-como a que apresentou } \\
\text { melhor correlação }\end{array}$ \\
\hline$\# 23$ & 22 & 7 \\
\hline$\# 29$ & 17 & 4 \\
\hline$\# 46$ & 16 & 3 \\
\hline$\# 25$ & 14 & 3 \\
\hline$\# 36$ & 10 & 3 \\
\hline$\# 22$ & 7 & 3 \\
\hline$\# 11$ & 17 & 2 \\
\hline$\# 5$ & 9 & 2 \\
\hline$\# 14$ & 9 & 2 \\
\hline$\# 24$ & 9 & 2 \\
\hline
\end{tabular}

Tabela 5-2 - Relação das instalações cuja distribuição de consumo irregular apresentou melhor correlação em comparação com as demais disponíveis na amostragem sendo: (a) frequência dentre as 5 melhores e (b) frequência sendo a de melhor correlação.

Para estas distribuições, todo o grupo foi destacado para a formação da curva típica de consumo, desconsiderando, como principal, a distribuição que já compunha um dos grupos. Neste caso e conforme apresentado pela Tabela 5-3, é selecionada a distribuição seguinte que apresentou maior frequência dentre as melhores o que, não necessariamente, significa que pertencem ao mesmo grupo - são perfis apenas similares.

\begin{tabular}{|l|c|c|c|c|c|c|}
\cline { 2 - 7 } \multicolumn{1}{c|}{} & $\begin{array}{c}\text { Distribuição } \\
\text { Principal }\end{array}$ & $\begin{array}{c}\text { Melhor } \\
\text { Correl. }\end{array}$ & $\begin{array}{c}\mathbf{2}^{\text {a }} \text { Melhor } \\
\text { Correl. }\end{array}$ & $\begin{array}{c}\mathbf{3}^{\text {a }} \text { Melhor } \\
\text { Correl. }\end{array}$ & $\begin{array}{c}\mathbf{4}^{\text {a }} \text { Melhor } \\
\text { Correl. }\end{array}$ & $\begin{array}{c}\mathbf{5}^{\text {a }} \text { Melhor } \\
\text { Correl. }\end{array}$ \\
\hline Grupo 1 & 23 & 29 & 11 & 37 & 50 & 25 \\
\hline Grupo 2 & 46 & 14 & 24 & 19 & 36 & 50 \\
\hline Grupo 3 & 22 & 24 & 46 & 12 & 44 & 28 \\
\hline Grupo 4 & 5 & 2 & 23 & 29 & 33 & 14 \\
\hline Grupo 5 & 27 & 25 & 7 & 43 & 6 & 23 \\
\hline
\end{tabular}

Tabela 5-3 - Formação dos 5 grupos que representam os perfis de consumo irregular típicos.

Aplicou-se, então, sob a distribuição normalizada de cada instalação pertencente ao grupo, o coeficiente de correlação de Pearson verificado em comparação com a distribuição principal, de forma que cada curva de perfil típica dispusesse da 
composição ponderada de 6 distribuições. A seleção dos 5 grupos de perfis de consumo irregular típicos são demonstrados pela Tabela 5-4.

\begin{tabular}{|l|c|c|c|c|c|c|}
\cline { 2 - 7 } \multicolumn{1}{c|}{} & $\begin{array}{c}\text { Distribuição } \\
\text { Principal }\end{array}$ & $\begin{array}{c}\text { Melhor } \\
\text { Correl. }\end{array}$ & $\begin{array}{c}\mathbf{2}^{\text {a }} \text { Melhor } \\
\text { Correl. }\end{array}$ & $\begin{array}{c}\mathbf{3}^{\text {a }} \text { Melhor } \\
\text { Correl. }\end{array}$ & $\begin{array}{c}\mathbf{4}^{\text {a }} \text { Melhor } \\
\text { Correl. }\end{array}$ & $\begin{array}{c}\mathbf{5}^{\text {a }} \text { Melhor } \\
\text { Correl. }\end{array}$ \\
\hline Grupo 1 & 1 & 0,86662 & 0,80541 & 0,72768 & 0,70008 & 0,65177 \\
\hline Grupo 2 & 1 & 0,56789 & 0,56200 & 0,55020 & 0,54853 & 0,53711 \\
\hline Grupo 3 & 1 & 0,57756 & 0,49276 & 0,45977 & 0,39988 & 0,39542 \\
\hline Grupo 4 & 1 & 0,67908 & 0,62506 & 0,59313 & 0,55076 & 0,54876 \\
\hline Grupo 5 & 1 & 0,70784 & 0,62728 & 0,62688 & 0,55185 & 0,54539 \\
\hline
\end{tabular}

Tabela 5-4 - Coeficientes de correlação Pearson utilizado na composição dos 5 grupos que representam os perfis de consumo irregular típicos.

Dessa forma, foram obtidos os cinco perfis de consumo irregular típicos disponíveis no modelo e apresentados pela Figura 5-4.

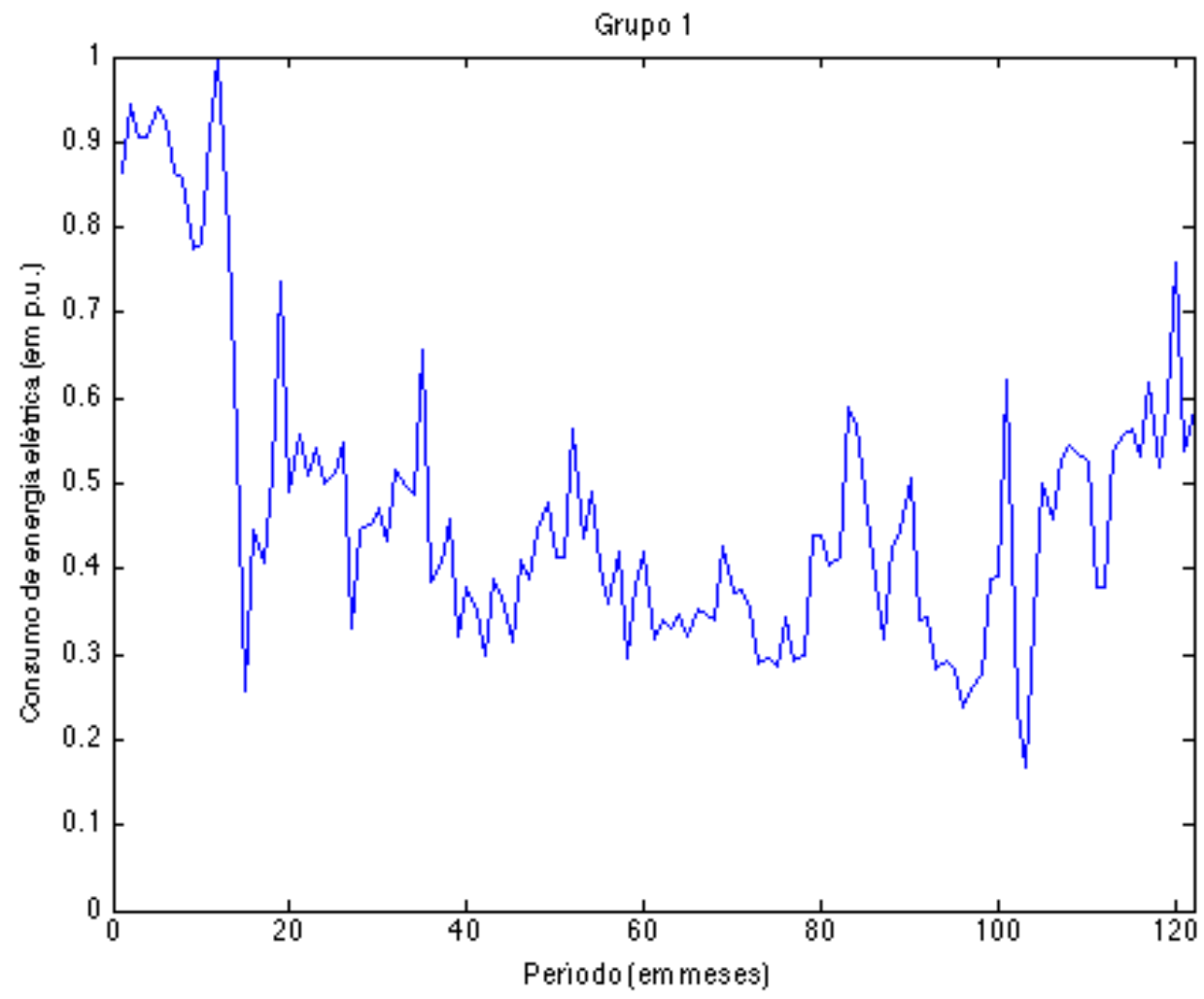



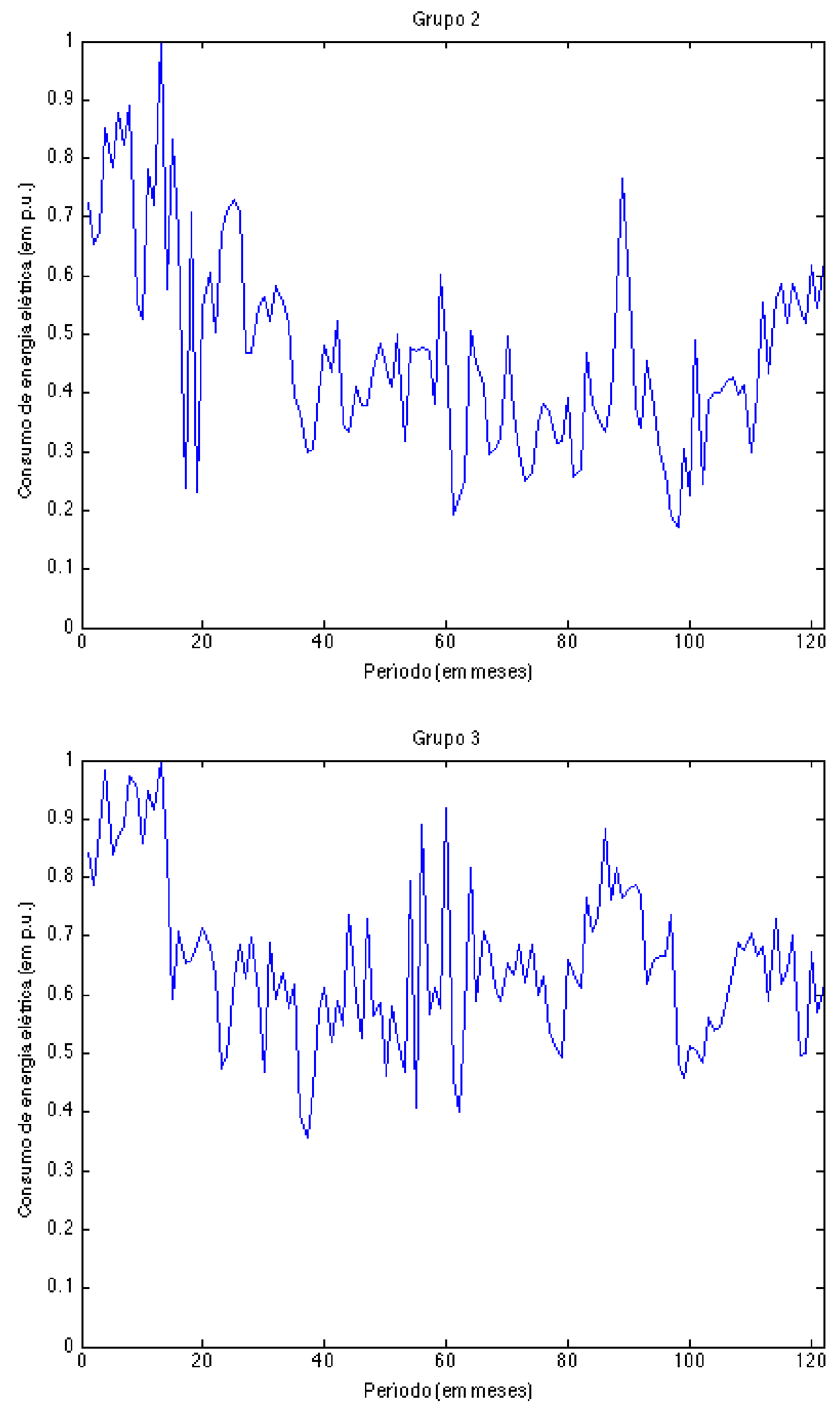

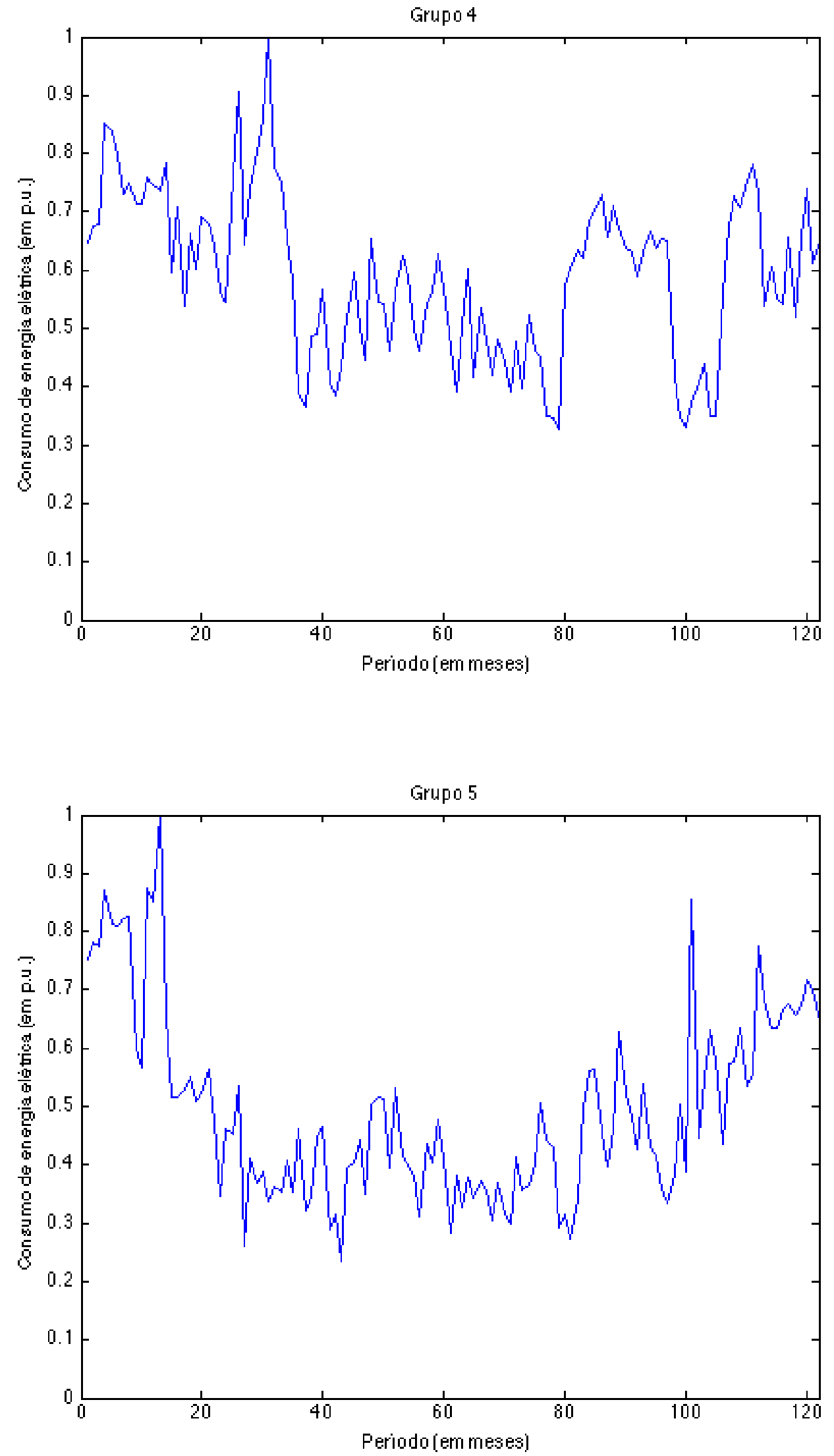

Figura 5-4 - Os cinco perfis típicos de instalações que apresentam consumo irregular, disponíveis no modelo. 


\section{Capítulo 6 - Resultados obtidos e Estudo de Caso}

A proposta deste capítulo é composta pelo estudo de caso aplicado ao modelo, visando a sua avaliação, contemplando um conjunto de dados hipotéticos. Na segunda seção do capítulo, são apresentados os resultados obtidos em duas avaliações distintas e independentes, através da aplicação da metodologia ao conjunto de dados, bem como a aplicação de pontos de consumo, com perturbação de seu histórico de consumo, por sobreposição com perfis típicos de consumo irregular, - apresentados no Capítulo 5 selecionados de forma aleatória. Ao final de cada avaliação, são analisadas a coerência e influência da metodologia na identificação de instalações que apresentem consumo irregular.

Todas as etapas descritas nas seções anteriores foram implementadas por meio de funções e algoritmos disponibilizados pela plataforma MATLAB ${ }^{\mathrm{TM}}$.

\subsection{Estudo de Caso}

Com o intuito de demonstrar a aplicabilidade do modelo proposto, tomou-se como exemplo informações hipotéticas de uma empresa do setor elétrico, atuando em Varginha/MG, município de médio/grande porte, ou seja, com volume populacional de 100 mil a 1 milhão de habitantes, segundo classificação do IBGE.

Neste submercado hipotético, a distribuidora realiza o fornecimento de energia elétrica para 905 pontos de consumo, utilizando cerca de 42 equipamentos transformadores em um alimentador cujo backbone contém 24 trechos, segundo a Figura 6-1. 


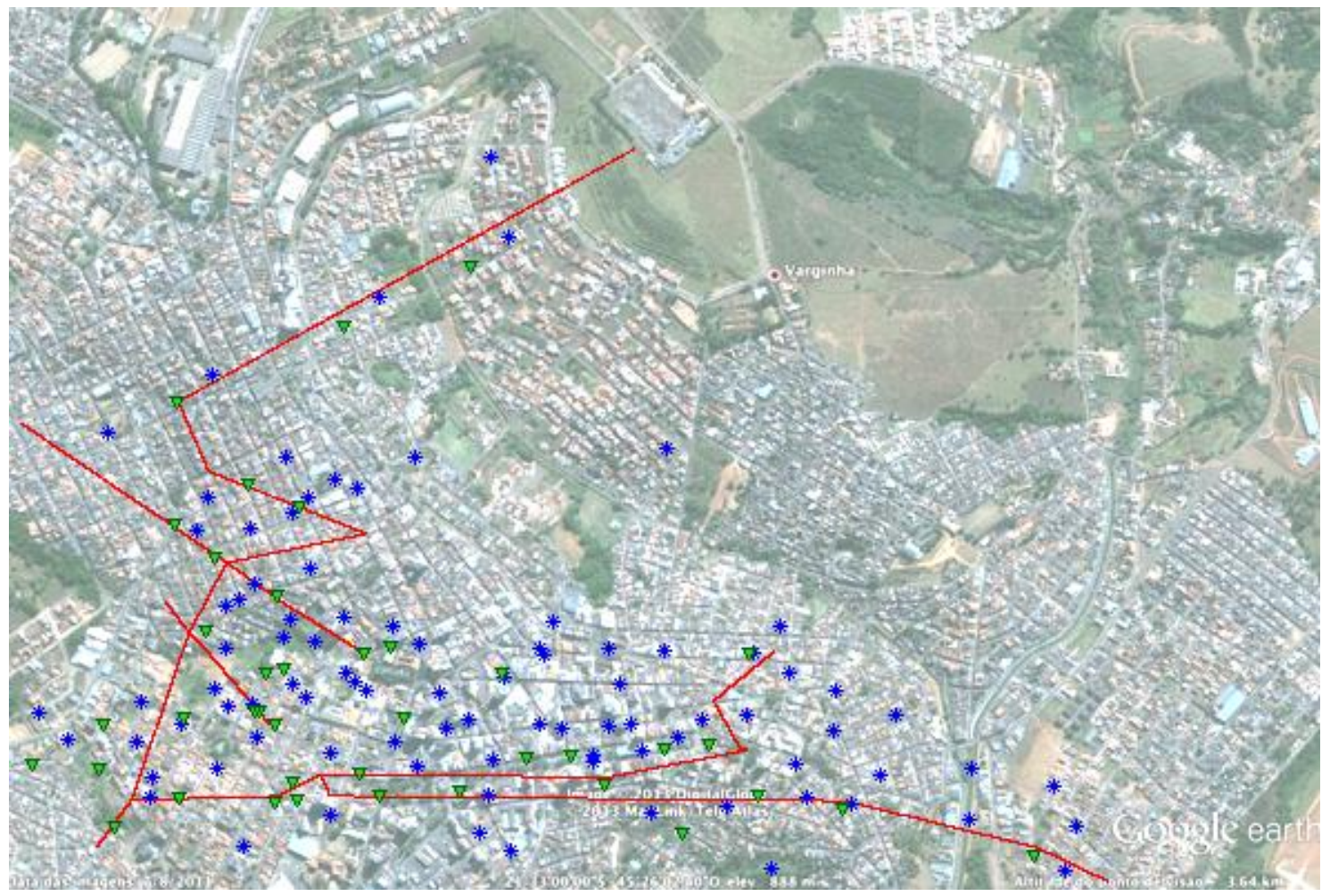

Figura 6-1 - Distribuição do alimentador por trecho (cor vermelha), pontos de instalação (destacados em azul) e transformadores de rede (destacados em verde) em um determinado município.

Créditos: Plataforma Google Earth, 2013

\subsection{Resultados Obtidos}

\subsubsection{Primeira avaliação}

Para avaliação do modelo, foram distribuídos, de forma aleatória, três pontos de consumo no sistema, com a aplicação dos perfis típicos de consumo 1, 3 e 4, dentre as disponíveis no modelo, apresentados no item 5.11 deste trabalho. A Tabela 6-1 apresenta as instalações-teste distribuídas para a avaliação do modelo.

\begin{tabular}{|c|c|c|}
\hline Codificação da Instalação & \#Curva Típica de Consumo Irregular & $\begin{array}{c}\text { \% Períodos com consumo } \\
\text { menor que o nominal }\end{array}$ \\
\hline 96 & 1 & $30 \%$ \\
\hline 352 & 3 & $13 \%$ \\
\hline 801 & 4 & $15 \%$ \\
\hline
\end{tabular}

Tabela 6-1 - Instalações-teste para o modelo, bem como suas respectivas curvas típicas, selecionadas de forma aleatória. 
Com histórico dos pontos de consumo de, no máximo, 60 meses disponível para a aplicação do modelo, o período-base selecionado para execução da rotina foi de 12 meses, aplicados em 4 iterações.

Os meses do histórico que seriam alvo de análise foram selecionados considerando o mês mais próximo da data atual para o mais antigo, sendo os demais desconsiderados. Para os pontos que possuem histórico de consumo menor que 12 meses, caracterizando novas conexões, a análise considerou normalização dos consumos verificados no período total para o número máximo de iterações sugerido, neste caso 4.

A cada iteração, foi possível perceber e avaliar a evolução de consumo de cada ponto e dos equipamentos elétricos (alimentador, distribuição da iluminação pública e transformadores) e que serviram de base para a fase de "Análise combinatória wavelet das imagens históricas", conforme apresentado pela Figura 6-2.

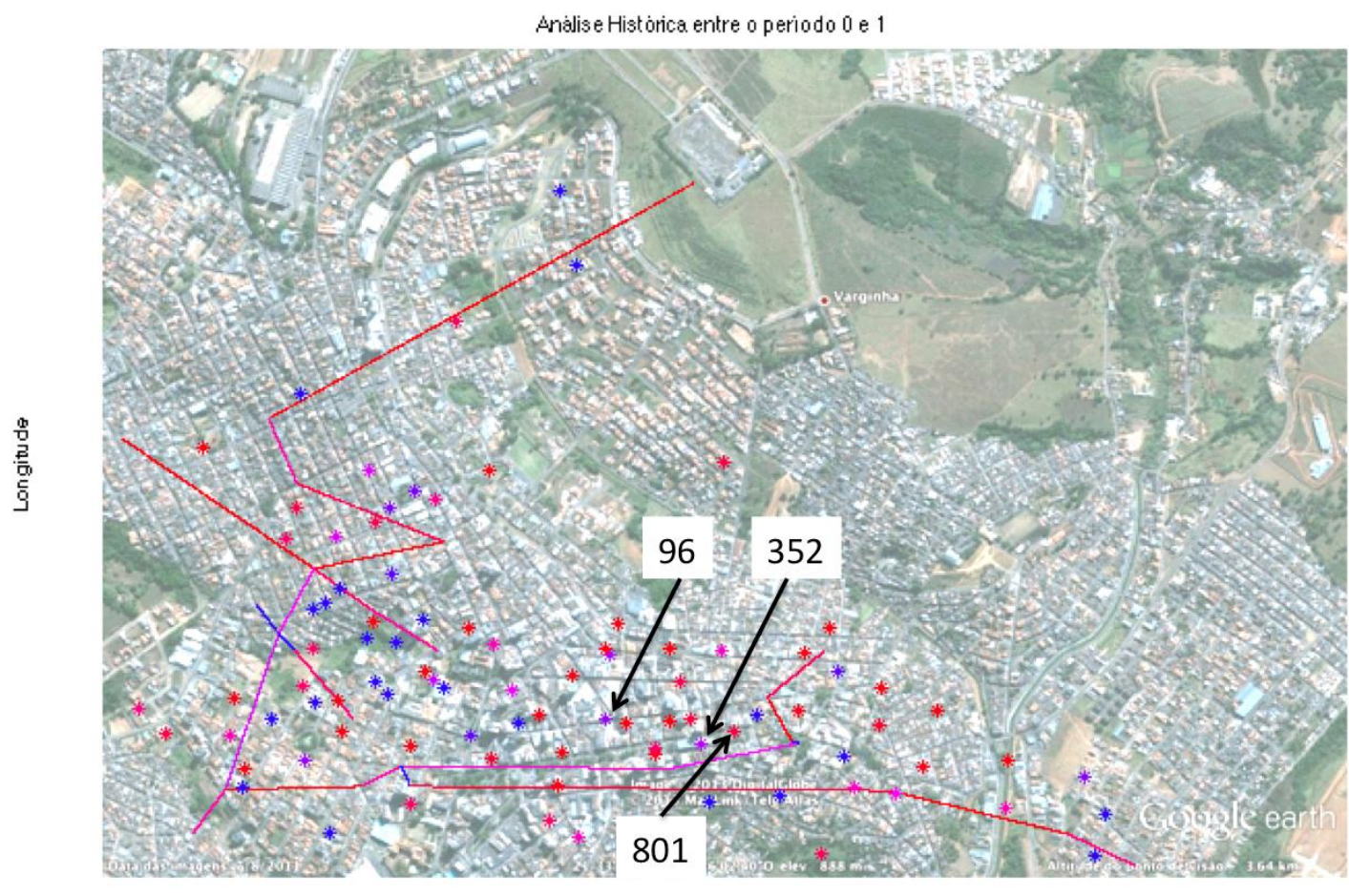

Latitude 


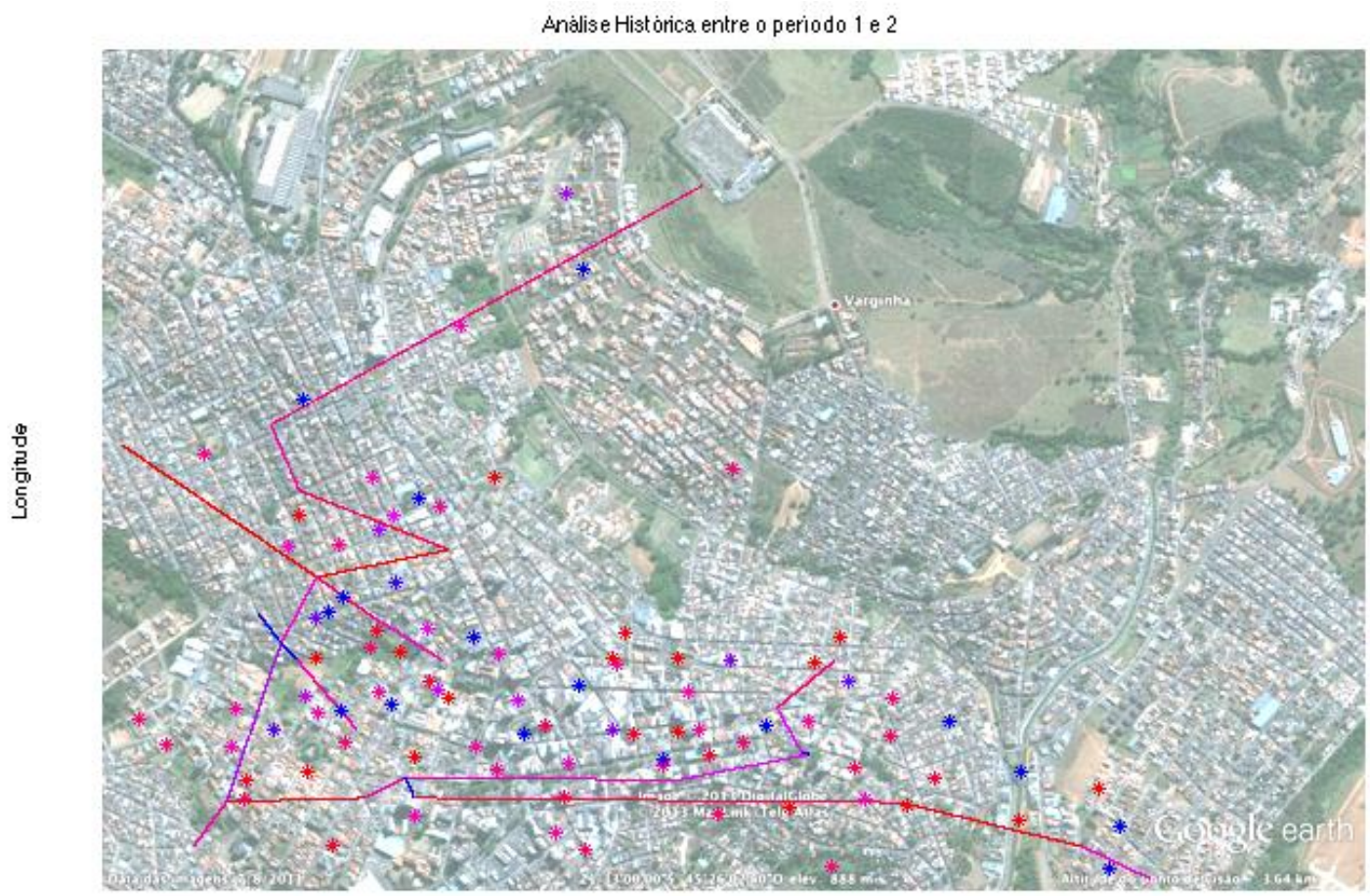

Latitude

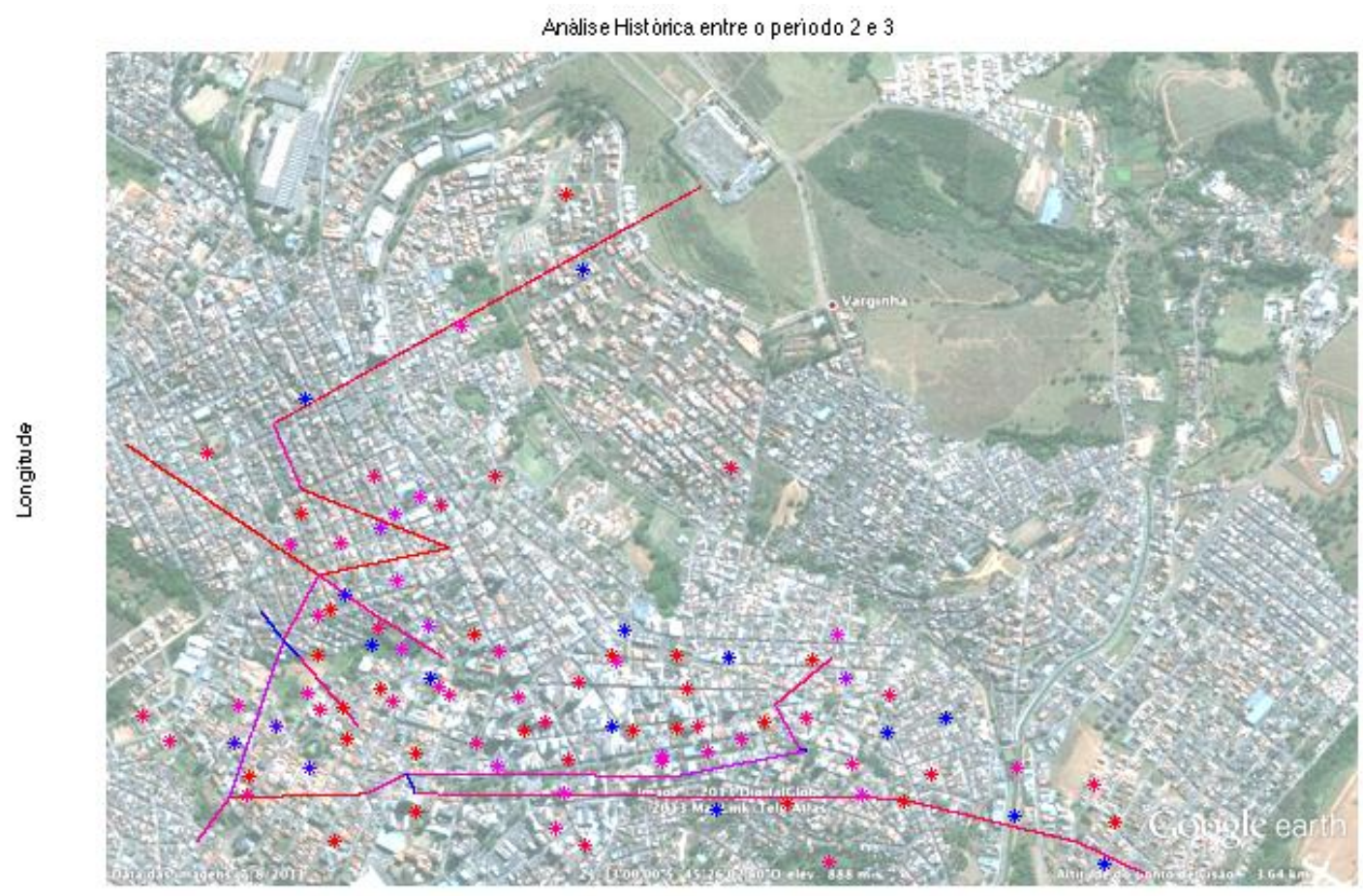

Latitude 


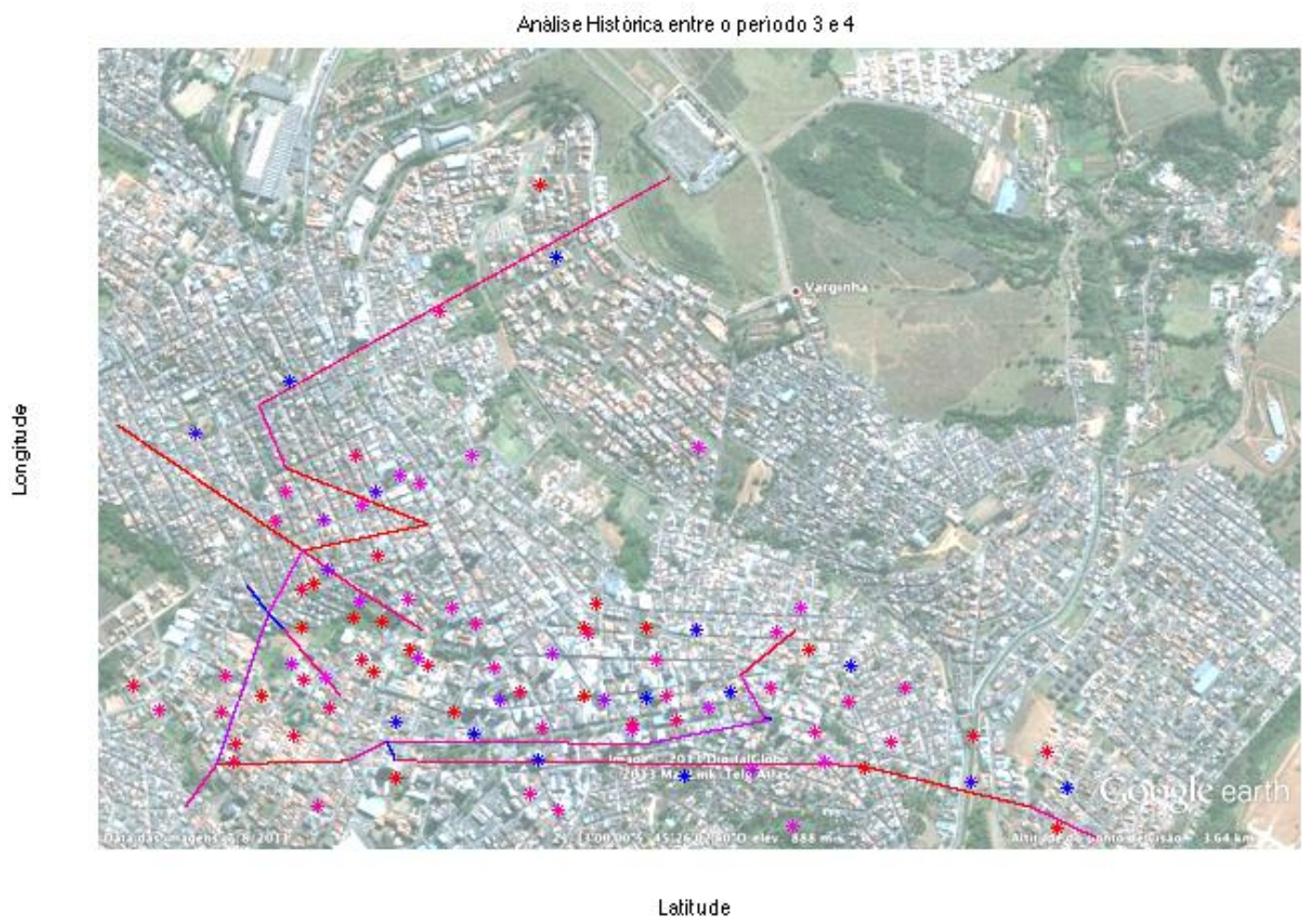

Figura 6-2 - Evolução de consumo de energia elétrica (regular e irregular) no alimentador e instalações. A análise visual é por temperatura de cor, sendo: "vermelho" - consumo a menor e; "azul" - consumo a maior em comparação com o período anterior. Na primeira das imagens são apresentadas as instalaçõesteste lançadas no modelo.

Analisando visualmente a Figura 6-2, observa-se que o consumo de energia elétrica é constantemente menor a cada período para a instalação-teste $\mathrm{n}^{\circ} 801$, considerando sua representação nos mapas: (i) período de 0 a 1: intensidade negativa crítica (cor vermelha); (ii) período de 1 a 2: intensidade média-crítica negativa (rosa escuro); (iii) período de 2 a 3: intensidade média negativa (magenta) e; (iv) intensidade média negativa (magenta).

Outro ponto a se destacar é a concentração de instalações, próximas à instalação-teste $\mathrm{n}^{\circ}$ 801, com características de consumo de energia menor ao período anterior, o que pode indicar, à princípio, necessidade de atuação mais drástica para identificação de PNT por parte da empresa responsável pelo sistema elétrico.

Avaliações visuais similares à supracitada podem ser realizadas para qualquer outra instalação ou trecho do alimentador. 
Além da evolução de consumo histórico em uma janela de 12 meses, é apresentada pela Figura 6-3, simbolicamente, - visto que a análise grosseira de evolução do consumo e, consequentemente das perdas elétricas, não consideram um período instantâneo, e sim o histórico - a evolução da queda de tensão em função do trecho do alimentador.

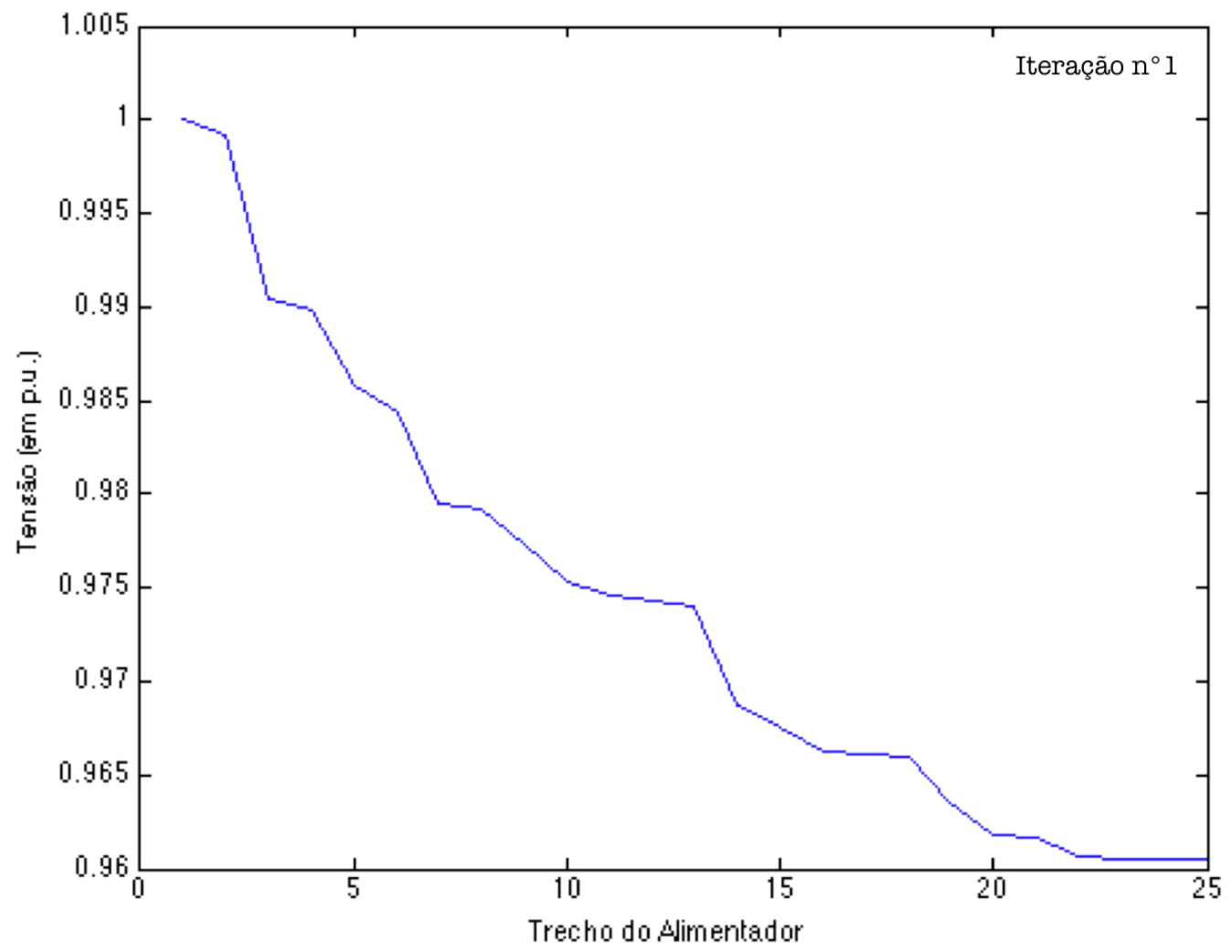



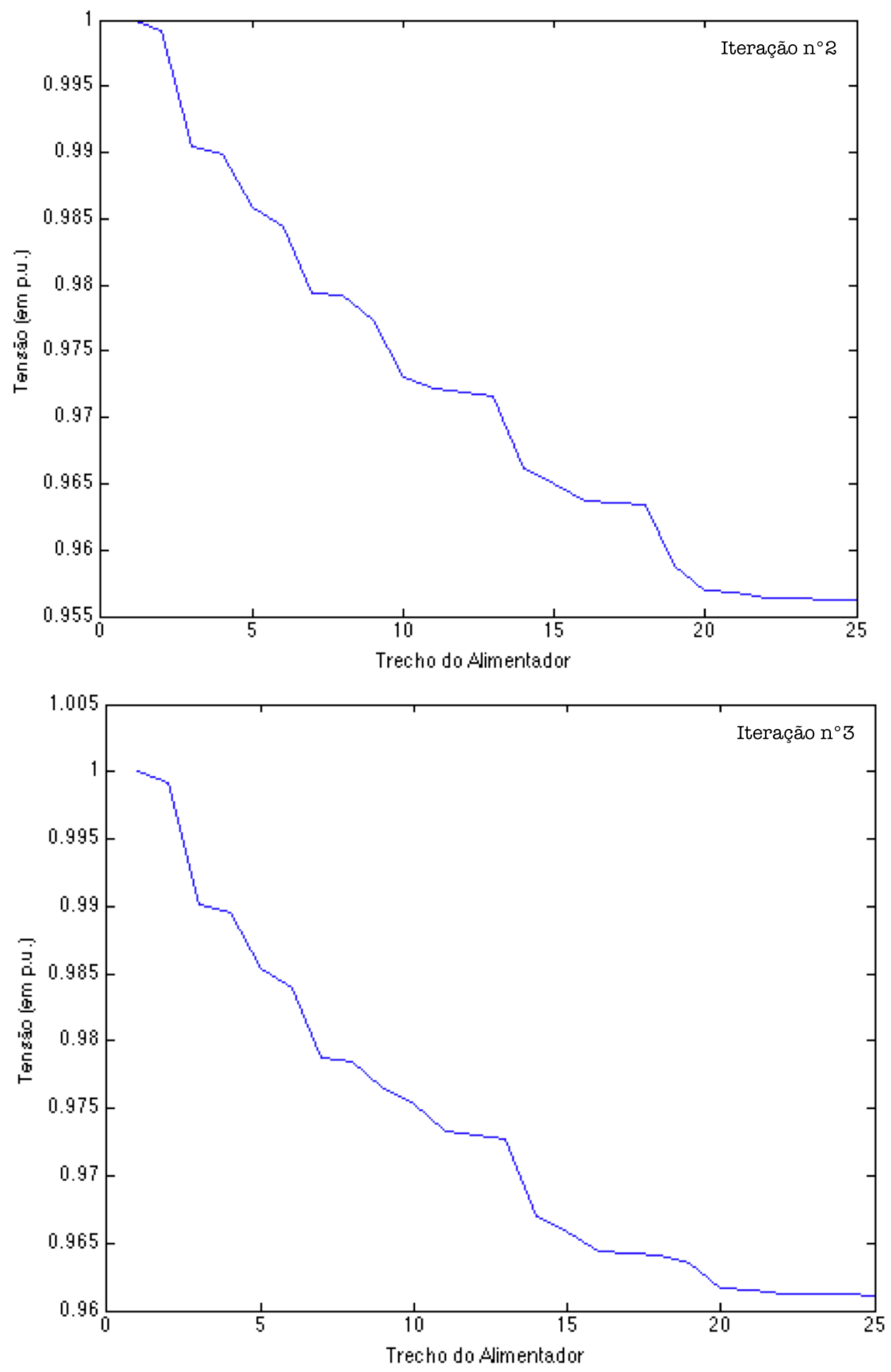

82 | P á g i n a 


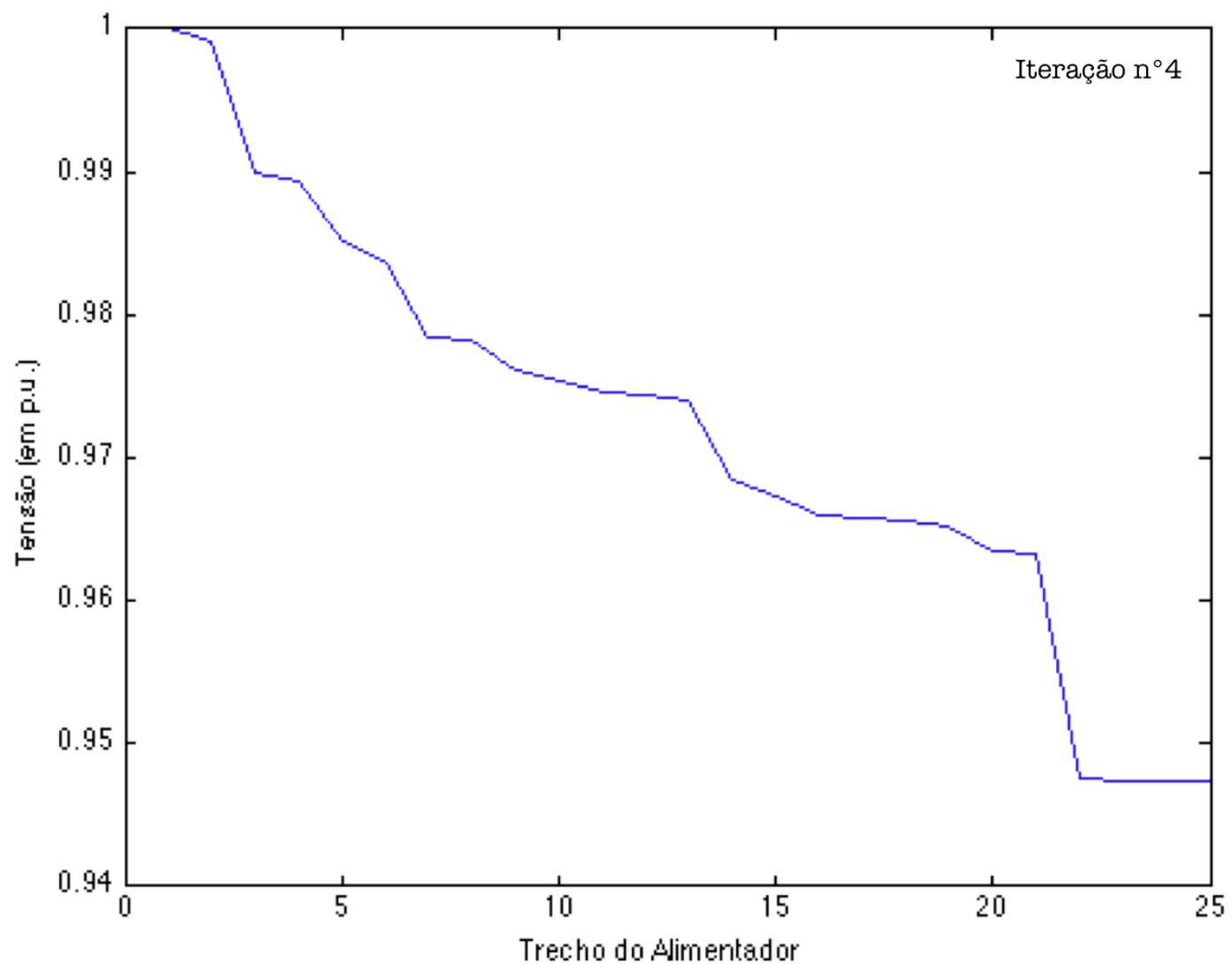

Figura 6-3 - Análise do Fluxo de Potência, especialmente em relação à queda de tensão (em p.u.) para cada trecho do alimentador, para cada uma das iterações.

Insta destacar que, pela última análise de Fluxo de Potência disposta pela Figura 6-3, o trecho $\mathrm{n}^{\circ} 21$ do alimentador apresentou queda de tensão expressiva se comparado aos demais trechos e esta pode estar relacionada ao aumento do número de instalações vinculada ao trecho com indícios de consumo irregular de energia elétrica (análise cruzada com a Figura 6-2), sugerindo ser interessante a averiguação em campo sobre a real situação do local. É possível observar também que, em todas as iterações, o trecho $\mathrm{n}^{\circ} 14$ do alimentador apresentou de queda de tensão significativa, porém, neste caso, pode indicar apenas que há maior consumo de energia visto o número de instalações vinculado àquele local.

Com a disponibilização das imagens que representam cada período histórico, adquirido a cada iteração, verificou-se a localização dos maiores focos de perdas, os quais são podem ser visualizados na Figura 6-4 pela informação de maior intensidade luminosa. 
Avaliando a Figura 6-4, a etapa "Fusão das séries" representa a diagonal principal da matriz de combinações, contendo assim a maior informação das séries analisadas.

Observando a Figura 6-4 por sua intensidade luminosa (quanto mais escura, maior foi a involução de consumo de energia elétrica), percebe-se também que, no caso estudado, os maiores focos de consumo irregular estão concentrados próximos ao centro do alimentador e na extremidade do mesmo, localizada no canto inferior esquerdo da figura.

Seguindo para a próxima etapa da metodologia, que trata do refinamento dos melhores alvos em termos de regularização do consumo de energia elétrica não-faturada, observase que os três pontos de teste lançados no sistema apresentaram qualificações intermediárias e críticas no modelo, sendo qualificados nas $163^{\mathrm{a}}, 267^{\mathrm{a}}$ e $75^{\mathrm{a}}$ posições, respectivamente, dentre as 905 instalações disponíveis para estudo, ou seja, dentre o patamar de $18 \%$ do total de instalações. 


\section{Séries Históricas}
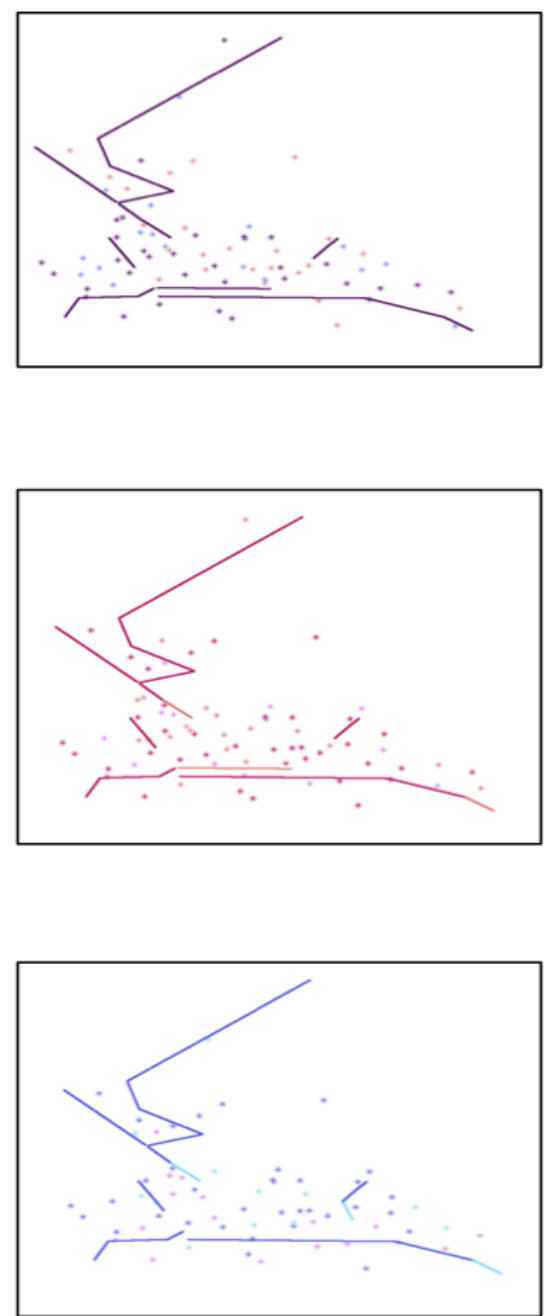

Figura 6-4 - Análise wavelet das imagens/séries históricas de cada período.
Transformadas Wavelet

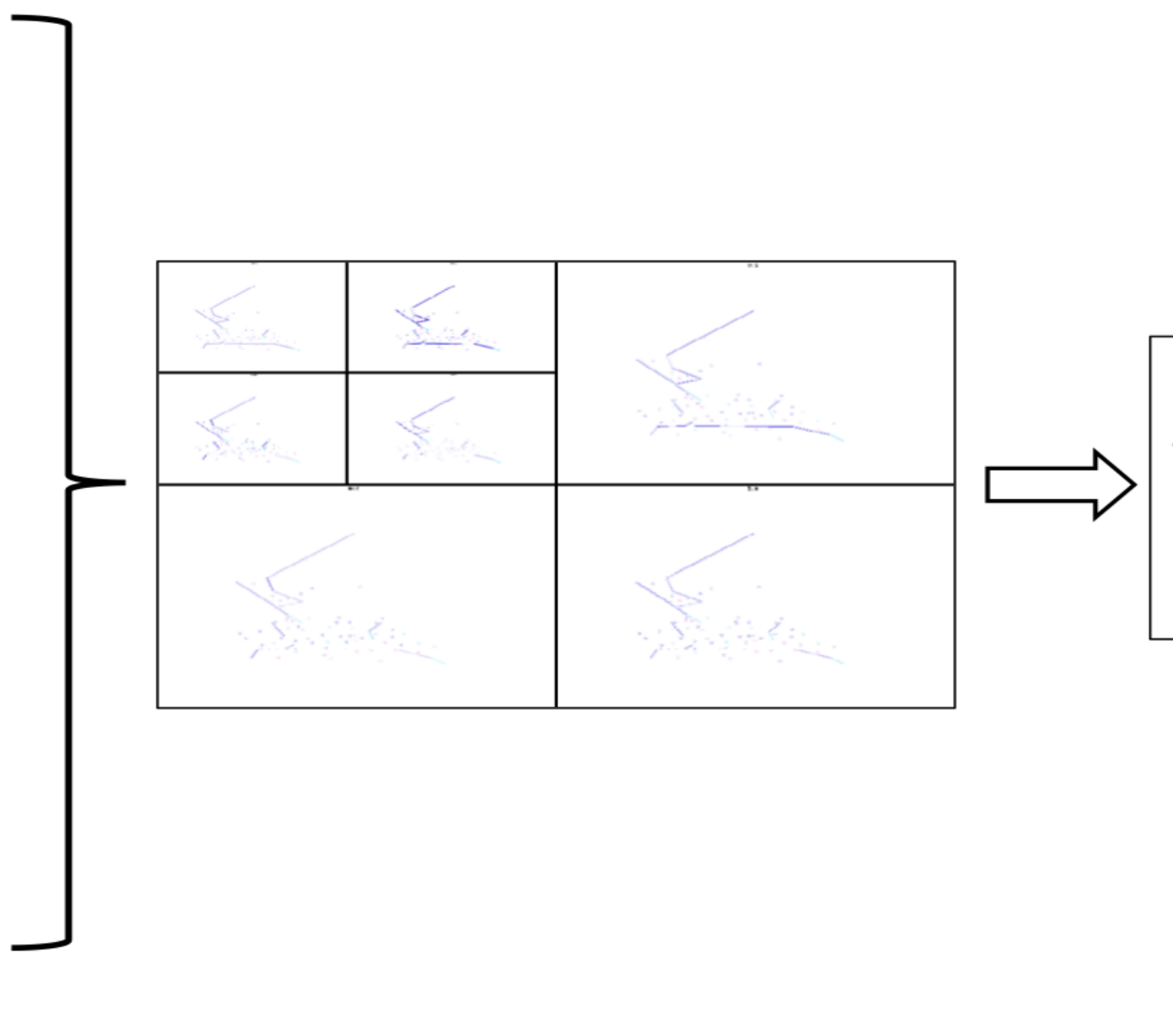

Fusão das séries

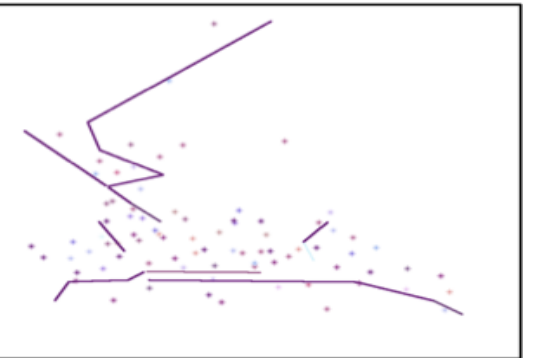


Selecionando a instalação com maior índice de criticidade dentre os três pontos lançados para análise de comparação, verifica-se que a variação de consumo histórico do ponto com relação aos seus vizinhos lógicos mais próximos, seu consumo nominal esperado e a média verificada para a classe de consumo esperado - neste caso, classe "Residencial" - é considerável, o que, somado ao fato de dispor a instalação em questão dentre os principais comprometedores em termos de consumo irregular, comprova a eficiência de identificação da metodologia proposta.

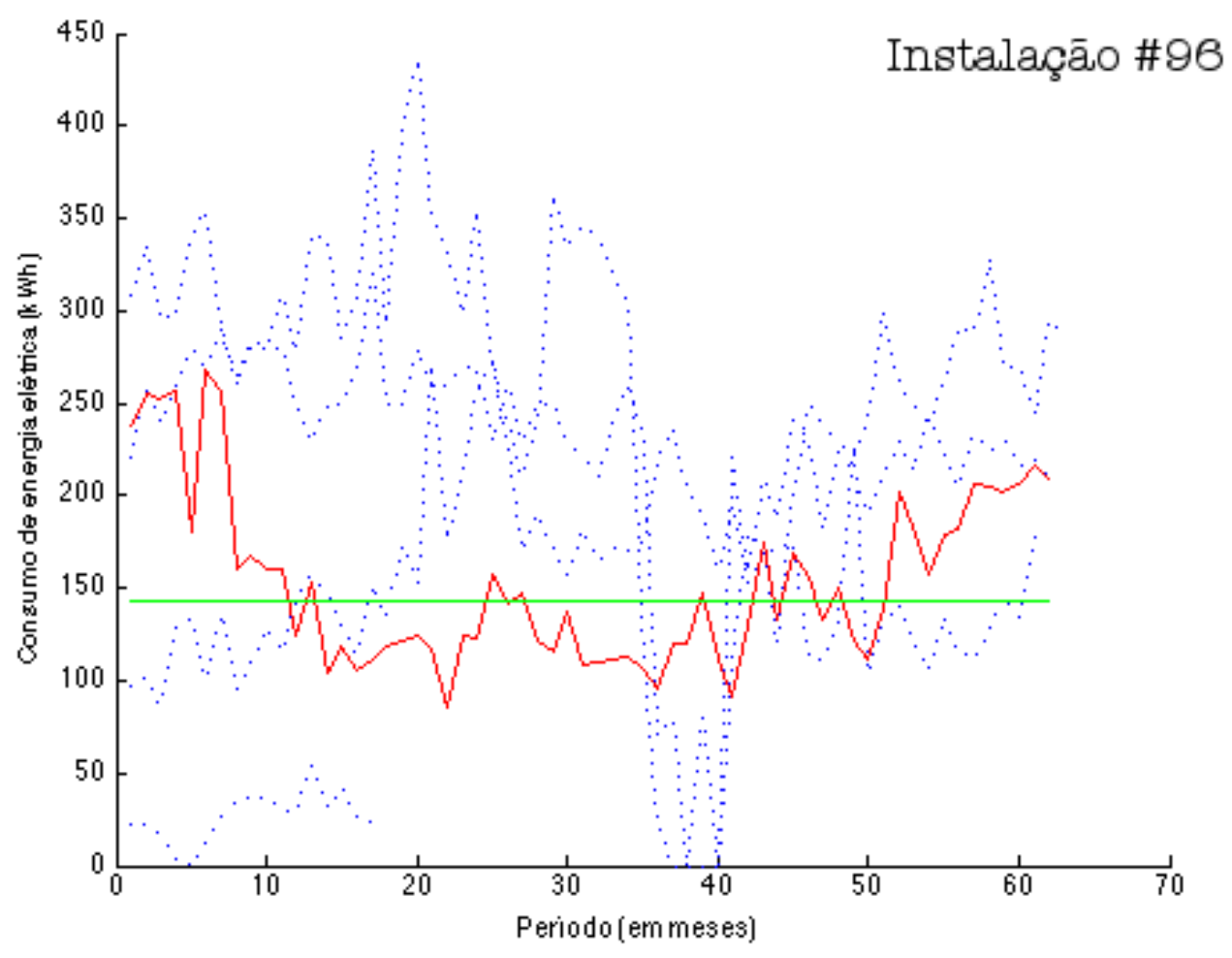



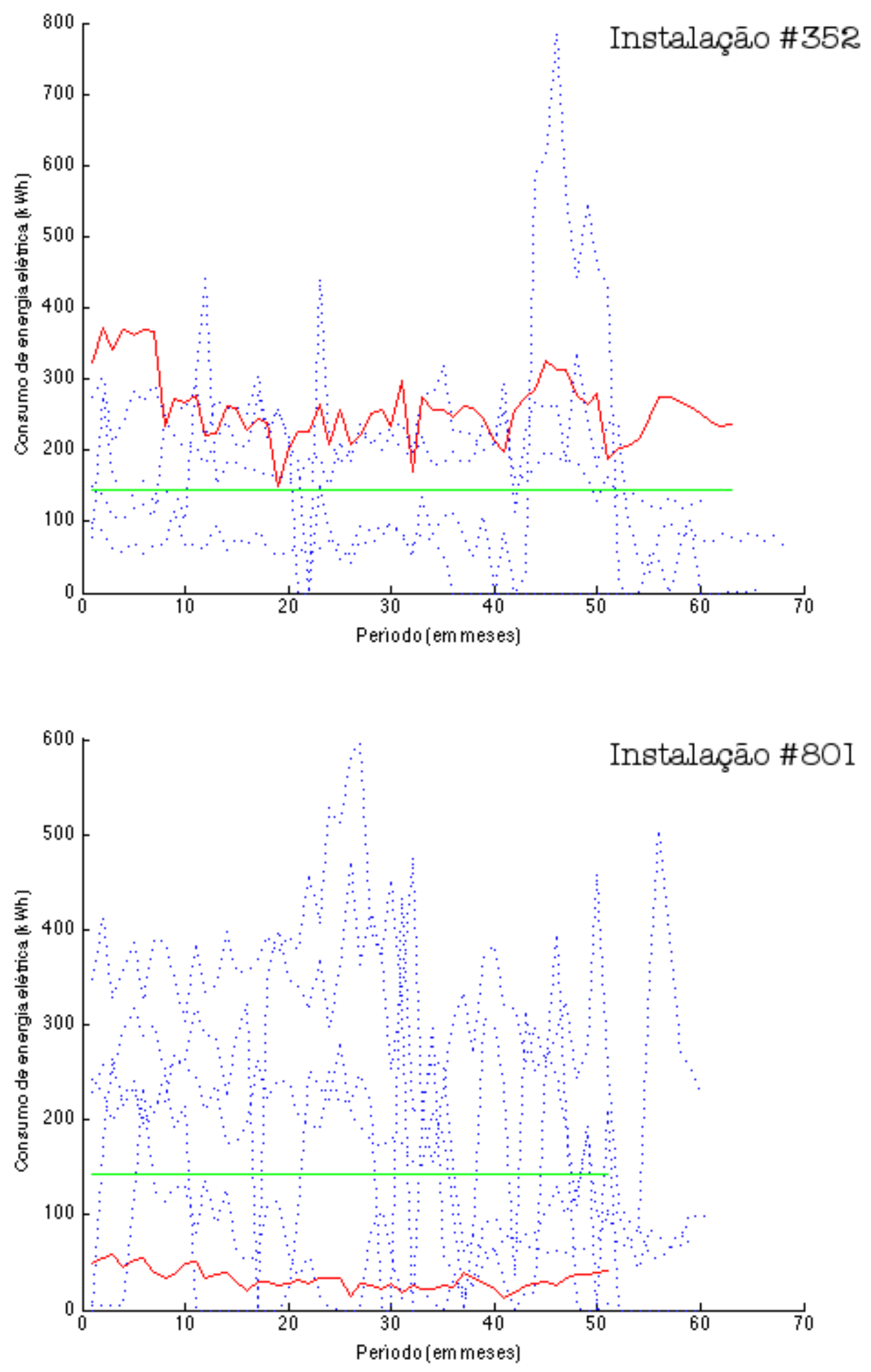

Figura 6-5 - Representação gráfica de consumo de energia elétrica dos pontos estudados. As linhas tracejadas representam o consumo dos 5 vizinhos lógicos mais próximos ao ponto estudado. A linha horizontal representa a média de consumo esperada na classe de consumo no qual a instalação se enquadra. 
Pela Figura 6-5 observa-se que a instalação-teste $n^{\circ} 801$ realmente apresenta consumo de energia elétrica consideravelmente menor que a média de consumo de sua classe e também menor que o de seus vizinhos lógicos mais próximos, justificando sua qualificação como a $75^{a}$ mais crítica em termos de índico de PNT. De maneira análoga, percebe-se que a instalação-teste $\mathrm{n}^{\circ}$ 352, qualificada em patamar intermediário, apresentou consumo de energia superior, em comparação, aos seus vizinhos e à media de sua classe a maior parte do período de 60 meses, apesar de verificada queda brusca de consumo entre o $9^{\circ}$ e $10^{\circ}$ mês.

\subsubsection{Segunda avaliação}

Para a segunda avaliação do modelo, foram distribuídos, de forma aleatória, cinco pontos de consumo no sistema que apresentam os perfis 2, 3, 4 e 5 dos cinco perfis de consumo típicos de instalações com consumo irregular disponíveis, conforme apresentado pela Tabela 6-2.

\begin{tabular}{|c|c|c|}
\hline Codificação da Instalação & \#Curva Típica de Consumo Irregular & $\begin{array}{c}\text { \% Períodos com consumo } \\
\text { menor que o nominal }\end{array}$ \\
\hline 659 & 4 & $65 \%$ \\
\hline 223 & 5 & $77 \%$ \\
\hline 655 & 4 & $31 \%$ \\
\hline 198 & 2 & $15 \%$ \\
\hline 298 & 3 & $58 \%$ \\
\hline
\end{tabular}

Tabela 6-2 - Informações das cinco instalações lançadas ao modelo para identificação das mesmas dentre os 905 alvos, bem como suas respectivas curvas típicas, selecionadas de forma aleatória.

Seguindo os mesmos passos apresentados na metodologia, neste caso, os pontos de teste lançados no sistema também apresentaram qualificações intermediárias e criticas no modelo, sendo qualificados nas $406^{\mathrm{a}}, 113^{\mathrm{a}}, 402^{\mathrm{a}}, 89^{\mathrm{a}}$ e $159^{\mathrm{a}}$ posições, respectivamente, dentre todo o mercado disponível para estudo, ou seja, em média dentre o patamar de $25 \%$ do mercado. 

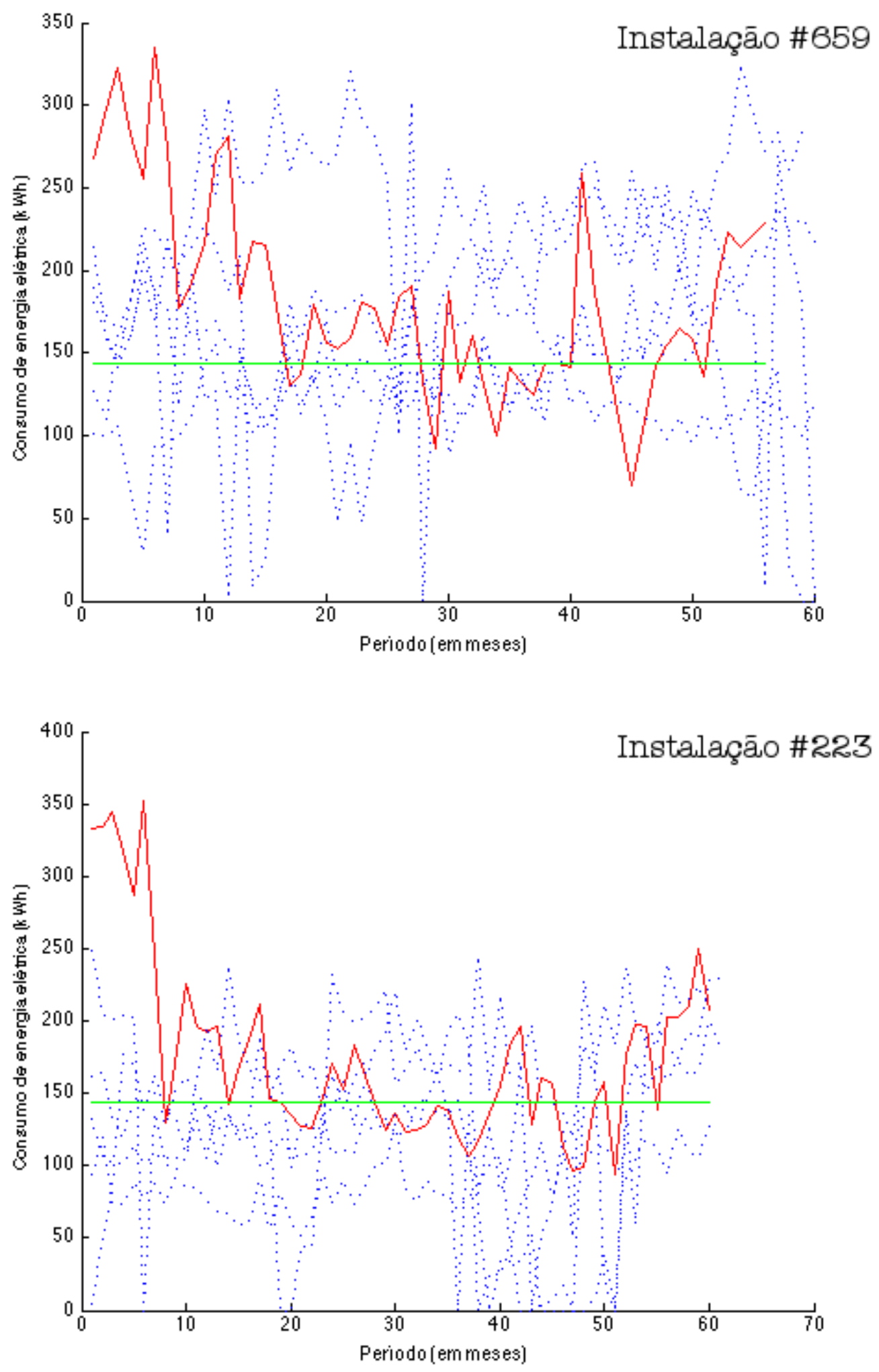

89 | P á g i n a 

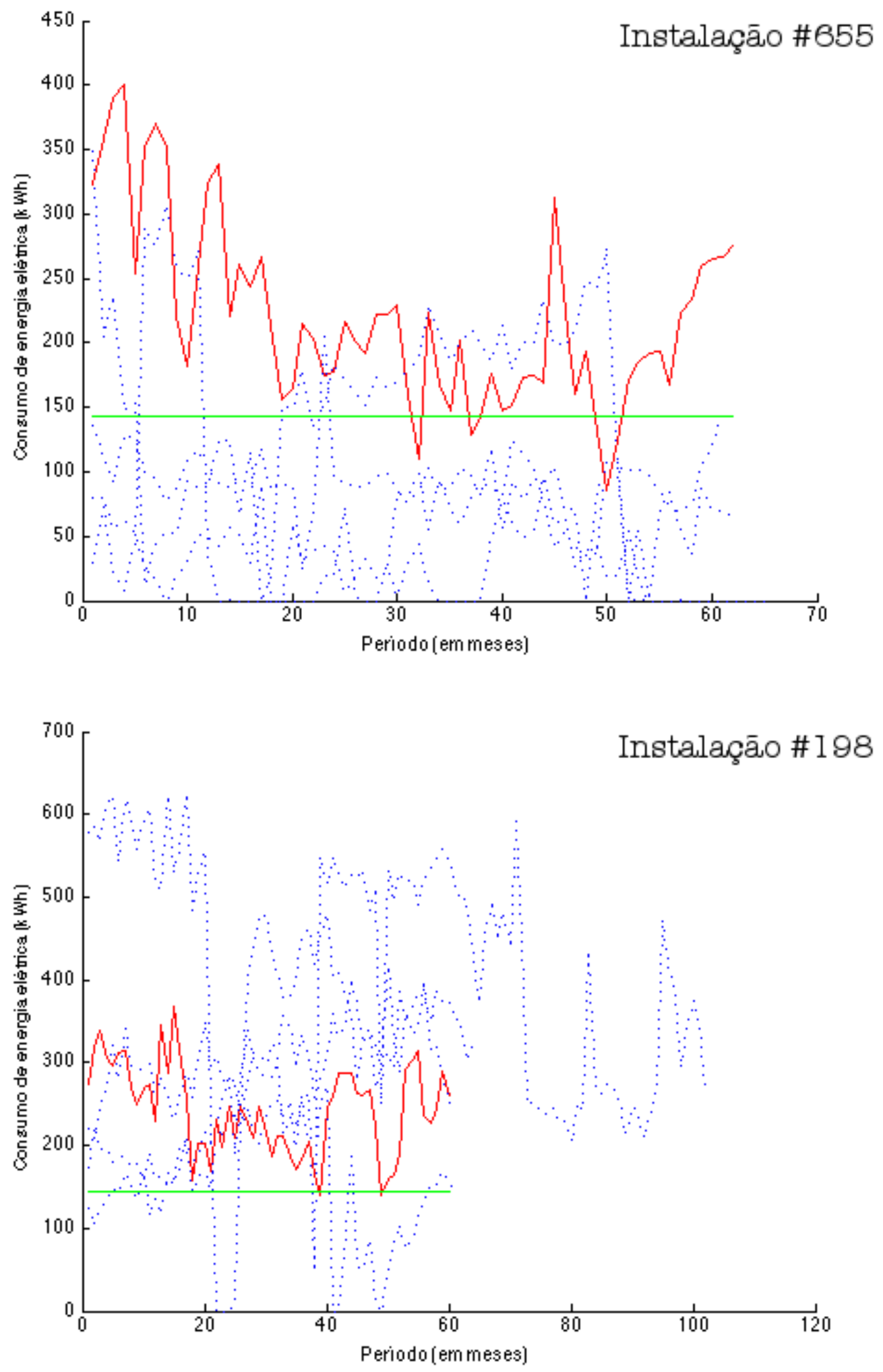


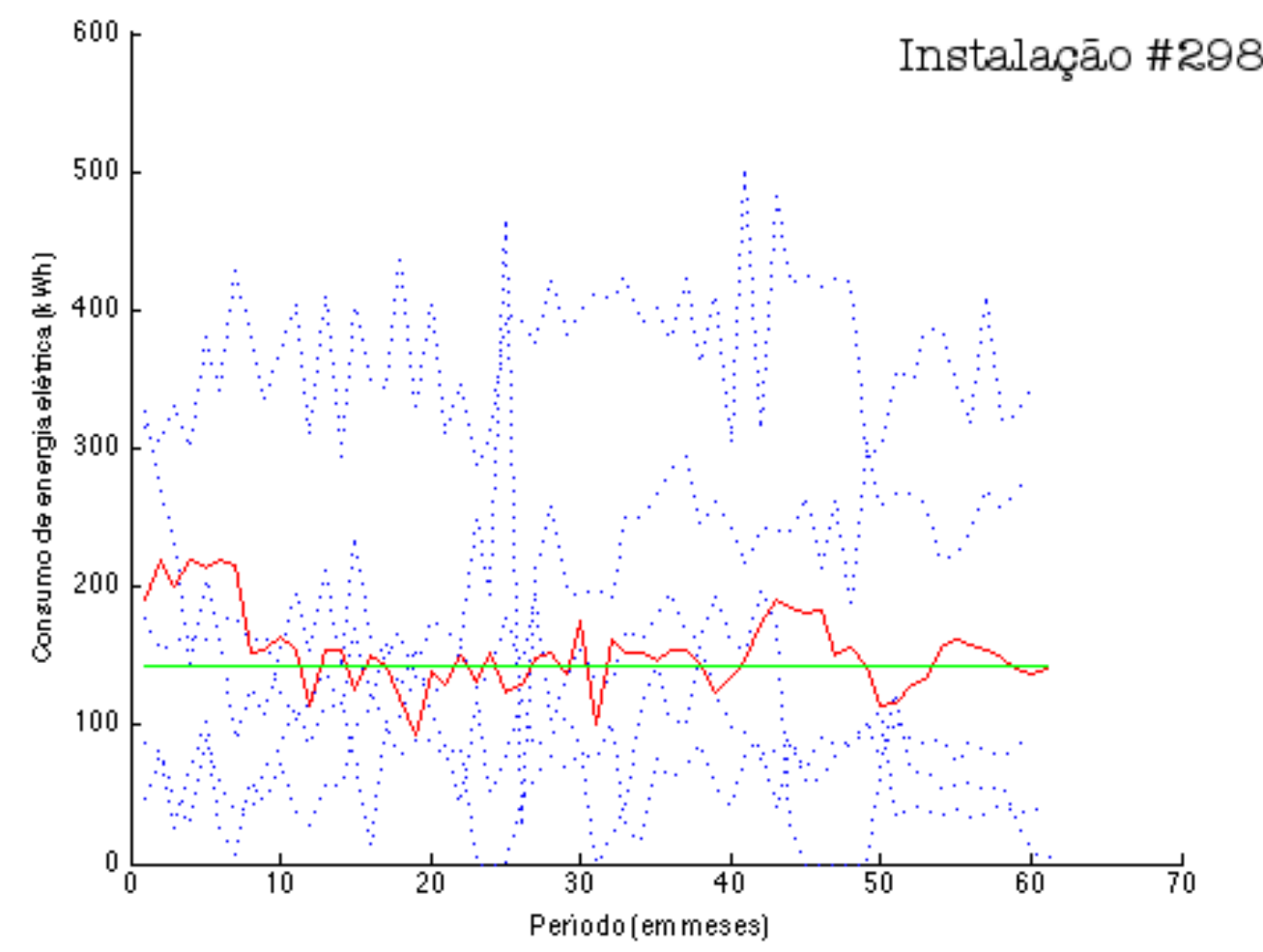

Figura 6-6 - Representação gráfica de consumo de energia elétrica dos pontos estudados, destacados pela linha vermelha de cada gráfico. A ordenação dos pontos de consumo é crescente e segue a seguinte: da parte superior para a inferior, da esquerda para a direita.

Pela Figura 6-6 percebe-se que a instalação-teste $n^{\circ} 198$, qualificada como a $89^{\mathrm{a}}$ mais crítica em termos de índico de PNT, apresenta consumo de energia elétrica consideravelmente menor que a média de consumo de seus vizinhos lógicos mais próximos, apesar de ser maior que a média de sua classe em todo o período. O fato pode indicar que a vizinhança onde a instalação se encontra seja de maior poder aquisitivo.

Fato interessante foi observado pelo histórico de consumo da a instalação-teste $n^{\circ} 655$. A instalação apresentou consumo superior ao de seus vizinhos lógicos e a média da classe por maior parte do período observado, porém seu perfil de consumo com demasiada quantidade de variações, a maioria destas indicando menor consumo (o maior delta/variação de consumo verificado foi de cerca de $300 \mathrm{kWh}$ ), a credenciou como bem-qualificada no modelo, sendo a como a $113^{\mathrm{a}}$ mais crítica.

O resultado demonstra que mesmo identificando os cinco pontos de teste dentre os alvos prioritários, há instalações com perfil crítico de consumo irregular ainda maior do que 
as curvas de consumo irregular típicas, levantadas no item 5.11, sendo um destes pontos representado pela Figura 6-7.

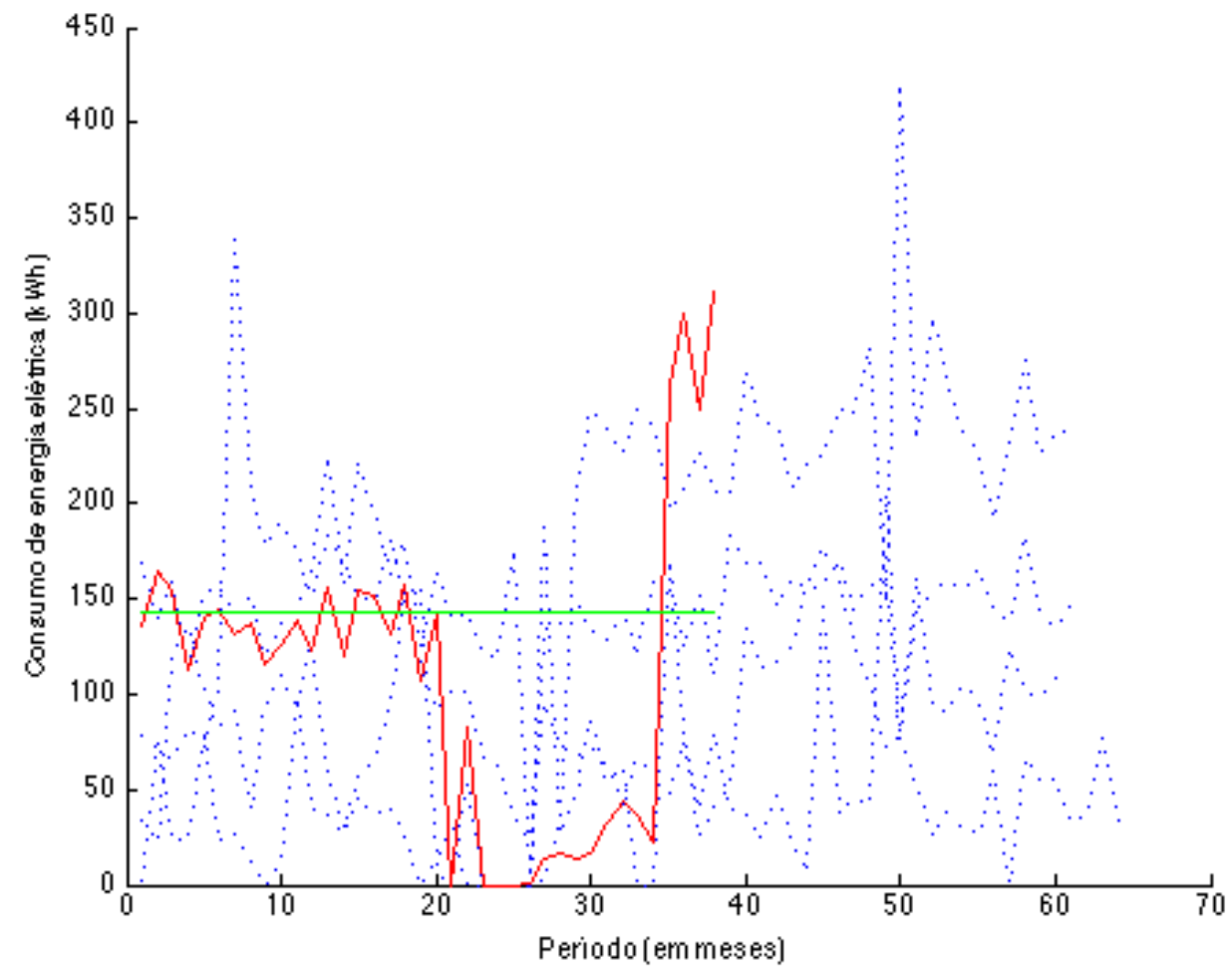

Figura 6-7 - Instalação com desempenho de consumo crítico identificado pelo modelo. Pela análise do gráfico, percebe-se que houve queda significativa de consumo por 15 períodos (cerca de $41 \%$ do total), entre os períodos 19 e 34 - recuperada no período 35. 


\section{Capítulo 7 - Conclusões e Recomendações}

Neste último capítulo do trabalho, apresentamos a conclusão da dissertação e a síntese da pesquisa suportada. Nesta seção, são destacados os avanços com relação aos objetivos planejados e iniciais do projeto no que tange a matéria: identificação de pontos com consumo irregular - bem como desafios enfrentados para sua realização. Finalmente, a última seção indica trabalhos que podem ser promovidos a partir deste.

\subsection{Conclusões}

Alinhado ao conjunto de técnicas já desenvolvidas, o presente trabalho pretendeu contribuir para estudos futuros sobre o problema de perdas não-técnicas que tem sido cada vez mais frequente em sistemas de distribuição de energia elétrica, o qual afeta negativamente a qualidade dos serviços prestados. Dessa forma, qualquer manifestação, contribuição ou crítica para melhoria dos resultados e metodologia são primordiais para o crescimento do trabalho.

A utilização de ferramentas robustas, como técnicas de classificação não-paramétricas $\mathrm{kNN}$, clusterização e transformadas wavelet para a solução do problema, mostrou-se eficiente e suficientemente aplicável, o que pode despertar interesses por esta área de estudo.

Independentemente do modelo de determinação e identificação de perdas não-técnicas em sistemas de distribuição de energia elétrica, a utilização de ferramentas que disponham de resultados que auxiliem as decisões dos gestores do sistema ou estejam próximos da realidade, configuram-se como importantes vetores na busca e construção de métodos cada vez mais eficazes para resolução do problema.

Verificou-se também a possibilidade de permitir compactação das informações de consumo de energia, através das imagens geradas (e descarte ou inutilização dos dados numéricos), e armazenamento de histórico de consumo e sua evolução. 
Considerando a forma de construção da metodologia, que valem-se os dados de histórico de consumo como essenciais, observa-se que possa haver sinergia entre a aplicação da mesma para gestão estratégica de outros ambientes/segmentos, como concessionárias de água/esgoto, gás distribuído ou, até mesmo - com os devidos ajustes - o setor de televisão por assinatura.

Os resultados apresentados na aplicação da metodologia, além de sinalizarem para a tendência de aprimoramento constante da ferramenta, são meramente ilustrativos e indicam a importância de validação da expectativa de recuperação do consumo irregular em campo.

\subsection{Recomendações para Trabalhos Futuros}

Entende-se que em toda teoria ou metodologia há pontos de melhoria, de modo que a pesquisa nesta área, a Proteção da Receita, deve ser continuamente melhorada, especialmente no que tange aos sistemas de detecção de fraude e consumo irregular, pelo seu dinamismo e evolução das formas e peripécias daqueles mais propensos a realização deste tipo de artificio.

Sugere-se, para trabalhos futuros, a aplicação de métodos mais complexos, como o de "Varredura" - algoritmo backward-forward sweep - para a etapa "Execução de análise de fluxo de potência". A utilização de métodos com esta característica pode ofertar à metodologia avanços no tempo de execução da rotina, que foi de aproximadamente 5 minutos para as 905 instalações, permitindo o suporte a um volume maior de informações.

Para a formação dos grupos de perfis típicos de consumo irregular, sugere-se também um estudo com maior número de amostras e a aplicação de técnicas de classificação de padrões, como a análise de componentes principais (ou Principal Component Analysis PCA).

Destaca-se também a posterior avaliação da metodologia em sistemas com maior e menor densidade populacional, bem como em áreas com diversidade social, de modo a 
garantir a confiabilidade da metodologia de identificação de clusterização de perdas não-técnicas. 


\section{Bibliografia e Referências}

1. VIEIRAlveS, E. D. X. Proposta de uma Metodologia para Avaliação das Perdas Comercias dos Sistemas Elétricos. O Caso Manaus. Campinas: Universidade Estadual de Campinas, 2005.

2. AlAM, M. S.; RAHMAN, M. M.; CHOWDHURY, M. A. K. Power Sector Reform in Bangladesh: Eletricity Distribuition System. [S.1.]: Energy, v. 29, 2004. 1773-1783 p.

3. BANK, T. W. The World Bank - Working for a World Free of Poverty. Electric power transmission and distribution losses (kWh), 2013. Disponivel em: <http://data.worldbank.org/indicator/EG.ELC.LOSS.KH/>. Acesso em: 01 Março 2013.

4. CASA CIVIL, S. P. A. J. Lei n 7.783, de 28 de Junho de 1989. Presidência da $\begin{array}{lllll}\text { República } & \text { Federativa } & \text { do } & \text { Brasil. } & \text { [S.1.]. }\end{array}$ http://www.planalto.gov.br/ccivil_03/leis/L7783.htm.

5. CASA CIVIL, S. P. A. J. Decreto-Lei n 2.848, de 7 de Dezembro de 1940. Presidência da República Federativa do Brasil. [S.l.]. 1940. http://www.planalto.gov.br/ccivil_03/decreto-lei/Del2848compilado.htm.

6. ANEEL, A. N. D. E. E. Resolução Normativa n 166, de 10 de Outubro de 2005. [S.1.]. 2005.

7. DAVIDSON, I. E. Evaluation and Effective Management of Non-Technical Losses in Electrical Power Networks. IEEE Africon. South Africa. 2002.

8. SURIYAMONGKOL, D. Non-Technical Losses in Electrical Power Systems. Ohio: Ohio University, 2002.

9. POVEDA, M. A New Method to Calculate Power Distribution Losses in an Environment of High Unregistered Loads. New Orleans: IEEE Transmission and Distribution Conference, 1999.

10 DORTOLINA, C. A.; NADIRA, R. The Loss that is Unknown is No Loss at All: . A Top-Down/Bottom-Up Approach for Estimating Distribution Losses. [S.1.]: IEEE Transactions on Power Systems, v. 20, 2005. 1119-1125 p. 
11 SMITH, T. B. Electricity Theft: A Comparative Analysis. Energy Policy. [S.1.], p. .2067-2076. 2004.

12 NIZAR, A. H. et al. Load Profiling Non-Technical Loss Activities in a Power . Utility. 1st International Power and Energy Conference (PECON). Putrajaya. 2006.

13 ANEEL, A. N. D. E. E. Nota Técnica n 298/2011 - Metodologia de tratamento regulatório para Perdas Não-Técnicas de energia elétrica. [S.1.]. 2011. http://www.aneel.gov.br/cedoc/nren2011457_5.pdf.

14 ANEEL, A. N. D. E. E. Resolução Normativa n 414, de 9 de Setembro de 2010. . [S.1.]. 2010. http://www.aneel.gov.br/cedoc/ren2010414comp.pdf.

15 DAVIDSON, I. E.; ODUBIYI, A. Technical loss computation and economic dispatch model for T\&D systems in deregulated ESI. [S.1.]. 2002.

16 CASA CIVIL, S. P. A. J. Lei no 8.987, de 13 de Fevereiro de 1995. [S.l.]. 1995. . http://www.planalto.gov.br/ccivil_03/leis/L8987compilada.htm.

17 FERREIRA, H. M. Uso de Ferramentas de Aprendizado de Máquina para . Prospecção de Perdas Comerciais em Distribuição de Energia Elétrica. Campinas: Universidade Estadual de Campinas, 2008.

18 QUEIROZ, L. M. O. D. Estimação e Análise das Perdas Técnicas na . Distribuição de Energia Elétrica. Campinas: Unicamp, 2010.

19 ORTEGA, G. V. C. Redes Neurais na Identificação de Perdas Comerciais do . Setor Elétrico. Rio de Janeiro: [s.n.], 2008.

20 PENIN, C. A. D. S. Combate, Prevenção e Otimização das Perdas Comerciais de . Energia Elétrica. São Paulo: [s.n.], 2008.

21 NAGI, J. An Intelligent System for Detection of Non-Technical Losses in . Tenaga Nasional Berhard (TNB) Malaysia Low Voltage Distribuiton Network. Kuala Lumpur: [s.n.], 2009.

22 GERBEC, D. et al. Allocation of the Load Profiles to Consumers Using . Probabilistic Neural Networks. Ljubljana: [s.n.], 2005.

23 FIGUEIREDO, V. et al. An Electric Energy Consumer Characterization . Framework Based on Data Mining Techniques. Portp: [s.n.], 2005.

24 FOURIE, J. W. A Strategy for the Management of Energy Losses in a Local . Electricity Distribuition Network. Pretoria: [s.n.], 2004. 
25 HUANG, S.-C.; LO, Y.- L.; LU, C.-N. Non-Technical Loss Detection Using Estimation and Analysis of Variance. Taipei: [s.n.], 2013.

26 DUDA, R. O.; HART, P. E.; STORK, D. G. Pattern Classification. 2nd Edition. . ed. San Jose: [s.n.], 2006.

27 AURENHAMMER, F. Voronei Diagrams - A Survey of Fundamental . Geometrica Data Structure. Institute für Informationsverarbeitung Technische Universität Graz. Austria. 1991.

28 VAPNIK, V. N. The Nature of Statistical Learning Theory. 2nd Edition. ed. New . Jersey: Springer-Verlag, 1999.

29 GONZALEZ, R. C.; WOODS, R. E. Digital Image Processing. 2nd Edition. ed. . New Jersey: Prentice-Hall, 2002.

30 KOVAčEVIć, J.; GOYAL, V. K.; VETTERLI, M. Fourier and Wavelet Signal . Processing. Lausanne: [s.n.], 2013.

31 ACHARYA, T.; RAY, A. K. Image Processing: Principles and Applications. New . Jersey: Jonh Wiley \& Sons, 2005.

32 Mallat, G. S. A Theory for Multiresolution Signal Decomposition: The . Wavelet Representation. Paris. 1989.

33 LEE, H. T.-H. Wavelet Analysis for Image Processing. Institute of . Communication Engineering. Taipei. 2007.

34 LIMA, P. C. D. Wavelets: Uma introdução. Belo Horizonte. 2003.

35 ABTN, A. B. D. N. T. NBR 5440 - Transformadores para redes aéreas de distribuição - Padronização. Associação Brasileira de Normas Técnicas. Rio de Janeiro. 1997.

36 ABNT, A. B. D. N. T. NBR 5380 - Transformador de Potência. Associação . Brasileira de Normas Técnicas. Rio de Janeio. 2011.

37 GOUDA, D. O. E.-S.; AMER, G. M.; SALEM, W. A. A. Predicting transformer . temperature rise and loss of life in the presence of harmonic load currents. Ain Shams Engineering Journal. Cairo. 2012.

38 ANEEL, A. N. D. E. E. Manual de Controle Patrimonial do Setor Elétrico. . Brasília. 2009. http://www.aneel.gov.br/cedoc/aren2009367_2.pdf. 
39 CPFL, C. P. F. E. L. Norma Técnica: Projeto - Iluminação Pública. Campinas. .2006.

40 CASA CIVIL, S. P. A. J. Constituição da República Federativa do Brasil de 1988. Presidência da República Federativa do Brasil. [S.1.]. 1988. http://www.planalto.gov.br/ccivil_03/constituicao/constituicao.htm.

41 IBGE, I. B. D. G. E. E. Domicílios particulares permanentes e moradores em domicílio particulares permanentes, por condição de ocupação do domicílio, segundo as características do entorno. Censo Brasil 2010. Brasília. 2010. ftp://ftp.ibge.gov.br/Censos/Censo_Demografico_2010/Entorno_dos_Domicilios/tab 1_1.pdf.

42 ELETROBRÁS. Iluminação Pública no Brasil. PROCEL - Programa Nacional de . Conservação de Energia Elétrica, 2008. Disponivel em: <http://www.eletrobras.com/elb/main.asp?TeamID=\%7BEB94AEA0-B206-43DE8FBE-6D70F3C44E57\%7D>. Acesso em: 22 Maio 2013.

43 MOntiCELli, A. J. Fluxo de Carga em Redes de Energia Elétrica. Campinas: . Edgard Blücher Ltda, 1983.

44 KAY, S. M. Intuitive Probability and Random Processes Using Matlab. New . York: University of Rhode Island, 2006.

45 CAMPOS FILHO, F. F. Algoritmos Numéricos. Belo Horizonte: Universidade . Federal de Minas Gerais, v. II, 2007.

46 ROCHA, F. A. D. As Irregularidades no Consumo de Energia Elétrica. [S.1.]: . [s.n.], 2011.

47 DIAS, H. B. P. Uma abordagem baseada em conhecimento para apoio ao . combate às Perdas Comerciais na distribuição de energia elétrica. Vitória: Universidade Federal do Espírito Santo, 2006.

48 MOREIRA, G. J. P. The Detection of Spatial Clusters: Graph and Dynamica . Programming based Methods. Universidade Federal de Minas Gerais. Belo Horizonte. 2011.

49 MILLARD, R.; EMMERTON, M. Non-technical losses - how do other countries . tackle the problem? [S.1.]. 2009.

50 NILSSON, J. W.; RIEDEL, S. A. Circuitos Elétricos. 8th Edition. ed. [S.1.]: 
. Pearson Prentice Hall, 2005.

51 GORDON, R. J. Macroeconomia. 7th Edition. ed. [S.1.]: Bookman, 2000.

52 JOULE, J. P. On the Effects of Magnetism upon the Dimensions of Iron and . Steel Bars. Manchester: The London, Edinburgh and Dublin Philosophical Magazine, 1847. 219-224 p.

53 DOEFFINGER, D. The Magic of Digital Printing. Toronto: Lark Books, 2006. 


\section{Apêndice A - Relação do consumo de energia elétrica das instalações que compuseram os perfis típicos de consumo irregular (em formato "Separado por vírgulas" - Comma- separated values - CSV)}

Esta seção disponibiliza os dados de consumo histórico das instalações que compuseram o estudo dos perfis típicos de consumo irregular de energia elétrica, relatado no item 5.11 deste trabalho, objetivando a qualquer pesquisador ou interessado reproduzi-lo, bem como contribuir para a definição de perfis mais aderentes à realidade.

Instalacao;2013/04;2013/03;2013/02;2013/01;2012/12;2012/11;2012/10;2012/09;2012/08;2012/07;2012/06;2012/05;2012/04;2012/03;2012/02;2 012/01;2011/12;2011/11;2011/10;2011/09;2011/08;2011/07;2011/06;2011/05;2011/04;2011/03;2011/02;2011/01;2010/12;2010/11;2010/10;201 0/09;2010/08;2010/07;2010/06;2010/05;2010/04;2010/03;2010/02;2010/01;2009/12;2009/11;2009/10;2009/09;2009/08;2009/07;2009/06;2009/0 $5 ; 2009 / 04 ; 2009 / 03 ; 2009 / 02 ; 2009 / 01 ; 2008 / 12 ; 2008 / 11 ; 2008 / 10 ; 2008 / 09 ; 2008 / 08 ; 2008 / 07 ; 2008 / 06 ; 2008 / 05 ; 2008 / 04 ; 2008 / 03 ; 2008 / 02 ; 2008 / 01 ; 2$ 007/12;2007/11;2007/10;2007/09;2007/08;2007/07;2007/06;2007/05;2007/04;2007/03;2007/02;2007/01;2006/12;2006/11;2006/10;2006/09;200 6/08;2006/07;2006/06;2006/05;2006/04;2006/03;2006/02;2006/01;2005/12;2005/11;2005/10;2005/09;2005/08;2005/07;2005/06;2005/05;2005/0 4;2005/03;2005/02;2005/01;2004/12;2004/11;2004/10;2004/09;2004/08;2004/07;2004/06;2004/05;2004/04;2004/03;2004/02;2004/01;2003/12;2 003/11;2003/10;2003/09;2003/08;2003/07;2003/06;2003/05;2003/04;2003/03

$1 ; 54 ; 57 ; 1 ; 22 ; 22 ; 23 ; 22 ; 71 ; 94 ; 73 ; 76 ; 89 ; 107 ; 93 ; 458 ; 12 ; 11 ; 98 ; 2 ; 0 ; 0 ; 2 ; 2 ; 13 ; 1 ; 1 ; 15 ; 0 ; 0 ; 0 ; 0 ; 0 ; 0 ; 0 ; 0 ; 0 ; 0 ; 0 ; 0 ; 0 ; 0 ; 0 ; 0 ; 0 ; 0 ; 0 ; 0 ; 0 ; 0 ; 0 ; 0 ; 1 ; 1 ; 0 ; 2 ; 3 ; 0 ; 4 ; 5 ; 0 ;$ $7 ; 9 ; 0 ; 14 ; 14 ; 4 ; 25 ; 14 ; 12 ; 30 ; 0 ; 8 ; 21 ; 2 ; 3 ; 0 ; 4 ; 7 ; 6 ; 1 ; 15 ; 20 ; 0 ; ;$,

$2 ; 194 ; 201 ; 178 ; 235 ; 188 ; 211 ; 227 ; 192 ; 229 ; 202 ; 208 ; 198 ; 172 ; 206 ; 148 ; 145 ; 65 ; 66 ; 81 ; 106 ; 103 ; 104 ; 89 ; 89 ; 107 ; 80 ; 43 ; 100 ; 124 ; 84 ; 93 ; 69 ; 78 ; 95 ; 65 ; 59 ; 7$ $6 ; 81 ; 71 ; 94 ; 80 ; 86 ; 86 ; 94 ; 123 ; 77 ; 61 ; 115 ; 44 ; 42 ; 65 ; 89 ; 71 ; 42 ; 89 ; 109 ; 100 ; 57 ; 90 ; 89 ; 69 ; 57 ; 39 ; 100 ; 85 ; 68 ; 78 ; 85 ; 103 ; 86 ; 69 ; 98 ; 53 ; 63 ; 78 ; 80 ; 98 ; 104 ; 99$; $118 ; 95 ; 124 ; 143 ; 118 ; 93 ; 82 ; 43 ; 67 ; 102 ; 68 ; 23 ; 65 ; 77 ; 84 ; 76 ; 30 ; 15 ; 21 ; 67 ; 67 ; 60 ; ; ; ; ; ; ; ; ; ; ; ; 135 ; 107 ; 116 ; 85 ; 88 ; 101 ; 88 ; 125$

$3 ; 134 ; 147 ; 137 ; 173 ; 178 ; 182 ; 145 ; 157 ; 139 ; 118 ; 122 ; 113 ; 117 ; 165 ; 146 ; 153 ; 139 ; 172 ; 128 ; 157 ; 85 ; 124 ; 160 ; 16 ; 0 ; 0 ; 0 ; 6 ; 45 ; 44 ; 46 ; 53 ; 67 ; 59 ; 63 ; 40 ; 42 ; 33 ;$ $35 ; 39 ; 32 ; 28 ; 3 ; 4 ; 67 ; 174 ; 167 ; 210 ; 188 ; 201 ; 185 ; 121 ; 183 ; 146 ; 130 ; 134 ; 148 ; 138 ; 180 ; 174 ; 120 ; 108 ; 121 ; 74 ; 41 ; 137 ; 129 ; 106 ; 77 ; 72 ; 60 ; 79 ; 71 ; 61 ; 72 ; 75$; $61 ; 56 ; 49 ; 85 ; 111 ; 130 ; 146 ; 135 ; 150 ; 149 ; 125 ; 130 ; 147 ; 142 ; 54 ; 12$ 
4;135;119;119;150;111;130;137;132;118;103;111;95;157;65;68;153;0;174;28;232;258;217;254;273;200;120;14;38;26;26;27;53;69;65;78;50;58; $55 ; 43 ; 49 ; 48 ; 110 ; 0 ; 42 ; 48 ; 45 ; 68 ; 60 ; 55 ; 59 ; 68 ; 67 ; 50 ; 134 ; 114 ; 122 ; 120 ; 30 ; 203 ; 112 ; ; ; 0 ; 105 ; 94 ; 95 ; ; ; 105 ; 65 ; 26 ; 18 ; 20 ; 44 ; 13 ; 10 ; ; 59 ; 114 ; 32 ; 6 ; 58 ; 0 ; ; 0 ;$ $100 ; 164 ; 131 ; 129 ; 0 ; 0 ; 0 ; 0 ; 0 ; 0 ; 0 ; 0 ; 0 ; 0 ; 0 ; 0 ; 0 ; 0 ; 0 ; 0 ; 0 ; 0 ; 0 ; 0 ; 0 ; 0 ; 0 ; ; 0 ; ; ; 0 ; ; ; 46$ $5 ; 209 ; 228 ; 219 ; 232 ; 234 ; 218 ; 211 ; 204 ; 223 ; 158 ; 235 ; 216 ; 220 ; 205 ; 57 ; 140 ; 34 ; 69 ; 200 ; 175 ; 180 ; 154 ; 180 ; 141 ; 112 ; 144 ; 101 ; 132 ; 138 ; 126 ; 113 ; 167 ; 147 ;$ $153 ; 131 ; 113 ; 120 ; 86 ; 80 ; 88 ; 67 ; 80 ; 77 ; 87 ; 67 ; 79 ; 71 ; 67 ; 114 ; 148 ; 123 ; 127 ; 147 ; 177 ; 149 ; 141 ; 148 ; 0 ; 120 ; 117 ; 107 ; 101 ; 127 ; 157 ; 119 ; 141 ; 133 ; 125 ; 148 ; 1$ $18 ; 127 ; 104 ; 99 ; 113 ; 91 ; 110 ; 105 ; 85 ; 113 ; 115 ; 112 ; 107 ; 133 ; 112 ; 85 ; 91 ; 73 ; 107 ; 105 ; 113 ; 113 ; 105 ; 98 ; 85 ; 117 ; 79 ; 85 ; 86 ; 82 ; 112 ; 101 ; 48 ; ; 11 ; 114 ; 113 ; 102$ $; 117 ; 75 ; 92 ; 79 ; 90 ; 101 ; 88 ; 80 ; 94 ; 123 ; 101 ; 96 ; 118 ; 90 ; 106$

$6 ; 132 ; 95 ; 82 ; 123 ; 87 ; 88 ; 92 ; 97 ; 95 ; 128 ; 78 ; 71 ; 77 ; 26 ; 24 ; 46 ; 58 ; 64 ; 134 ; 0 ; 40 ; 49 ; 41 ; 43 ; 59 ; 50 ; 27 ; 45 ; 23 ; 48 ; 49 ; 52 ; 45 ; 32 ; 131 ; 25 ; 32 ; 93 ; 28 ; 58 ; 54 ; 41 ; 64 ; 5$ $8 ; 26 ; 34 ; 53 ; 61 ; 55 ; 43 ; 59 ; 102 ; 49 ; 48 ; 3 ; 14 ; 27 ; 24 ; 24 ; 29 ; 27 ; 29 ; 21 ; 20 ; 20 ; 19 ; 15 ; 19 ; 40 ; 31 ; 20 ; 30 ; 17 ; 16 ; 21 ; 32 ; 16 ; 28 ; 119 ; 117 ; 111 ; 80 ; 72 ; 73 ; 64 ; 72 ; 50 ; 57$ $; 56 ; 58 ;$

7;205;185;214;200;166;192;190;180;246;184;207;220;267;188;186;207;191;100;187;86;72;36;140;141;141;149;135;104;177;152;267;106;90;9 $0 ; 138 ; 146 ; 145 ; 128 ; 157 ; 153 ; 181 ; 146 ; 133 ; 135 ; 171 ; 93 ; 142 ; 106 ; 159 ; 163 ; 127 ; 187 ; 148 ; 155 ; 143 ; 171 ; 152 ; 148 ; 155 ; 184 ; 111 ; 203 ; 129 ; 137 ; 106 ; 144 ; 16$ $3 ; 184 ; 201 ; 139 ; 187 ; 112 ; 120 ; 101 ; 115 ; 130 ; 100 ; 116 ; 124 ; 135 ; 189 ; 45 ; 137 ; 0 ; 0 ; 74 ; 67 ; 72 ; 85 ; 46 ; 87 ; 126 ; 76 ; 97 ; 78 ; 77 ; 73 ; 72 ; 72 ; 75 ; 68 ; 74 ; 84 ; 70 ; 63 ; 93 ; 9$ $5 ; 89 ; 97 ; 99 ; 110 ; 82 ; 1 ; ; ; 17 ; ; 63 ; 63 ; 66 ; 64$

8;123;126;102;120;138;97;149;128;100;107;119;105;110;238;139;121;134;119;119;129;122;98;129;90;130;385;0;0;117;118;118;134;123;116;1 $11 ; 109 ; 132 ; 111 ; 130 ; 154 ; 138 ; 72 ; 72 ; 35 ; 110 ; 71 ; 72 ; 64 ; 98 ; 155 ; 82 ; 65 ; 32 ; 82 ; 88 ; 16 ; 119 ; 108 ; 96 ; 94 ; 53 ; 62 ; 42 ; 115 ; 49 ; 91 ; 85 ; 30 ; 79 ; 63 ; 52 ; 71 ; 57 ; 65 ; 89$; $22 ; 14 ; 2 ; 42 ; 26 ; 32 ; 38 ; 0 ; 38 ; 36 ; 42 ; 37 ; 64 ; 47 ; 23 ; 15 ; 37 ; 41 ; 38 ; 139 ; 25 ; 98 ; 144 ; 88 ; 157 ; 129 ; 104 ; 88 ; 76 ; 87 ; 94 ; 84 ; 77 ; 63 ; 53 ; 47 ; 48 ; 38 ; 42 ; 40 ; 41 ; 56 ; 43 ; 42 ; 5$ $0 ; 43 ; 43$

$9 ; 161 ; 169 ; 163 ; 197 ; 184 ; 202 ; 186 ; 153 ; 173 ; 196 ; 172 ; 58 ; 97 ; 68 ; 60 ; 116 ; 113 ; 116 ; 80 ; 89 ; 92 ; 85 ; 89 ; 60 ; 80 ; 48 ; 73 ; 126 ; 86 ; 70 ; 74 ; 80 ; 106 ; 119 ; 134 ; 70 ; 58 ; 61 ;$ $55 ; 103 ; 42 ; 54 ; 69 ; 65 ; 70 ; 72 ; 58 ; 82 ; 55 ; 57 ; 61 ; 101 ; 75 ; 61 ; 64 ; 61 ; 66 ; 64 ; 81 ; 65 ; 52 ; 75 ; 59 ; 78 ; 55 ; 56 ; 61 ; 57 ; 67 ; 55 ; 53 ; 59 ; 38 ; 39 ; 42 ; 55 ; 50 ; 45 ; 44 ; 47 ; 53 ; 55 ; 63$ ;114;104;127;113;115;110;120;102;120;106;113;114;128;128;120;106;133;125;135;117;114;127;109;108;140;23;;;;;;;;;;;0;

$10 ; 118 ; 123 ; 112 ; 144 ; 113 ; 98 ; 101 ; 112 ; 163 ; 101 ; 137 ; 105 ; 106 ; 128 ; 104 ; 150 ; 162 ; 153 ; 165 ; 172 ; 162 ; 146 ; 61 ; 0 ; 0 ; 1 ; 0 ; 0 ; 0 ; 0 ; 0 ; 0 ; 0 ; 57 ; 4 ; 139 ; 0 ; 0 ; 150 ; 88 ; 0 ;$ $91 ; 21 ; 87 ; 43 ; 76 ; 37 ; 64 ; 75 ; 136 ; 38 ; 89 ; 73 ; 54 ; 47 ; 0 ; 87 ; 73 ; 101 ; 0 ; 80 ; 154 ; 62 ; 75 ; 96 ; 100 ; 68 ; 62 ; 66 ; 60 ; 79 ; 116 ; 106 ; 129 ; 119 ; 134 ; 105 ; 84 ; 56 ; 89 ; 47 ; 64 ; 66 ; 8$ 8;91;124;154;151;84;75;78;55;57;56;84;84;60;76;91;61;176;139;209;205;187;72;73;101;81;100;118;191;82;49;77;68;118;50;61;102;62;64 $11 ; 262 ; 244 ; 247 ; 288 ; 239 ; 260 ; 280 ; 240 ; 275 ; 227 ; 273 ; 212 ; 295 ; 288 ; 232 ; 252 ; 242 ; 249 ; 265 ; 277 ; 263 ; 258 ; 211 ; 292 ; 267 ; 311 ; 270 ; 287 ; 264 ; 263 ; 291 ; 259$; $291 ; 255 ; 288 ; 267 ; 249 ; 281 ; 250 ; 279 ; 211 ; 276 ; 242 ; 228 ; 257 ; 215 ; 210 ; 252 ; 219 ; 207 ; 197 ; 257 ; 186 ; 248 ; 211 ; 192 ; 233 ; 238 ; 206 ; 271 ; 195 ; 144 ; 172 ; 206 ; 14$ $3 ; 168 ; 160 ; 149 ; 163 ; 154 ; 145 ; 148 ; 128 ; 160 ; 133 ; 138 ; 125 ; 129 ; 127 ; 133 ; 149 ; 136 ; 156 ; 137 ; 128 ; 167 ; 135 ; 133 ; 125 ; 148 ; 134 ; 131 ; 116 ; 138 ; 136 ; 148 ; 180 ; 1$ $27 ; 133 ; 137 ; 126 ; 119 ; 121 ; 154 ; 118 ; 102 ; 150 ; 161 ; 180 ; 181 ; 162 ; 197 ; 159 ; 187 ; 167 ; 162 ; 187 ; 166 ; 164 ; 176 ; 166 ; 167$ 
$12 ; 166 ; 116 ; 128 ; 151 ; 119 ; 141 ; 137 ; 155 ; 148 ; 122 ; 93 ; 89 ; 103 ; 101 ; 92 ; 62 ; 90 ; 52 ; 103 ; 27 ; 122 ; 93 ; 79 ; 75 ; 83 ; 90 ; 74 ; 88 ; 99 ; 39 ; 9 ; 11 ; 107 ; 64 ; 122 ; 37 ; 57 ; 53 ; 77$ ;51;72;42;49;59;110;46;99;96;91;96;85;96;54;81;82;86;81;78;72;88;75;74;97;79;57;57;49;38;49;39;44;41;34;31;29;30;26;35;35;44;33;26;49;18; 65;87;66;96;71;97;89;106;115;89;81;68;54;39;41;57;75;80;74;71;80;81;103;40;68;80;72;80;27;68;100;136;155;157;153;117;92;

$13 ; 0 ; 0 ; 98 ; 237 ; 215 ; 240 ; 2 ; 0 ; 14 ; 133 ; 132 ; 95 ; 138 ; 156 ; 125 ; ; ; ; ; ; ; ; ; 328 ; 329 ; 295 ; 0 ; 599 ; 706 ; 687 ; 553 ; 498 ; 356 ; 12 ; 4 ; 12 ; 7 ; 15 ; 12 ; 0 ; 6 ; 14 ; 15 ; 19 ; 9 ; 18 ; 22 ; 23$ $; 11 ; 10 ; 9 ; 21 ; 24 ; 31 ; 42 ; 29 ; 31 ; 30 ; 16 ; 25 ; 25 ; 24 ; 26 ; 31 ; 40 ; 58 ; 47 ; 29 ; 42 ; 25 ; 27 ; 30 ; 24 ; 13 ; 16 ; 17 ; 30 ; 0 ; 4 ; 4 ; 0 ; 38 ; 51 ; 39 ; 38 ; 25 ; 32 ; 54 ; 25 ; 23 ; 16 ; 20 ; 15 ; 21 ; 33 ; 2$ $4 ; 91 ; 10 ; 1 ; 40 ; 182 ; 217 ; 127 ; 165 ; 174 ; 163 ; 131 ; 116 ; 111 ; 136 ; 220 ; 187 ; 213 ; 194 ; 158 ; 153 ; 151 ; 187 ; 234 ; 173 ; 193$

$14 ; 154 ; 156 ; 117 ; 149 ; 120 ; 147 ; 134 ; 123 ; 131 ; 131 ; 133 ; 155 ; 118 ; 132 ; 121 ; 141 ; 133 ; 80 ; 80 ; 90 ; 78 ; 64 ; 43 ; 110 ; 119 ; 96 ; 92 ; 111 ; 91 ; 105 ; 88 ; 82 ; 77 ; 69 ; 72 ; 70 ; 8$ $4 ; 75 ; 70 ; 66 ; 75 ; 130 ; 53 ; 43 ; 52 ; 64 ; 49 ; 64 ; 49 ; 59 ; 57 ; 92 ; 70 ; 97 ; 89 ; 73 ; 76 ; 78 ; 86 ; 90 ; 85 ; 70 ; 58 ; 79 ; 60 ; 57 ; 65 ; 64 ; 61 ; 72 ; 56 ; 69 ; 66 ; 106 ; 69 ; 82 ; 71 ; 69 ; 69 ; 68 ; 60$; $48 ; 63 ; 40 ; 23 ; 32 ; 87 ; 95 ; 82 ; 92 ; 79 ; 89 ; 85 ; 93 ; 83 ; 70 ; 83 ; 65 ; 85 ; 110 ; 69 ; 72 ; 66 ; 44 ; 82 ; 75 ; 88 ; 84 ; 78 ; 80 ; 67 ; 72 ; 47 ; 59 ; 70 ; 69 ; 90 ; 72 ; 84 ; 94 ; 70 ; 75$

$15 ; 51 ; 44 ; 40 ; 19 ; 26 ; 24 ; 22 ; 44 ; 84 ; 77 ; 86 ; 87 ; 96 ; 20 ; 56 ; 110 ; 100 ; 110 ; 133 ; 115 ; 146 ; 105 ; 116 ; 125 ; 133 ; 133 ; 105 ; 133 ; 114 ; 108 ; 84 ; 46 ; 41 ; 31 ; 31 ; 32 ; 34 ; 37 ; 41$ ;38;33;34;38;39;29;35;32;36;34;37;20;36;29;33;28;24;31;27;29;31;39;66;69;83;59;71;77;59;62;55;58;63;70;68;51;65;48;42;37;37;46;37;42;45;4 $6 ; 57 ; 42 ; 53 ; 41 ; 44 ; 43 ; 42 ; 32 ; 13 ; 55 ; 68 ; 58 ; 60 ; 71 ; 76 ; 78 ; 80 ; 68 ; 89 ; 80 ; 76 ; 76 ; 58 ; 71 ; 69 ; 48 ; 0 ; 59 ; 75 ; 83 ; 69 ; 79 ; 69 ; 86 ; 72 ; 76 ; 86$

$16 ; 708 ; 608 ; 350 ; 392 ; 370 ; 363 ; 521 ; 608 ; 486 ; 350 ; 326 ; 394 ; 449 ; 94 ; 0 ; 0 ; 41 ; 483 ; 532 ; 554 ; 105 ; 148 ; 166 ; 136 ; 173 ; 99 ; 102 ; 150 ; 174 ; 133 ; 210 ; 190 ; 164 ; 93 ; 1$ 26;102;63;84;87;148;56;55;61;73;122;123;81;541;0;69;193;250;196;255;218;159;237;490;548;424;139;467;300;446;;;473;394;447;410;;;;;;;;;;;;;

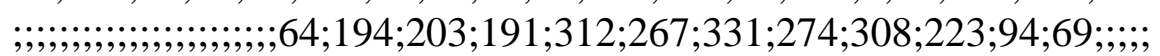

$17 ; 0 ; 0 ; 0 ; 0 ; 88 ; 106 ; 0 ; 91 ; 7 ; 204 ; 0 ; 49 ; 185 ; 96 ; 78 ; 87 ; 73 ; 77 ; 3 ; 0 ; 0 ; 0 ; 5 ; 72 ; 89 ; 120 ; ; 0 ; 68 ; 65 ; 66 ; 66 ; 65 ; 56 ; 69 ; 72 ; 61 ; 75 ; 82 ; 100 ; 48 ; 85 ; 82 ; 110 ; 65 ; 71 ; 58 ; 67$; $65 ; 59 ; 77 ; 86 ; 57 ; 87 ; 84 ; 79 ; 53 ; 80 ; 68 ; 70 ; 58 ; 47 ; 67 ; 100 ; 52 ; 66 ; 164 ; 128 ; 148 ; 182 ; 146 ; 193 ; 142 ; 161 ; 138 ; 178 ; 168 ; 207 ; 213 ; 223 ; 197 ; 222 ; 214 ; 244 ; 206 ; 16$ 7;123;118;106;118;114;121;107;123;116;226;42;127;0;0;117;115;117;119;109;125;99;105;54;138;111;138;122;125;113;116;110;101;117;126;1 $03 ; 93$

$18 ; 289 ; 223 ; 181 ; 271 ; 277 ; 219 ; 228 ; 215 ; 189 ; 202 ; 209 ; 188 ; 138 ; 190 ; 66 ; 157 ; 1 ; 135 ; 68 ; 98 ; 111 ; 135 ; 72 ; 71 ; 152 ; 177 ; 144 ; 182 ; 184 ; 183 ; 197 ; 139 ; 84 ; 65 ; 68$ ;64;71;57;56;69;59;19;96;102;114;74;85;113;77;52;45;68;49;85;101;62;77;101;90;106;86;75;106;135;99;73;66;65;78;73;74;70;58;81;69;159;12 $5 ; 116 ; 137 ; 129 ; 122 ; 120 ; 111 ; 109 ; 114 ; 130 ; 121 ; 140 ; 110 ; 99 ; 116 ; 98 ; 110 ; 110 ; 108 ; 90 ; 106 ; 106 ; 123 ; 148 ; 137 ; 127 ; 128 ; 113 ; 91 ; 108 ; 110 ; 126 ; 136 ; 141 ; 1$ $15 ; 113 ; ; ; ; ; 145 ; ; 146 ; 118 ; 128 ; 105$

$19 ; 148 ; 105 ; 113 ; 125 ; 307 ; 0 ; 158 ; 141 ; 161 ; 134 ; 142 ; 141 ; 127 ; 140 ; 118 ; 137 ; 167 ; 43 ; 67 ; 142 ; 56 ; 117 ; 88 ; 85 ; 76 ; 85 ; 255 ; 0 ; 119 ; 146 ; 125 ; 150 ; 136 ; 99 ; 100 ; 1$ $04 ; 123 ; 124 ; 106 ; 129 ; 109 ; 132 ; 117 ; 103 ; 103 ; 79 ; 74 ; 73 ; 86 ; 74 ; 61 ; 92 ; 85 ; 96 ; 84 ; 92 ; 129 ; 96 ; 98 ; 82 ; 68 ; 64 ; 65 ; 92 ; 67 ; 84 ; 81 ; 73 ; 66 ; 82 ; 68 ; 77 ; 61 ; 70 ; 79 ; 94 ; 1$ $00 ; 103 ; 92 ; 91 ; 86 ; 76 ; 85 ; 64 ; 56 ; 81 ; 75 ; 78 ; 56 ; 55 ; 60 ; 67 ; 59 ; 46 ; 44 ; 47 ; 40 ; 36 ; 28 ; 34 ; 54 ; 177 ; 48 ; 44 ; 53 ; 46 ; 71 ; 115 ; 154 ; 172 ; 120 ; 175 ; 155 ; 156 ; 170 ; 160 ; 139$ $; 126 ; 154 ; 138 ; 168 ; 194$

$20 ; 147 ; 112 ; 93 ; 157 ; 121 ; 173 ; 175 ; 172 ; 172 ; 192 ; 158 ; 168 ; 322 ; 0 ; 217 ; 217 ; 217 ; 272 ; 217 ; 217 ; 217 ; 272 ; 93 ; 0 ; 0 ; 303 ; 303 ; 113 ; 51 ; 265 ; 152 ; 0 ; 60 ; 46 ; 74 ; 61 ; 2$ $68 ; 237 ; 303 ; 254 ; 254 ; 285 ; 222 ; 129 ; 213 ; 85 ; 226 ; 274 ; 260 ; 186 ; 36 ; 84 ; 82 ; 99 ; 107 ; 99 ; 9 ; 92 ; 93 ; 81 ; 26 ; 14 ; 13 ; 161 ; 152 ; 179 ; 204 ; 107 ; 92 ; 192 ; 98 ; 0 ; 117 ; 70 ; 4$ 
$4 ; 51 ; 37 ; 62 ; 65 ; 94 ; 101 ; 162 ; 119 ; 128 ; 108 ; 122 ; 131 ; 123 ; 137 ; 119 ; 114 ; 161 ; 67 ; 106 ; 101 ; 65 ; 142 ; 162 ; 139 ; 246 ; 101 ; 72 ; 40 ; 183 ; 144 ; 61 ; 79 ; 46 ; 59 ; 225 ; 73 ; 7$ $6 ; 74 ; 71 ; 40 ; 72 ; 189 ; 204 ; 95 ; ; ; 0$

$21 ; 214 ; 139 ; 203 ; 244 ; 169 ; 191 ; 182 ; 229 ; 181 ; 192 ; 220 ; 222 ; 213 ; 107 ; 0 ; 0 ; 0 ; 0 ; 0 ; 0 ; 0 ; 0 ; 0 ; 0 ; 0 ; 2 ; 0 ; 0 ; 0 ; 0 ; 0 ; 0 ; 0 ; 1 ; 0 ; 0 ; 0 ; 0 ; 0 ; 0 ; 7 ; 0 ; 0 ; 139 ; 0 ; 0 ; 190 ; 0 ; 112 ; 0 ; 77$ ;49;60;212;0;338;0;0;0;242;;;23;176;140;141;144;129;119;138;124;154;153;170;131;178;157;151;146;149;126;92;198;160;140;161;145;168;15 $5 ; 163 ; 162 ; 156 ; 139 ; 155 ; 155 ; 148 ; 180 ; 148 ; 142 ; 175 ; 153 ; 146 ; 177 ; 151 ; 178 ; 141 ; 146 ; 161 ; 143 ; 160 ; 141 ; 172 ; 137 ; 172 ; 166 ; 138 ; 138 ; 128 ; 124 ; 153 ; 121 ; 1$ 53

$22 ; 236 ; 199 ; 225 ; 205 ; 246 ; 224 ; 209 ; 216 ; 0 ; 30 ; 231 ; 158 ; 273 ; 105 ; 96 ; 81 ; 49 ; 88 ; 83 ; 76 ; 80 ; 42 ; 94 ; 83 ; 100 ; 111 ; 67 ; 86 ; 95 ; 101 ; 62 ; 91 ; 86 ; 88 ; 56 ; 71 ; 67 ; 76 ; 82 ;$ $72 ; 80 ; 52 ; 71 ; 75 ; 101 ; 67 ; 39 ; 84 ; 86 ; 84 ; 68 ; 80 ; 84 ; 87 ; 90 ; 62 ; 86 ; 106 ; 97 ; 123 ; 62 ; 63 ; 59 ; 61 ; 65 ; 75 ; 70 ; 60 ; 59 ; 66 ; 67 ; 75 ; 84 ; 68 ; 73 ; 76 ; 75 ; 60 ; 10 ; 8 ; 10 ; 5 ; 105 ; 15$ $2 ; 134 ; 133 ; 123 ; 177 ; 150 ; 156 ; 125 ; 150 ; 140 ; 139 ; 81 ; 67 ; 34 ; 0 ; 155 ; 23 ; 272 ; 22 ; 115 ; 159 ; 131 ; 134 ; 131 ; 122 ; 146 ; 131 ; 156 ; 158 ; 135 ; 163 ; 143 ; 136 ; 167 ; 145 ; 1$ $41 ; 139 ; 138 ; 138$

23;223;252;208;202;224;209;209;226;211;185;218;189;233;211;191;204;215;208;218;212;223;166;202;189;202;215;178;220;166;161;181;165; $180 ; 152 ; 160 ; 145 ; 180 ; 150 ; 163 ; 139 ; 126 ; 148 ; 118 ; 130 ; 150 ; 119 ; 109 ; 132 ; 140 ; 135 ; 110 ; 124 ; 110 ; 150 ; 112 ; 112 ; 143 ; 134 ; 122 ; 138 ; 108 ; 98 ; 123 ; 122 ; 93 ; 1$ $31 ; 115 ; 97 ; 108 ; 78 ; 112 ; 103 ; 102 ; 94 ; 109 ; 123 ; 103 ; 84 ; 92 ; 110 ; 111 ; 103 ; 106 ; 87 ; 121 ; 105 ; 95 ; 117 ; 96 ; 110 ; 113 ; 117 ; 98 ; 102 ; 99 ; 106 ; 114 ; 103 ; 96 ; 97 ; 103 ; 9$ $1 ; 103 ; 90 ; 88 ; 89 ; 82 ; 94 ; 91 ; 93 ; 99 ; 93 ; 80 ; 97 ; 80 ; 76 ; 73 ; 70 ; 79 ; 91 ; 84 ; 88$

$24 ; 89 ; 200 ; 201 ; 192 ; 197 ; 198 ; 231 ; 175 ; 187 ; 168 ; 166 ; 155 ; 179 ; 63 ; 1 ; 28 ; 51 ; 52 ; 40 ; 43 ; 57 ; 54 ; 48 ; 57 ; 60 ; 63 ; 32 ; 49 ; 46 ; 62 ; 46 ; 51 ; 51 ; 47 ; 62 ; 42 ; 46 ; 42 ; 32 ; 31 ;$ $24 ; 21 ; 8 ; ; 0 ; 53 ; 68 ; 83 ; 92 ; 49 ; 56 ; 72 ; 58 ; 57 ; 59 ; 55 ; 49 ; 0 ; 7 ; 43 ; 17 ; 24 ; 28 ; 34 ; 22 ; 30 ; 29 ; 22 ; 39 ; 35 ; 34 ; 38 ; 33 ; 33 ; 22 ; 27 ; 21 ; 29 ; 28 ; 38 ; 20 ; 58 ; 138 ; 126 ; 119 ; 4 ; 21$; $29 ; 53 ; 107 ; 72 ; 62 ; 38 ; 40 ; 39 ; 47 ; 92 ; 127 ; 114 ; 154 ; 221 ; 110 ; 0 ; 97 ; 110 ; 58 ; 126 ; 129 ; 146 ; 131 ; 21 ; 76 ; 90 ; 101 ; 111 ; 94 ; 103 ; 95 ; 109 ; 83 ; 100 ; 89$

$25 ; 40 ; 38 ; 48 ; 45 ; 36 ; 53 ; 60 ; 66 ; 63 ; 44 ; 63 ; 68 ; 65 ; 66 ; 57 ; 47 ; 59 ; 68 ; 70 ; 33 ; 36 ; 34 ; 32 ; 64 ; 71 ; 63 ; 77 ; 58 ; 72 ; 69 ; 77 ; 58 ; 71 ; 53 ; 54 ; 53 ; 31 ; 59 ; 51 ; 75 ; 60 ; 62 ; 48 ; 52 ; 7$ $7 ; 76 ; 43 ; 57 ; 24 ; 61 ; 63 ; 77 ; 74 ; 82 ; 63 ; 35 ; 26 ; 0 ; 23 ; 19 ; 6 ; 21 ; 46 ; 77 ; 40 ; 77 ; 110 ; 111 ; 97 ; 91 ; 116 ; 102 ; 86 ; 98 ; 178 ; 179 ; 197 ; 192 ; 201 ; 204 ; 160 ; 174 ; 172 ; 185 ; 162$ ;217;166;191;190;183;183;197;157;169;164;192;177;154;177;183;207;182;197;214;176;187;178;170;206;198;169;191;160;208;178;153;161;15 $1 ; 141 ; 185 ; 136 ; 141$

26;188;228;191;125;198;203;100;161;226;225;225;461;50;214;113;186;223;253;254;265;244;222;217;196;194;203;116;144;186;138;162;165;1 $84 ; 202 ; 237 ; 158 ; 160 ; 124 ; 110 ; 118 ; 118 ; 94 ; 160 ; 148 ; 143 ; 191 ; 133 ; 135 ; 118 ; 98 ; 93 ; 142 ; 97 ; 128 ; 145 ; 126 ; 136 ; 192 ; 172 ; 141 ; 103 ; 114 ; 90 ; 73 ; 98 ; 90 ; 103 ; 1$ $24 ; 137 ; 131 ; 163 ; 118 ; 78 ; 87 ; 90 ; 103 ; 96 ; 107 ; 91 ; 84 ; 87 ; 115 ; 114 ; 90 ; 70 ; 80 ; 45 ; 56 ; 72 ; 53 ; 58 ; 60 ; 43 ; 76 ; 79 ; 69 ; 58 ; 58 ; 76 ; 113 ; 83 ; 55 ; 92 ; 115 ; 210 ; 231 ; 231 ; 2$ $39 ; 227 ; 229 ; 199 ; 107 ; 221 ; 216 ; 236 ; 212 ; 247 ; 174 ; 275 ; 276 ; 269 ; 325$

$27 ; ; ; ; ; ; ; ; ; ; ; ; ; ; ; ; ; 0 ; 0 ; 0 ; 0 ; 0 ; 0 ; 0 ; 0 ; 0 ; 0 ; 0 ; 0 ; 0 ; 0 ; 0 ; 0 ; 0 ; 0 ; 0 ; 0 ; 0 ; 0 ; 0 ; 0 ; 0 ; 0 ; 0 ; 0 ; 0 ; 0 ; 0 ; 0 ; 0 ; 0 ; 0 ; 0 ; 0 ; 0 ; 0 ; 0 ; 0 ; 0 ; 43 ; 0 ; 0 ; 0 ; 0 ; 177 ; 180 ; ; ; 140 ; 0 ; 0 ; 0 ; 0 ; 0 ; 0 ; 0 ; 0 ; 0 ; 0 ; 0 ; 0 ; 0$ $; 1 ; 0 ; 0 ; 0 ; 115 ; 350 ; 346 ; 212 ; 180 ; 234 ; 272 ; 272 ; 270 ; 223 ; 297 ; 245 ; 294 ; 268 ; 210 ; 235 ; 322 ; 341 ; 418 ; 412 ; 388 ; 332 ; 257 ; 221 ; 297 ; 245 ; 238 ; 264 ; 272 ; 410 ; 219$ $; 390 ; 634 ; 69 ; 69 ; 305 ; 342 ; 259$ 
$28 ; 98 ; 85 ; 85 ; 139 ; 118 ; 136 ; 112 ; 138 ; 83 ; 81 ; 105 ; 154 ; 170 ; 33 ; 63 ; 88 ; 87 ; 79 ; 61 ; 64 ; 75 ; 80 ; 70 ; 85 ; 110 ; 111 ; 78 ; 104 ; 99 ; 83 ; 72 ; 68 ; 74 ; 66 ; 89 ; 73 ; 65 ; 69 ; 50 ; 115$ ;71;87;73;79;86;90;70;111;101;85;79;115;63;73;65;59;53;59;52;53;25;25;70;79;65;64;77;59;69;46;24;25;20;35;75;121;115;113;91;69;69;100;9 $8 ; 92 ; 98 ; 82 ; 13 ; 9 ; 215 ; 87 ; 109 ; 70 ; 169 ; 101 ; 102 ; 88 ; 48 ; 60 ; 52 ; 78 ; 83 ; 44 ; 58 ; 47 ; 39 ; 60 ; 93 ; 84 ; 95 ; 10 ; 78 ; 138 ; 117 ; 133 ; 133 ; 110 ; 120 ; 103 ; 99 ; 115 ; 136 ; 111$ $29 ; 160 ; 183 ; 252 ; 331 ; 231 ; 232 ; 231 ; 224 ; 91 ; 191 ; 158 ; 207 ; 196 ; 134 ; 36 ; 128 ; 196 ; 204 ; 193 ; 35 ; 169 ; 158 ; 160 ; 168 ; 174 ; 173 ; 120 ; 150 ; 141 ; 146 ; 180 ; 160 ; 37$; $104 ; 101 ; 100 ; 126 ; 121 ; 94 ; 102 ; 91 ; 93 ; 72 ; 75 ; 81 ; 67 ; 69 ; 119 ; 94 ; 94 ; 88 ; 108 ; 81 ; 126 ; 0 ; 6 ; 2 ; 1 ; 1 ; 0 ; 0 ; 5 ; 7 ; 0 ; 0 ; 0 ; 0 ; 0 ; 0 ; 0 ; 0 ; 0 ; 0 ; 0 ; 0 ; 0 ; 0 ; 0 ; 0 ; 1 ; ; ; ; ; ; ; ; ; ; ; ; ; ; ; ; ; ; ; ; ; ; ; ; ; ;$ $; ;, ;, ;, ;, ;, ;, ; ;$

$30 ; 0 ; 0 ; 0 ; 0 ; 0 ; 18 ; 65 ; 3 ; 123 ; 99 ; 218 ; 300 ; 320 ; 130 ; 47 ; 58 ; 66 ; 61 ; 57 ; 80 ; 51 ; 49 ; 54 ; 23 ; 36 ; 34 ; 41 ; 80 ; 70 ; 0 ; 30 ; 71 ; 0 ; 92 ; 0 ; 0 ; 25 ; 23 ; 22 ; 20 ; 10 ; 0 ; 22 ; 25 ; 22 ; 20 ; 14 ;$ $26 ; 20 ; 17 ; 15 ; 18 ; 14 ; 18 ; 20 ; 15 ; 18 ; 21 ; 14 ; 20 ; 17 ; 17 ; 20 ; 23 ; 16 ; 22 ; 26 ; 19 ; 29 ; 24 ; 28 ; 21 ; 17 ; 21 ; 24 ; 24 ; 17 ; 27 ; 19 ; 22 ; 28 ; 20 ; 28 ; 27 ; 19 ; 17 ; 16 ; 23 ; 23 ; 38 ; 35 ; 39 ; 3$ $4 ; 20 ; 22 ; 15 ; 16 ; 11 ; 32 ; 29 ; 35 ; 26 ; 27 ; 26 ; 23 ; 22 ; 25 ; 22 ; 21 ; 24 ; 15 ; 16 ; 37 ; ; ; 85 ; 114 ; 128 ; 125 ; 141 ; 129 ; 136$

$31 ; 211 ; 220 ; 158 ; 72 ; 48 ; 63 ; 137 ; 233 ; 275 ; 240 ; 247 ; 199 ; 219 ; 254 ; 207 ; 180 ; 220 ; 236 ; 204 ; 216 ; 166 ; 193 ; 244 ; 247 ; 220 ; 236 ; 283 ; 228 ; 204 ; 144 ; 4 ; 8 ; 6 ; 4 ; 31 ; 2$ $0 ; 24 ; 27 ; 16 ; 24 ; 16 ; 21 ; 10 ; 11 ; 10 ; 11 ; 7 ; 14 ; 14 ; 12 ; 12 ; 13 ; 14 ; 14 ; 14 ; 13 ; 12 ; 13 ; 9 ; 15 ; 9 ; 5 ; 100 ; 141 ; 92 ; 113 ; 105 ; 101 ; 73 ; 115 ; 104 ; 119 ; 86 ; 98 ; 91 ; 105 ; 100 ; 123 ;$ $92 ; 116 ; 104 ; 105 ; 107 ; 103 ; 140 ; 143 ; 77 ; 137 ; 96 ; 108 ; 137 ; 138 ; 103 ; 175 ; 124 ; 129 ; 143 ; 114 ; 118 ; 114 ; 96 ; 105 ; 24 ; 0 ; 0 ; 0 ; 0 ; 4 ; 109 ; 142 ; 131 ; 146 ; 128 ; 139 ; 137$; $137 ; 118 ; 132 ; 135 ; 138 ; 115 ; 146$

$32 ; 108 ; 119 ; 117 ; 133 ; 122 ; 178 ; 249 ; 254 ; 211 ; 143 ; 144 ; 126 ; 139 ; 226 ; 211 ; 239 ; 79 ; 183 ; 25 ; 0 ; 0 ; 0 ; 73 ; 64 ; 46 ; 160 ; 184 ; 209 ; 82 ; 71 ; 90 ; 135 ; 94 ; 126 ; 102 ; 132 ; 5$ $5 ; 51 ; 196 ; 198 ; 207 ; 196 ; 197 ; 94 ; 124 ; 133 ; 148 ; 119 ; 191 ; 164 ; 140 ; 177 ; 69 ; 73 ; 107 ; 136 ; 118 ; 151 ; 95 ; 111 ; 95 ; 123 ; 104 ; 170 ; 142 ; 93 ; 102 ; 162 ; 178 ; 181 ; 167 ; 1$ 49;94;118;112;139;136;109;102;118;108;131;143;102;95;89;79;99;117;89;119;104;102;112;90;81;96;73;84;115;102;115;135;148;178;162;133; $136 ; 115 ; 124 ; 105 ; 158 ; 92 ; 168 ; 228 ; 209 ; 234 ; 237 ; 205 ; 279 ; 191 ; 227$

$33 ; 303 ; 333 ; 294 ; 415 ; 276 ; 317 ; 253 ; 189 ; 216 ; 157 ; 140 ; 117 ; 106 ; 96 ; 79 ; 103 ; 103 ; 117 ; 115 ; 147 ; 145 ; 151 ; 102 ; 143 ; 99 ; 102 ; 84 ; 132 ; 124 ; 118 ; 117 ; 163 ; 144 ;$ $161 ; 171 ; 132 ; 132 ; 136 ; 102 ; 135 ; 97 ; 35 ; 119 ; 129 ; 115 ; 115 ; 110 ; 98 ; 74 ; 85 ; 91 ; 172 ; 151 ; 94 ; 139 ; 189 ; 165 ; 214 ; 169 ; 139 ; 131 ; 111 ; 126 ; 148 ; 112 ; 96 ; 134 ; 194 ;$ 218;217;194;146;88;99;74;92;85;137;129;173;175;167;185;154;95;117;70;107;93;84;111;;;;;;;;;;;;;167;188;246;200;176;;;;;;;218;222;251;202; $152 ; 2$

$34 ; 72 ; 55 ; 59 ; 38 ; 71 ; 90 ; 80 ; 83 ; 81 ; 73 ; 78 ; 77 ; 86 ; 112 ; 80 ; 68 ; 84 ; 75 ; 81 ; 95 ; 96 ; 89 ; 39 ; 84 ; 85 ; 87 ; 60 ; 124 ; 77 ; 74 ; 85 ; 86 ; 89 ; 67 ; 84 ; 98 ; 92 ; 66 ; 58 ; 83 ; 62 ; 71 ; 89 ; 92$ $; 83 ; 87 ; 78 ; 84 ; 87 ; 62 ; 62 ; 91 ; 68 ; 87 ; 80 ; 70 ; 78 ; 72 ; 96 ; 105 ; 70 ; 58 ; 48 ; 67 ; 47 ; 63 ; 59 ; ; 69 ; 57 ; 62 ; 51 ; 66 ; 44 ; 48 ; 56 ; 45 ; 108 ; 90 ; 89 ; 59 ; 106 ; 87 ; 110 ; 121 ; 116 ; 80 ; 95$ $; 87 ; 29 ; 0 ; 0 ; 0 ; 0 ; 0 ; 67 ; 61 ; 43 ; 69 ; ; ; 104 ; 86 ; ; ; 141 ; 129 ; 138 ; 129 ; 119 ; 108 ; 95 ; 145 ; 129 ; 79 ; 41 ; 70 ; 83 ; 79 ; 96 ; 86$

$35 ; 139 ; 109 ; 30 ; 132 ; 140 ; 145 ; 121 ; 118 ; 114 ; 64 ; 139 ; 127 ; 110 ; 120 ; 76 ; 62 ; 137 ; 136 ; 80 ; 106 ; 107 ; 136 ; 123 ; 89 ; 85 ; 132 ; 78 ; 92 ; 80 ; 74 ; 124 ; 95 ; 129 ; 130 ; 142 ; 4$ $5 ; 94 ; 53 ; 85 ; 57 ; 26 ; 84 ; 67 ; 24 ; 53 ; 39 ; 7 ; 126 ; 61 ; 77 ; 8 ; 171 ; 441 ; 166 ; 141 ; 24 ; 89 ; 81 ; 104 ; 58 ; 85 ; 35 ; 104 ; 181 ; 101 ; 156 ; 188 ; 77 ; 133 ; ; ; ; 40 ; 171 ; 168 ; 191 ; 185 ; 17$ $0 ; 175 ; 189 ; 159 ; 149 ; 178 ; 211 ; 210 ; 159 ; 189 ; 183 ; 205 ; 155 ; 159 ; 161 ; 175 ; 176 ; 195 ; 180 ; 169 ; 196 ; 172 ; 163 ; 181 ; 143 ; 132 ; 153 ; 168 ; 141 ; 139 ; 142 ; 162 ; 148 ; 2$ $54 ; 234 ; 129 ; 157 ; 149 ; 160 ; 200 ; 179 ; 196 ; 179 ; 184 ; 162$ 
$36 ; 140 ; 108 ; 74 ; 117 ; 78 ; 98 ; 111 ; 129 ; 125 ; 144 ; 195 ; 260 ; 241 ; 275 ; 210 ; 79 ; 82 ; 74 ; 75 ; 76 ; 73 ; 78 ; 30 ; 200 ; 71 ; 77 ; 72 ; 81 ; 70 ; 72 ; 71 ; 78 ; 73 ; 73 ; 71 ; 74 ; 71 ; 74 ; 72 ; 6$ $7 ; 73 ; 72 ; 72 ; 75 ; 71 ; 71 ; 73 ; 71 ; 70 ; 69 ; 72 ; 71 ; 73 ; 73 ; 69 ; 70 ; 74 ; 77 ; 142 ; 91 ; 0 ; 71 ; 69 ; 74 ; 73 ; 71 ; 68 ; 68 ; 76 ; 72 ; 67 ; 72 ; 68 ; 55 ; 73 ; 71 ; 67 ; 69 ; 66 ; 56 ; 63 ; 62 ; 69 ; 60 ; 10$ 7;64;49;61;54;47;62;50;49;27;73;18;58;35;41;63;82;68;55;83;80;78;78;74;91;80;97;95;208;107;88;206;103;234;235;231;242;198 37;0;0;0;0;0;0;0;0;0;0;0;0;0;0;0;0;0;1;0;0;0;0;0;0;0;0;0;0;0;0;0;0;0;23;0;0;51;26;0;0;38;0;0;0;0;46;43;0;0;0;43;0;0;74;68;68;88;104;95;95;70;61; $66 ; 97 ; 73 ; 58 ; 79 ; 114 ; 75 ; 53 ; 58 ; 64 ; 57 ; 52 ; 65 ; 71 ; 60 ; 62 ; 64 ; 65 ; 71 ; 54 ; 63 ; 61 ; 63 ; 64 ; 50 ; 60 ; 62 ; 52 ; 45 ; 56 ; 22 ; 40 ; 83 ; 93 ; 63 ; 0 ; 50 ; 44 ; 49 ; 60 ; 54 ; 46 ; 51 ; 44 ; 49 ; 5$ $0 ; 46 ; 48 ; 38 ; 56 ; 82 ; 102 ; 110 ; 84 ; 60 ; 51 ; 53 ; 74 ; 85 ; 92$

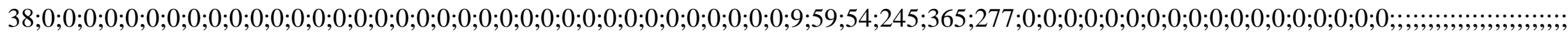

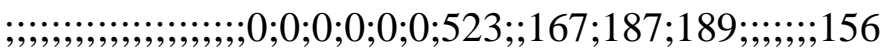

$39 ; 39 ; 127 ; 218 ; 287 ; 9 ; 0 ; 0 ; 0 ; 52 ; 269 ; 282 ; 41 ; 166 ; 279 ; 224 ; 190 ; 269 ; 254 ; 379 ; 203 ; 225 ; 210 ; 175 ;$,

$; ;, ;, ;, ;, ;, ;, ;, ; ; ;$

$40 ; 611 ; 586 ; 544 ; 611 ; 563 ; 609 ; 568 ; 583 ; 574 ; 486 ; 527 ; 462 ; 535 ; 449 ; 456 ; 253 ; 578 ; 361 ; 372 ; 251 ; 232 ; 0 ; 0 ; 0 ; 0 ; 0 ; 541 ; 704 ; 619 ; 931 ; 0 ; 0 ; 0 ; 0 ; 104 ; 93 ; 229 ; 1$ $91 ; 270 ; 197 ; 232 ; 277 ; 245 ; 275 ; 249 ; 199 ; 240 ; 261 ; 203 ; 352 ; 207 ; 308 ; 514 ; 0 ; 225 ; 237 ; 169 ; 0 ; 156 ; 100 ; 129 ; 209 ; 218 ; 234 ; 178 ; 240 ; 238 ; 214 ; 199 ; 263 ; 243 ;$ $276 ; 272 ; 277 ; 246 ; 52 ; 157 ; 244 ; 241 ; 68 ; 247 ; 83 ; 82 ; 142 ; 56 ; 100 ; 177 ; 108 ; 97 ; 121 ; 88 ; 109 ; 16 ; 77 ; 57 ; 119 ; 20 ; 22 ; 49 ; 51 ; 75 ; 97 ; 230 ; 84 ; 92 ; 11 ; 86 ; 76 ; 56 ; 38 ; 1$ $43 ; 52 ; 18 ; 14 ; 15 ; 71 ; 45 ; 136 ; 127 ; 131 ; 133 ; 130$

$41 ; 446 ; 461 ; 331 ; 727 ; 0 ; 371 ; 368 ; 0 ; 462 ; 977 ; 0 ; 442 ; 929 ; 87 ; 370 ; 0 ; 80 ; 156 ; 135 ; 179 ; 93 ; 92 ; 90 ; 92 ; 86 ; 102 ; 155 ; 60 ; 83 ; 152 ; 71 ; 72 ; 68 ; 73 ; 75 ; 56 ; 78 ; 0 ; 0 ; 0 ; 6$ $4 ; 0 ; 92 ; 102 ; 74 ; 101 ; 133 ; 89 ; 107 ; 107 ; 73 ; 111 ; 86 ; 84 ; 95 ; 78 ; 81 ; 92 ; 73 ; 78 ; 97 ; 94 ; 83 ; 113 ; 72 ; 81 ; 58 ; 30 ; 73 ; 73 ; 41 ; 58 ; 47 ; 67 ; 82 ; 77 ; 86 ; 72 ; 81 ; 64 ; 47 ; 46 ; 53 ; 5$ $2 ; 71 ; 44 ; 38 ; 57 ; 50 ; 51 ; 49 ; 45 ; 47 ; 52 ; 48 ; 51 ; 36 ; 37 ; 36 ; 41 ; 41 ; 42 ; 42 ; 29 ; 53 ; 97 ; 101 ; 85 ; 131 ; 137 ; 116 ; 119 ; 91 ; 112 ; 108 ; 87 ; 111 ; 107 ; 115 ; 114 ; 121 ; 103$

$42 ; 60 ; 50 ; 55 ; 42 ; 45 ; 65 ; 49 ; 56 ; 53 ; 66 ; 70 ; 55 ; 33 ; ; ; 0 ; 37 ; 39 ; 47 ; 21 ; 47 ; 36 ; 43 ; 39 ; 45 ; 49 ; 46 ; 54 ; 57 ; 53 ; 60 ; 54 ; 45 ; 27 ; 39 ; 49 ; 48 ; 47 ; 52 ; 46 ; 60 ; 54 ; 51 ; 57 ; 55 ; 60 ; 4$ $4 ; 48 ; 32 ; 42 ; 49 ; 39 ; 55 ; 48 ; 0 ; 44 ; 56 ; 52 ; 39 ; 85 ; 104 ; 108 ; 102 ; 95 ; 103 ; 113 ; 88 ; 87 ; 65 ; 28 ; 49 ; 32 ; 34 ; 49 ; 63 ; 47 ; 34 ; 58 ; 49 ; 35 ; 48 ; 55 ; 45 ; 34 ; 33 ; 41 ; 72 ; 81 ; 73 ; 56 ; 6$ $3 ; 42 ; 23 ; 31 ; 26 ; 29 ; 26 ; 28 ; 21 ; 25 ; 23 ; 23 ; 24 ; 22 ; 21 ; 28 ; 27 ; 34 ; 41 ; 26 ; 21 ; 218 ; 222 ; 218 ; 215 ; 220 ; 236 ; 193 ; 752 ; 76 ; 84$

$43 ; 180 ; 178 ; 184 ; 208 ; 171 ; 170 ; 204 ; 217 ; 270 ; 201 ; 203 ; 213 ; 227 ; 244 ; 179 ; 255 ; 263 ; 255 ; 235 ; 230 ; 234 ; 231 ; 0 ; 0 ; 204 ; 204 ; 204 ; 204 ; 204 ; 0 ; 204 ; 204 ; 204 ; 20$ $4 ; 204 ; 0 ; 0 ; 0 ; 204 ; 204 ; 204 ; 204 ; 204 ; 204 ; 204 ; 204 ; 174 ; 162 ; 42 ; 74 ; 161 ; 81 ; 69 ; 88 ; 81 ; 118 ; 227 ; 263 ; 228 ; 236 ; 191 ; 163 ; 190 ; 203 ; 170 ; 206 ; 197 ; 206 ; 168 ; 21$ $3 ; 223 ; 225 ; 194 ; 185 ; 180 ; 223 ; 199 ; 191 ; 173 ; 198 ; 160 ; 172 ; 182 ; 180 ; 159 ; 180 ; 134 ; 174 ; 212 ; 162 ; 167 ; 183 ; 27 ; 0 ; 4 ; 0 ; 1 ; 23 ; 27 ; 24 ; 23 ; 22 ; 22 ; 29 ; 35 ; 38 ; 35 ; 27$; $32 ; 29 ; 18 ; 19 ; 17 ; 18 ; 15 ; 47 ; 0 ; 1 ; ; ; ;$

44;126;163;159;105;61;134;163;157;117;118;80;80;0;28;99;110;112;95;122;100;57;53;28;20;20;43;35;100;71;75;40;10;99;42;28;20;14;0;8;9;0; $17 ; 18 ; 22 ; 19 ; 15 ; 6 ; 8 ; 2 ; 0 ; 0 ; 0 ; 0 ; 0 ; 0 ; 0 ; 117 ; 105 ; 121 ; 113 ; 88 ; 80 ; 76 ; 77 ; 54 ; 63 ; 60 ; 45 ; 59 ; 50 ; 48 ; 22 ; 27 ; 40 ; 22 ; 11 ; 6 ; 2 ; 3 ; 30 ; 95 ; 95 ; 101 ; 95 ; 99 ; 160 ; 120 ; 112 ; 1$ $35 ; 133 ; 146 ; 162 ; 78 ; 89 ; 82 ; 84 ; 78 ; 57 ; 53 ; 51 ; 42 ; 39 ; 49 ; 41 ; 96 ; 223 ; 147 ; 139 ; 127 ; 97 ; 86 ; 97 ; 86 ; 112 ; 67 ; 80 ; 81 ; 94 ; 106 ; 86 ; 99$

$45 ; 17 ; 39 ; 72 ; 78 ; 72 ; 75 ; 72 ; 85 ; 88 ; 84 ; 73 ; 94 ; 84 ; 82 ; 82 ; 108 ; 64 ; 73 ; 85 ; 107 ; 82 ; 92 ; 87 ; 72 ; 72 ; 80 ; 86 ; 97 ; 81 ; 87 ; 118 ; 77 ; 83 ; 76 ; 85 ; 44 ; ; 66 ; 70 ; 101 ; 70 ; 78 ; 87 ; 87$ ;90;84;72;104;80;92;86;73;71;88;67;78;77;86;111;77;61;65;81;88;66;91;63;72;67;98;72;84;66;90;69;14;0;1;0;85;101;123;114;132;135;158;134; $141 ; 125 ; 121 ; 122 ; 107 ; 111 ; 132 ; 125 ; 132 ; 121 ; ; ; ; ; ; ; ; ; 87 ; 114 ; 131 ; 113 ; 127 ; 130 ; 95 ; 90 ; 100 ; 89 ; 90 ; 94 ; 85 ; 85 ; 117 ; 78 ; 96$ 
46;288;232;215;253;261;245;209;345;317;298;340;211;266;248;252;225;338;122;110;123;125;110;135;109;154;0;112;94;122;132;106;91;73;8 $3 ; 70 ; 71 ; 102 ; 72 ; 80 ; 69 ; 59 ; 97 ; 98 ; 97 ; 76 ; 58 ; 49 ; 34 ; 55 ; 59 ; 47 ; 60 ; 34 ; 55 ; 56 ; 48 ; 61 ; 76 ; 68 ; 65 ; 63 ; 55 ; 75 ; 81 ; 66 ; 74 ; 70 ; 72 ; 67 ; 67 ; 68 ; 66 ; 84 ; 71 ; 96 ; 95 ; 77 ; 82 ; 8$ $2 ; 89 ; 77 ; 86 ; 81 ; 77 ; 91 ; 84 ; 62 ; 64 ; 75 ; 82 ; 81 ; 76 ; 83 ; 85 ; 94 ; 86 ; 67 ; 78 ; 85 ; 72 ; 70 ; 59 ; 65 ; 65 ; 125 ; 179 ; 214 ; 239 ; 276 ; 255 ; 249 ; 288 ; 214 ; 270 ; 227 ; 178 ; 189 ; 164 ; 1$ $72 ; 169 ; 220 ; 217$

47;236;196;174;214;196;220;209;222;227;199;3;0;0;1;0;0;1;0;0;0;0;0;979;11;10;0;0;0;13;18;10;12;34;13;6;17;0;18;18;16;0;19;0;16;13;0;3;11;0 $; 0 ; 0 ; 0 ; 0 ; 15 ; 0 ; 0 ; 0 ; 0 ; 0 ; 0 ; 0 ; 1 ; 0 ; 33 ; 45 ; 56 ; 46 ; 92 ; 88 ; 106 ; 90 ; 61 ; 56 ; 71 ; 74 ; 63 ; 57 ; 80 ; 150 ; 140 ; 124 ; 132 ; 57 ; 91 ; 134 ; 157 ; 114 ; 145 ; 180 ; 165 ; 152 ; 194 ; 163 ; 16$ $3 ; 165 ; 150 ; 156 ; 186 ; 165 ; 162 ; 177 ; 145 ; 157 ; 172 ; 163 ; 357 ; 347 ; 329 ; 354 ; 291 ; 325 ; 358 ; 284 ; 304 ; 280 ; 231 ; 293 ; 253 ; 300 ; 274 ; 324 ; 254$

48;55;44;33;34;19;14;9;66;172;384;567;938;236;681;122;0;0;0;0;0;294;0;158;265;288;279;266;384;412;472;405;420;431;410;0;429;952;0;64;4 $5 ; 11 ; 123 ; 24 ; 0 ; 28 ; 45 ; 19 ; 20 ; 19 ; 20 ; 56 ; 56 ; 51 ; 100 ; 35 ; 34 ; 18 ; 15 ; 42 ; 75 ; 67 ; 25 ; 35 ; 37 ; 52 ; 105 ; 119 ; 123 ; 87 ; 73 ; 28 ; 56 ; 64 ; 64 ; 62 ; 126 ; 63 ; 37 ; 41 ; 58 ; 43 ; 40 ; 42 ;$ $53 ; 68 ; 59 ; 81 ; 83 ; 142 ; 43 ; 81 ; 41 ; 23 ; 50 ; 88 ; 49 ; 170 ; 160 ; 153 ; 75 ; 94 ; 107 ; 81 ; 92 ; 79 ; 72 ; 100 ; 98 ; 143 ; 131 ; 117 ; 107 ; 351 ; 161 ; 240 ; 185 ; 219 ; 443 ; ; 244 ; 190 ; 234$ 49;152;168;170;169;144;142;167;147;134;144;147;139;149;177;119;137;152;164;135;142;180;125;67;129;180;269;38;152;107;128;148;139;12 8;130;130;104;129;148;103;138;79;0;0;118;153;141;123;155;158;140;139;169;114;107;99;123;147;134;146;179;131;76;72;96;45;61;77;65;105; $74 ; 61 ; 147 ; 87 ; 79 ; 69 ; 113 ; 88 ; 115 ; 73 ; 90 ; 103 ; 90 ; 76 ; 97 ; 74 ; 69 ; 59 ; 62 ; 94 ; 100 ; 68 ; 76 ; 114 ; 92 ; 69 ; 78 ; 97 ; 154 ; 103 ; 67 ; 96 ; 129 ; 148 ; 90 ; 85 ; 75 ; 147 ; 137 ; 160 ; 1$ $74 ; 142 ; 183 ; 151 ; 158 ; 154 ; 154 ; 127 ; 137 ; 137 ; 147 ; 127 ; 140$

$50 ; 198 ; 193 ; 102 ; 73 ; 159 ; 123 ; 163 ; 181 ; 391 ; 142 ; 140 ; 193 ; 340 ; 136 ; 135 ; 127 ; 163 ; 119 ; 113 ; 130 ; 151 ; 118 ; 137 ; 102 ; 112 ; 107 ; 104 ; 120 ; 132 ; 123 ; 152 ; 122 ; 1$ $58 ; 92 ; 117 ; 86 ; 73 ; 39 ; 58 ; 44 ; 50 ; 41 ; 41 ; 38 ; 45 ; 40 ; 31 ; 40 ; 36 ; 35 ; 39 ; 42 ; 6 ; 0 ; 109 ; 144 ; 75 ; 108 ; 65 ; 54 ; 41 ; 76 ; 51 ; 100 ; 126 ; 82 ; 59 ; 68 ; 54 ; 63 ; 71 ; 67 ; 35 ; 59 ; 45 ; 55 ;$ $45 ; 37 ; 37 ; 47 ; 22 ; 81 ; 34 ; 40 ; 78 ; 100 ; 9 ; 67 ; 27 ; 4 ; 22 ; 53 ; 90 ; 59 ; 33 ; 28 ; 56 ; 55 ; 69 ; 28 ; 13 ; 36 ; 24 ; 46 ; 15 ; 49 ; 9 ; 58 ; 65 ; 63 ; 72 ; 154 ; 23 ; 139 ; 87 ; 47 ; 26 ; 12 ; 35 ; 26 ; 67 ; 4$ 7 


\section{Apêndice B - Interpolação de funções}

O método de interpolação linear e polinomial foi utilizado no trabalho para representar, por meio de aproximação, a função $f(x)$ original em outra suposta função que consideraria a exposição de intervalos descontínuos contidos no domínio da original, conforme apresentado pela Figura B-1.

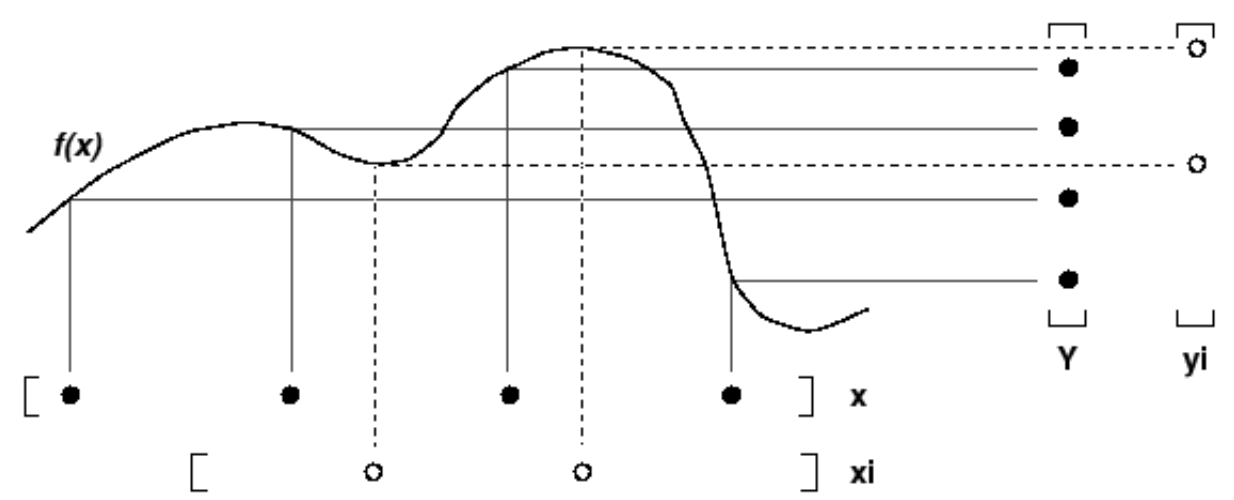

Figura B-1 - Representação gráfica de um método de interpolação. Os pontos preenchidos, representam os valores $\boldsymbol{x}$ e $\boldsymbol{y}$ da função original $\boldsymbol{f}(\boldsymbol{x})$, enquanto os pontos destacados sem preenchimento são resultantes da operação de interpolação (representados pelos vetores $\boldsymbol{x}_{\boldsymbol{i}}$ e $\boldsymbol{y}_{\boldsymbol{i}}$ ).

Fonte: Mathworks, 2013.

\section{B.1 Interpolação Linear}

A necessidade de obtenção de um valor intermediário não representado em um conjunto de dados é bem comum, especialmente quando trata-se de uma base carente de informações ou que apresenta descontinuidades. O objetivo principal da ferramenta de "Interpolação Linear" consiste na aproximação de valores em pontos intermediários de uma função unidimensional $f(x)$, que representa a base de dados, a partir de pontos conhecidos.

Quanto mais próximo o valor aproximado estiver de um ponto contido na função original $f(x)$, melhor será o resultado obtido através da operação de interpolação.

Tomando como modelo o exemplo disposto por Campos et al. [45], supondo dois pontos-base $\left(x_{0}, y_{0}\right)$ e $\left(x_{1}, y_{1}\right)$, com $x_{0} \neq x_{1}$ e pertencentes à função $f(x)$, a forma 
geral de obtenção da aproximação da função original, por meio de interpolação linear, pode ser expressa por:

$$
f(x) \approx P_{1}(x)=a_{0}+a_{1} x
$$

onde

$P_{1}(x)$ representa o polinômio interpolador de primeiro grau.

Considerando que no polinômio $P_{1}(x)$ estejam contidos os pontos-base supracitados, obtém-se o seguinte sistema de equações lineares:

$$
\begin{aligned}
& P_{1}\left(x_{0}\right)=y_{0} \\
& P_{1}\left(x_{1}\right)=y_{1}
\end{aligned} \rightarrow\left\{\begin{array}{l}
a_{0}+a_{1} x_{0}=y_{0} \\
a_{0}+a_{1} x_{1}=y_{1}
\end{array} \rightarrow\left[\begin{array}{ll}
1 & x_{0} \\
1 & x_{1}
\end{array}\right]\left[\begin{array}{l}
a_{0} \\
a_{1}
\end{array}\right]=\left[\begin{array}{l}
y_{0} \\
y_{1}
\end{array}\right]\right.
$$

Aplicando, na equação (B-2), a operação elementar de matrizes do Tipo $1^{12}$ com a finalidade de transformar o sistema linear em um sistema equivalente triangular, tem-se o seguinte resultado e solução:

$$
\begin{gathered}
{\left[\begin{array}{cc}
1 & x_{0} \\
0 & x_{1}-x_{0}
\end{array}\right]\left[\begin{array}{l}
a_{0} \\
a_{1}
\end{array}\right]=\left[\begin{array}{c}
y_{0} \\
y_{1}-y_{0}
\end{array}\right]} \\
a_{1}=\frac{y_{1}-y_{0}}{x_{1}-x_{0}} \text { e } a_{0}=y_{0}-a_{1} x_{0}
\end{gathered}
$$

Dessa forma, o polinômio interpolador, de forma geral, pode ser expresso como:

$$
\begin{gathered}
P_{1}(x)=a_{0}+a_{1} x \rightarrow y_{0}-a_{1} x_{0}+a_{1} x=y_{0}+a_{1}\left(x-x_{0}\right) \\
P_{1}(x)=y_{0}+\frac{y_{1}-y_{0}}{x_{1}-x_{0}}\left(x-x_{0}\right)
\end{gathered}
$$

\footnotetext{
${ }^{12}$ Uma operação elementar do tipo I, representada por $\mathrm{A}_{\mathrm{ij}}$, consiste na troca das linhas i e j.
} 


\section{B.2 Interpolação Polinomial: Polinômios de Lagrange}

Em casos em que a função $f(x)$ original apresente maior complexidade, representada pela sua ordem essencial, o resultado da aplicação de interpolação pode ser melhorado através da elevação da ordem do polinômio interpolador. Uma forma constantemente utilizada de se representar e descobrir pontos desconhecidos em funções prédeterminadas é disposta pela ferramenta matemática "Polinômios de Lagrange". Como o próprio nome sugere, trata-se uma de metodologia desenvolvida pelo matemático italiano Joseph-Louis Lagrange, ao qual também são atribuídas outras técnicas conhecidas na Engenharia.

O método consiste em encontrar uma função polinomial que contenha o conjunto de $n+1$ pontos distribuídos e conhecidos pela função original $f(x)$ e que disponha de menor ordem/grau possível.

Exemplificando, conforme prova e representação disposta pelo mestre Campos et al. [45], dispondo do conjunto de $n+1$ pontos, $\left(x_{0}, y_{0}\right),\left(x_{1}, y_{1}\right), \ldots,\left(x_{n}, y_{n}\right)$, espera-se desenvolver o polinômio $L_{n}(x)$ de ordem inferior a $n$ e que possua, nos pontos $x_{i}$, o mesmo resultado da função original $f(x)$, ou seja:

$$
L_{n}\left(x_{i}\right)=y_{i}, \quad i=0,1,2, \ldots, n
$$

Considerando os polinômios de ordem $n, P_{i}(x), \quad i=0,1,2, \ldots, n$, tal que $P_{i}(x) \neq$ 0 e $P_{i}\left(x_{j}\right)=0$, têm-se que:

$$
\begin{gathered}
P_{0}(x)=\left(x-x_{1}\right)\left(x-x_{2}\right)\left(x-x_{3}\right) \ldots\left(x-x_{n}\right) \\
P_{1}(x)=\left(x-x_{0}\right)\left(x-x_{2}\right)\left(x-x_{3}\right) \ldots\left(x-x_{n}\right) \\
P_{2}(x)=\left(x-x_{0}\right)\left(x-x_{1}\right)\left(x-x_{3}\right) \ldots\left(x-x_{n}\right) \\
\vdots \\
P_{n}(x)=\left(x-x_{0}\right)\left(x-x_{1}\right)\left(x-x_{2}\right) \ldots\left(x-x_{n-1}\right)
\end{gathered}
$$

Ou, reescrevendo na forma básica de polinômios de Lagrange: 


$$
P_{i}(x)=\prod_{\substack{j=0 \\ j \neq i}}^{n}\left(x-x_{j}\right), \quad i=0,1,2, \ldots, n
$$

Considerando que $L_{n}(x)$ é de ordem inferior a $n$, pode ser representado com uma combinação linear dos polinômios $P_{i}(x)$, como sendo:

$$
\begin{gathered}
L_{n}(x)=c_{0} P_{0}(x)+c_{1} P_{1}(x)+c_{2} P_{2}(x)+\cdots+c_{n} P_{n}(x) \\
L_{n}(x)=\sum_{i=0}^{n} c_{i} P_{i}(x)
\end{gathered}
$$

Analisando e agrupando as equações (B-7) e (B-8), obtém-se:

$$
L_{n}\left(x_{i}\right)=y_{i}=c_{i} P_{i}\left(x_{i}\right) \rightarrow c_{i}=\frac{y_{i}}{P_{i}\left(x_{i}\right)}
$$

Substituindo o valor de $c_{i}$ em (B-9), tem-se:

$$
L_{n}(x)=\sum_{i=0}^{n} \frac{y_{i}}{P_{i}\left(x_{i}\right)} P_{i}(x)
$$

E, finalmente, em função da equação (B-10), é apresentado a equação geral do polinômio interpolar de Lagrange de ordem $n$ como:

$$
L_{n}(x)=\sum_{i=0}^{n} y_{i} \prod_{\substack{j=0 \\ j \neq i}}^{n} \frac{x-x_{j}}{x_{i}-x_{j}}
$$

Como já apresentado anteriormente, a ordem do polinômio de interpolação de Lagrange deve ser igual ou menor que $n$, onde é desejável que seja a menor ordem possível e o resultado encontrado seja único. Há outras técnicas de calcular e representar um polinômio de interpolação, porém o método de Lagrange é uma das mais simples, com alto grau de comprovação/validação do polinômio gerado, e sua respectiva ordem, em 
relação a função original $f(x)$. A Figura B-2 exemplifica a aplicação do método de interpolação por Polinômios de Lagrange, aplicada na função tangente.

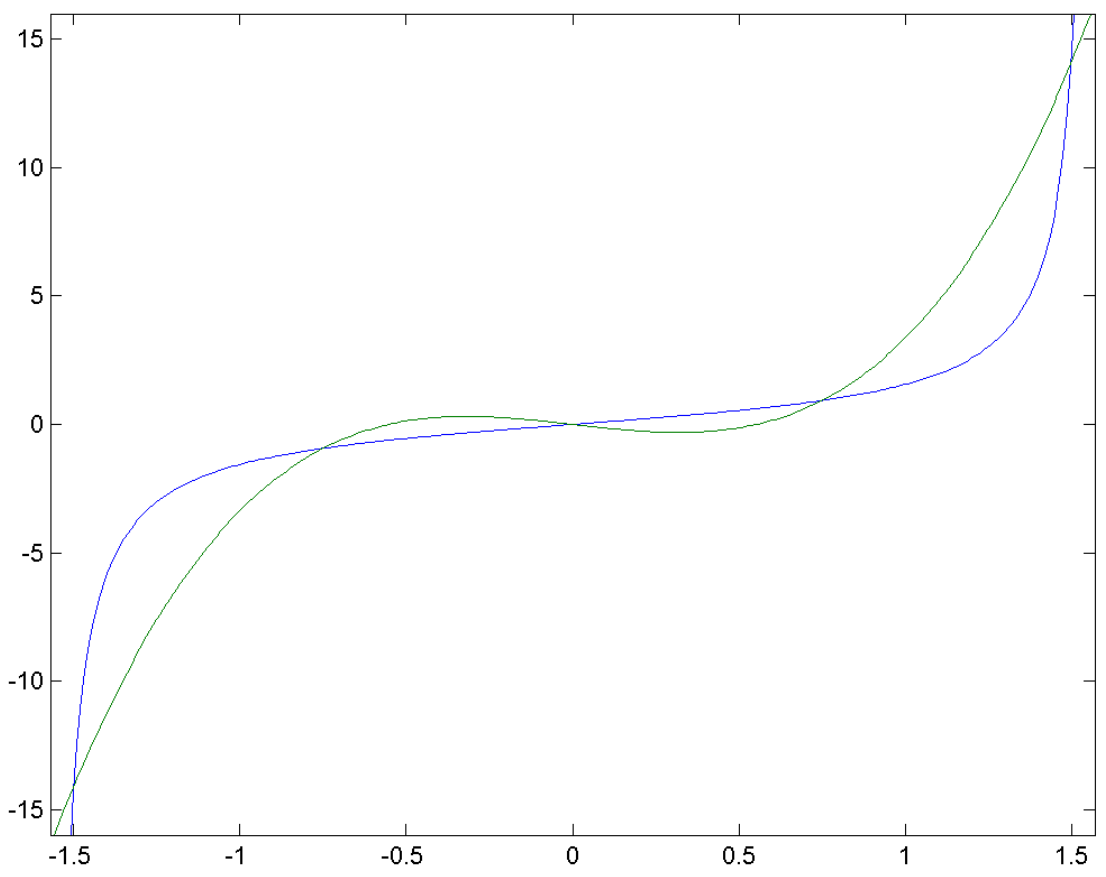

Figura B-2 - Representação gráfica da utilização de interpolação por Polinômios de Lagrange. Em azul, a função original (função tangente: $\boldsymbol{f}(\boldsymbol{x})=\boldsymbol{t a n}(\boldsymbol{x})$ ) e em verde, a função interpolada. 